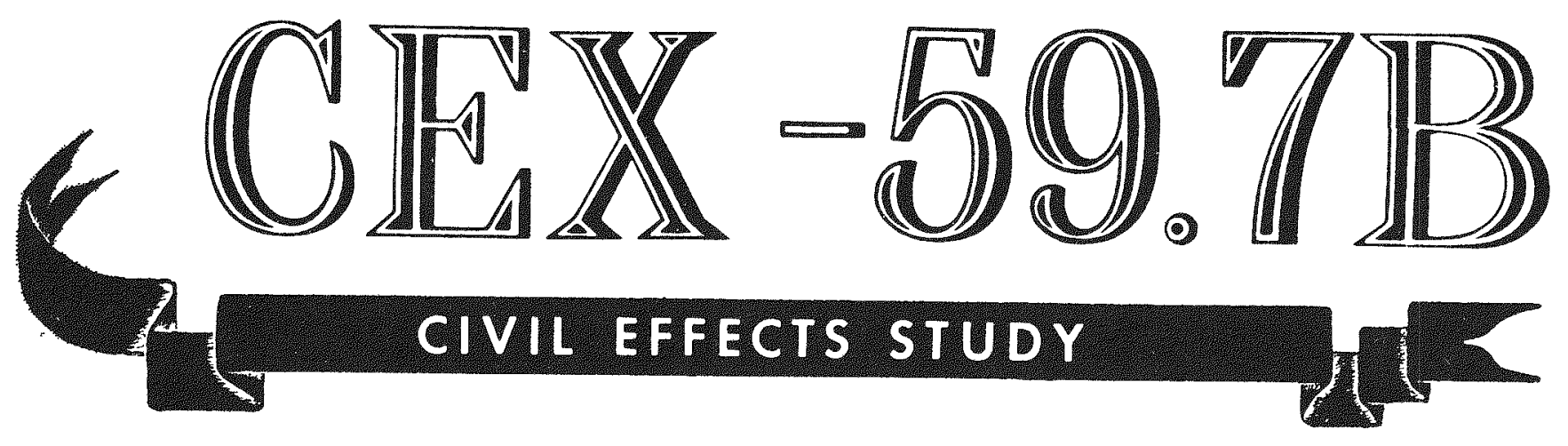

EXPERIMENTAL RADIATION MEASUREMENTS

IN CONVENTIONAL STRUCTURES

Part III

THE ATTENUATION OF AIR-SCATTERED

RADIATION IN A BASEMENT

Z. G. Burson

Issued: November 1965

CIVIL EFFECTS TEST OPERATIONS U.S. ATOMIC ENERGY COMMISSION 


\section{LEGAL NOTICE}

This report was prepared as an account of Government sponsored work. Neither the Unted States, nor the Commission, nor any person acting on behalf of the Commission:

A. Makes any warranty or representation, expressed or implied, with respect to the accuracy, completeness, or usefulness of the information contained in this report, or that the use of any information, apparatus, method, or process disciosed in this repoxt may not unfringe privately owned rights; or

B. Assumes any liablilies with respect to the use of, or for damages resulting from the use of any information, apparatus, method, or process disclosed in this report,

As used in the above, "person acting on behalf of the Commission" includes any enployee or contractor of the Commission, or employee of such contractor, to the extent that such employee or contractor of the Commission, or employee of such contractor prepares, disseminates, or provides access to, any information pursuant to his employment or contract with the Commission, or his employment with such contractor.

This report has been reproduced directly from the best available copy.

Printed in USA. Price $\$ 1.00$. Available from the Clearinghouse for Federal Scientific and Technical Information, $\mathrm{Na}-$ tional Bureau of Standards, U. S. Department of Commerce, Springfield, Va. 


\section{DISCLAIMER}

This report was prepared as an account of work sponsored by an agency of the United States Government. Neither the United States Government nor any agency Thereof, nor any of their employees, makes any warranty, express or implied, or assumes any legal liability or responsibility for the accuracy, completeness, or usefulness of any information, apparatus, product, or process disclosed, or represents that its use would not infringe privately owned rights. Reference herein to any specific commercial product, process, or service by trade name, trademark, manufacturer, or otherwise does not necessarily constitute or imply its endorsement, recommendation, or favoring by the United States Government or any agency thereof. The views and opinions of authors expressed herein do not necessarily state or reflect those of the United States Government or any agency thereof. 


\section{DISCLAIMER}

Portions of this document may be illegible in electronic image products. Images are produced from the best available original document. 


\title{
EXPERIMENTAL RADIATION MEASUREMENTS IN CONVENTIONAL STRUCTURES. PART III, THE ATTENUATION OF AIR-SCATTERED RADIATION IN A BASEMENT
}

\author{
By \\ Z. G. Burson
}

Approved by: L.J. DEAL, Chief

Civil Effects Branch

Edgerton, Germeshausen \& Grier, Inc.

Las Vegas, Nevada

April 1965 


\section{NO T IC E}

This report is published in the interest of providing information which may prove of value to the reader in his study of effects data derived principally from nuclear weapons tests and from experiments designed to duplicate various characteristics of nuclear weapons.

This document is based on information available at the time of preparation which may have subsequently been expanded and re-evaluated. Also, in preparing this report for publication, some classified material may have been removed. Users are cautioned to avoid interpretations and conclusions based on unknown or incomplete data. 


\section{ABSTRACT}

An experimental study was conducted to determine the airscattered radiation contribution to a basement structure from a simulated plane source of ${ }^{60} \mathrm{Co}$ on the ground outside and to determine its attenuation through various structural components.

A sealed radioactive source was pumped at a uniform speed through a long length of flexible tubing to simulate both an area and a ring source. Exposure measurements were made with ionization chamber detectors. $\nu^{\prime}$

A bare, open basement was used as the basic structure. A series of radiation measurements was made in this order:

In the open basement.

Within shelter walls constructed in one end of the basement. Within these shelter walls surrounded by sandbags.

In the fully constructed shelter, no sandbags.

In both the basement and shelter after a wood roof was constructed over the entire basement.

In the basement and shelter after a 4-in. layer of concrete planks was placed over the wood roof.

In the basement and shelter after an additional 4-in. (total of 8 in.) layer of concrete planks was placed over the wood roof.

The top of the materials (basement walls, wood roof, or concrete planks) was flush with ground level. This assured that radiation reaching the detectors had been scattered at least once in the air.

The results for all stages of construction compared well with prior theoretical calculations and with other experimental data in similar configurations. Comparisons were also made with data taken in a similar basement below a two-story brick house.

The results are useful for design of basement shelters and for the analysis of protection provided by basement structures from fallout radiation. 


\section{ACKNOWLEDGMENTS}

The author wishes to acknowledge the many valuable contributions made by the following:

Dr. C. M. Huddleston of the Naval Civil Engineering Laboratory (NCEL) for his thorough review of the manuscript.

P. H. Huff, formerly of Holmes and Narver, Inc., for architectural and engineering contributions to the project.

H. M. Borella, J. T. Brashears, W. G. Markland, P. C. Murphy, D. L. Parry, and F. W. Young of EG\&G for assistance in planning and performing the experiments.

This work was sponsored by the Civil Effects Test Operations (CETO), Division of Biology and Medicine, USAEC. Thanks are expressed to R. L. Corsbie (formerly of CETO), L. J. Deal and other members of CETO for their continued support and guidance during the experiments. 


\section{CONTENTS}

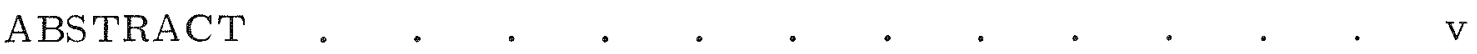

ACKNOWLEDGMENTS . . . . . . . . . . . . vi

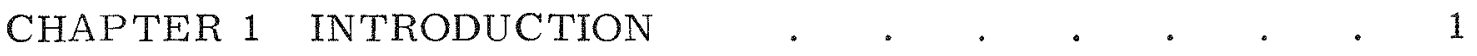

1.1 Background . . . . . . . . . . 1

1.2 Description of Structure and Components . . . 2

1.3 Objectives . . . . . . . . . . . . 6

CHAPTER 2 DESCRIPTION OF EXPERIMENTAL METHOD - 8

2.1 General Description . . . . . . . 8

2.2 Sources and Instrumentation . . . . . . . . 8

2.3 Experimental Technique . . . . . . . . 9

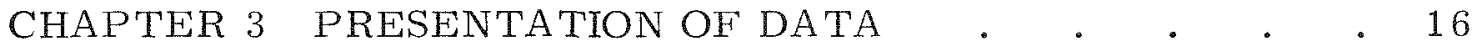

CHAPTER 4 ANALYSIS . . . . . . . . . . . . . 39

CHAPTER 5 SUMMARY . • • . . . . . . . 60

APPENDIX A DETAIL DRAWINGS OF STRUCTURAL COMPONENTS OF BASEMENT AND SHELTER • 63

\section{ILLUSTRATIONS}

\section{CHAPTER 1 INTRODUCTION}

1. 1 Open Basement and Surrounding Area Before Repair . 3

1.2 Placement of Sandbags Around Shelter Walls . . 4

1. 3 Construction of Shelter Roof . . . . . . 5 


\section{ILLUSTRATIONS (Continued)}

CHAPTER 2 DESCRIPTION OF EXPERIMENTAL METHOD

2.1260 -Curie ${ }^{60}$ Co Source, Photo and Detail Drawing . 10

2.2 Ionization Chambers and Charger-Reader . . . 11

2.3 Tubing Layout Around Open Basement . . . 12

2.4 Sample of Tubing Distribution Around Basement . 13

2.5 Tubing Distribution on Basement Roof and Ground Surrounding Basement . . . . . . . 15

\section{CHAPTER 3 PRESENTATION OF DATA}

3. 1 Dosimeter Positions for Bare Basement Measurements 18

3. 2 Dosimeter Positions for Basement with Shelter • 19

3. 3 Exposure Rates at Position 13 (Center) from Simulated Area Source on Ground for Various Stages of Construction . . . . . . . . . . 28

3. 4 Exposure Rates at Position 13 (Center) from a Simulated Ring Source at 127-ft Radius for Various Stages of Construction . . . . . . . . .

3.5 Exposure Rates at Positions 1 and 5 (Averaged) from a Simulated Area Source on the Ground for Various Stages of Construction . . . . . . . 30

3. 6 Exposure Rates at Positions 1 and 5 (Averaged) from a Simulated Ring Source at 127 -ft Radius for Various Stages of Construction . . . . . . . 31

3. 7 Exposure Rates at Positions 7 and 9 (Averaged) from a Simulated Area Source on the Ground for Various Stages of Construction . . . . . . . 32

3. 8 Exposure Rates at Positions 7 and 9 (Averaged) from a Simulated Ring Source at 127-ft Radius for Various Stages of Construction . . . . . . $\quad 33$

3.9 Exposure Rates at Positions 18, 19, 22, and 23 (Averaged) from a Simulated Area Source on the Ground for Various Stages of Construction . . . . . 34

3.10 Exposure Rates at Positions 18, 19, 22, and 23 (Averaged from a Simulated Ring Source at $127-\mathrm{ft}$ Radius for Various Stages of Construction . . . . . 35

3.11 Exposure Rates at Position 28 from a Simulated Area Source on the Ground for Various Stages of Construction 


\section{ILLUSTRATIONS (Continued)}

3. 12 Exposure Rates at Position 28 from a Simulated Ring Source at 127-ft Radius for Various Stages of Construction . . . . . . . . .

3.13 Exposure Rates at Positions 18, 19, 22, and 23 from a Simulated Area Source on the Roof over the Basement . . . . . . . . . .

CHAPTER 4 ANALYSIS

4.1 Conical Detector Pointing $90^{\circ}$ Away from the SourceDetector Line, Isotropic Point ${ }^{60}$ Co Source, Source and Detector at the Air-Ground Interface . . . 40

4.2 Simple Detector-Source-Medium Arrangements . 42

4. 3 Calculated and Measured Exposure Rates in Bare, Open Basement from a Ring Source of ${ }^{60} \mathrm{Co}$ at $127-\mathrm{ft}$ Radius

4. 4 Calculated and Measured Exposure Rates in Open Shelter (with Sandbags Around Shelter Walls) from a Ring Source of ${ }^{60} \mathrm{Co}$ at $127-\mathrm{ft}$ Radius . .

4.5 Calculated and Measured Exposure Rates in Bare, Open Basement (without Shelter) from an Area Source of ${ }^{60} \mathrm{Co}$ from Basement Edge to an Effective Radius of $60 \mathrm{ft}$

4. 6 Calculated and Measured Exposure Rates in Open Shelter (with Sandbags Around Shelter Walls) from an Area Source of ${ }^{60} \mathrm{Co}$ from Basement Edge to an Effec-

4.7 Calculated and Measured Exposure Rates at Position 13 (Center) from an Area Source of ${ }^{60} \mathrm{Co}$ on Top of the

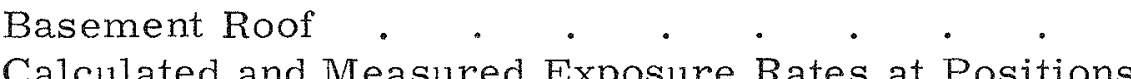

4. 8 Calculated and Measured Exposure Rates at Positions 1 and 5 (Corner) from an Area Source of $60 \mathrm{Co}$ on Top of the Basement Roof . . . . . . . . 51

4.9 Calculated and Measured Exposure Rates at Position 28 (Center of Shelter) from an Area Source of ${ }^{60} \mathrm{Co}$ on Top of the Basement Roof . $\cdot{ }^{6} \cdot{ }^{6} \cdot$

4.10 Comparison of Measurements made by $\mathrm{TO}^{6}$ and by this Experiment in a Bare, Open Basement

4.11 Wall and Framing Structure of the Open Basement (This Experiment) and the Basement of 2SB House (CEX 59.7B, Part I) . . . . . . . . 56 


\section{ILLUSTRATIONS (Continued)}

4.12 Exposure Rates in Open Basement and in 2SB House Basement 7 at $3 \mathrm{ft}$ Above the Floor from a Ring Source of ${ }^{60} \mathrm{Co}$ at a Radius of $127 \mathrm{ft}$. . . . . . 57

4.13 Calculated Exposure Rates in a Fictitious Structure with Infinite High, Above-Ground Walls from a Ring Source of $60 \mathrm{Co}$ at 127 -ft Radius . . . . . . . 58

APPENDIX A DETAIL DRAWINGS OF STRUCTURAL COMPONENTS OF BASEMENT AND SHELTER — 63

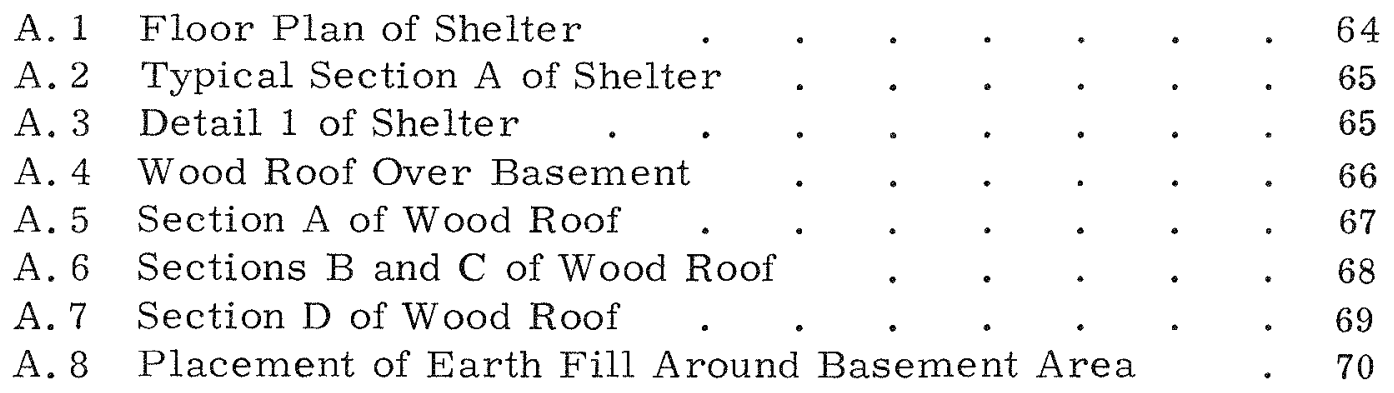

\section{TABLES}

\section{CHAPTER 3 PRESENTATION OF DATA}

3.1 Information used in Correcting and Normalizing Data 17

3.2 Exposure Rate in Bare, Open Basement . . . 21

3. 3 Exposure Rates in Open Basement with Only the Shelter Walls Constructed . . . . . . . . 22

3. 4 Exposure Rates in Open Basement with Sandbags Around Shelter Walls . . . . . . $\quad 23$

3.5 Exposure Rates in Basement with Roof over Shelter 24

3. 6 Exposure Rates in Basement with Wood Roof over Basement . . . . . . . . . . 25

3.7 Exposure Rates in Basement with Wood Roof and 4 in. of Concrete over Basement . . . . . . . 26

3. 8 Exposure Rates in Basement with Wood Roof and 8 in. of Concrete over Basement . • • • . . 27 


\section{TABLES (Continued)}

CHAPTER 4 ANALYSIS

4.1 Calculated and Measured Exposure Rates in Open Base-

4.2 Calculated and Measured Exposure Rates from an Area Source on the Basement Roof 


\section{Chapter 1}

\section{INTRODUCTION}

\section{1 BACKGROUND}

An important part of the Civil Effects Program of the Division of Biology \& Medicine, U.S. Atomic Energy Commission, has been the experimental determination of shielding against ionizing radiations afforded by conventional and special structures. Laboratory and field work in the program has led to the development of techniques for simulation of the radiation field from fallout and for measurements to characterize the field at various points. Using these methods, a series of tests has been made to evaluate the protection in homes, shelters, and large office buildings.

Measurements 6,7 at the Nevada Test Site were conducted simultaneously with an architectural-engineering study to determine some practical modifications of existing structures to improve protection. Measurements and results described in this report are a part of this NTS series.

In the past few years fallout radiation shielding has been intensively investigated with strong emphasis on shelters. Calculations ${ }^{8}$ of gamma-ray data have been generated for infinite, homogeneous media and for many elementary detector-source-medium arrangements. These data have been applied to elementary structures in developing an engineering methodology ${ }^{9}$ for analyzing complicated and simple structures.

Some experiments have been done to evaluate protection offered by total structures. $1-6$ While these measurements are necessary to evaluate the general applicability of the engineering methodology, they do not yield basic information about shielding effectiveness of various components of a structure.

A fallout shelter in a basement of a house is one way of providing radiation protection. For an effective design one should know the radiation contribution: (1) through the shelter walls; (2) through 
the shelter roof; and (3) through the basement roof. The purpose of this study was to evaluate these components.

\subsection{DESCRIPTION OF STRUCTURE AND COMPONENTS}

An open basement was used for the measurements. Its inside dimensions were $24 \mathrm{ft}$ by $32.8 \mathrm{ft}$ by $7.3 \mathrm{ft}$ deep. It had been used in aboveground weapons-test programs in Operation Teapot and later used for radiation measurements by Technical Operations. $10 \mathrm{~A}$ photograph of the structure appears in Fig. 1.1.

Before measurements were begun, defects or breaks in the walls were repaired, the window wells and entrance door were blocked up, and the stairwell was filled with dirt. The ground surrounding the basement was graded such that the tops of the basement walls were flush with ground level. (Appendix A contains drawings of the basement and shelter.)

The first construction component consisted only of walls of a shelter built in the center of one end of the basement. The shelter was identical to the one in the basement of a 2-story brick (2SB) house used for earlier measurements. 6 Its position within the basement was also identical to that in the $2 \mathrm{SB}$ so that comparisons of data could be made.

Next, sandbags were placed around the outside of the shelter walls and across the entrance, up to wall height (see Fig. 1.2). After measurements were made, the sandbags were removed and the shelter roof was constructed. Figure 1.3 shows workmen smoothing the concrete.

The shelter roof consisted of a 2-in. precast lightweight (87 lb/cu ft) concrete plank and a 4-in. poured concrete slab, making a total mass thickness of about $65 \mathrm{lb} / \mathrm{sq} \mathrm{ft}$. The shelter walls were of 8-in. lightweight concrete blocks with all cells filled with poured concrete, making a total mass thickness of about $80 \mathrm{lb} / \mathrm{sq} \mathrm{ft}$.

A wood roof was constructed over the entire basement. Two steel beams were necessary for support, as seen in the drawings in Appendix A. An access hole was left open near the center of the roof. It was covered with an equivalent thickness of wood for the measurements. If all the mass of wood beams were spread uniformly over the entire roof area, the effective mass thickness of the wood roof would be about $10 \mathrm{lb} / \mathrm{sq} \mathrm{ft}$, of which about half is for the plywood and sheathing and the other half, for the wood beams. 


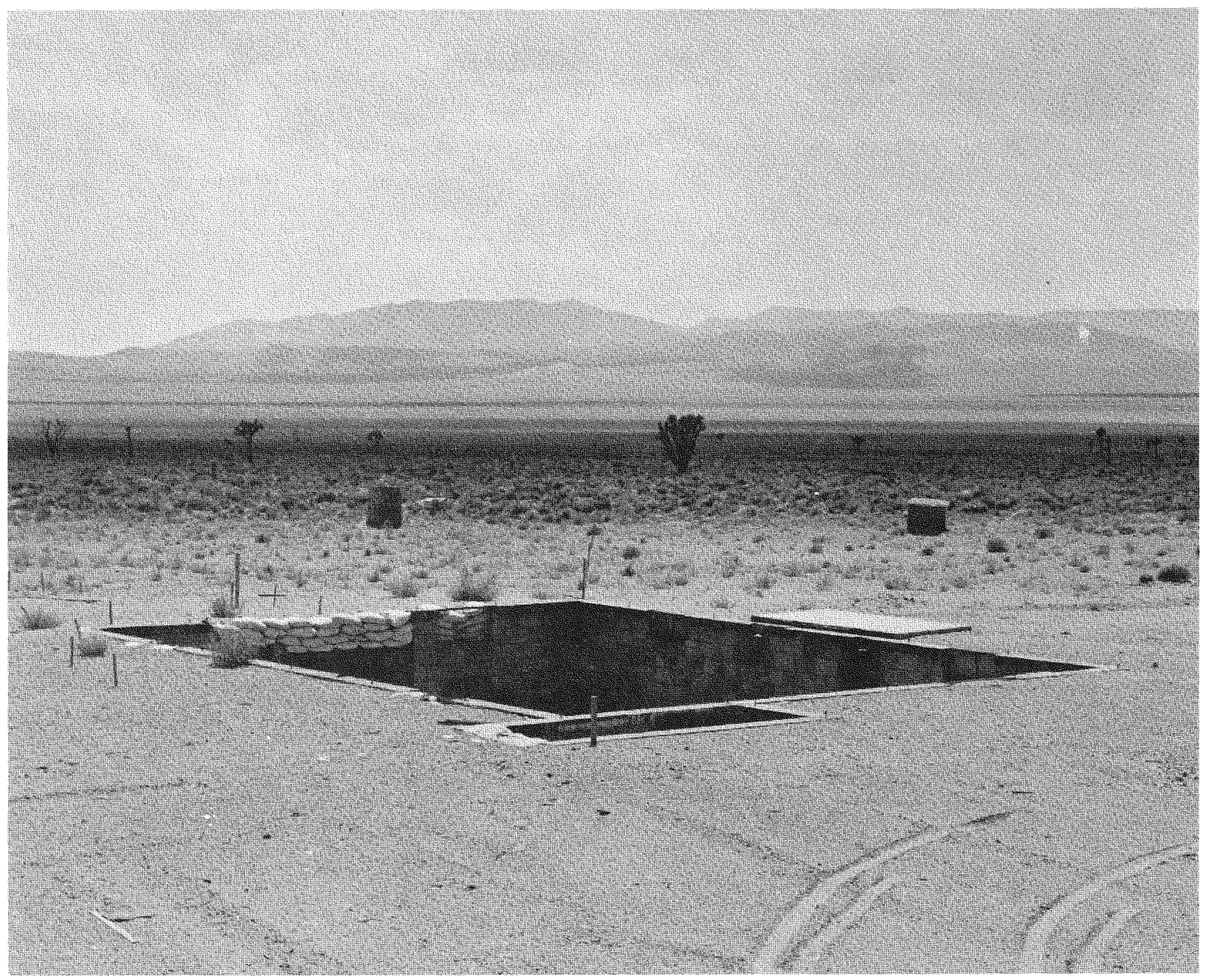

Fig. 1.1-Open basement and surrounding area before repair. 


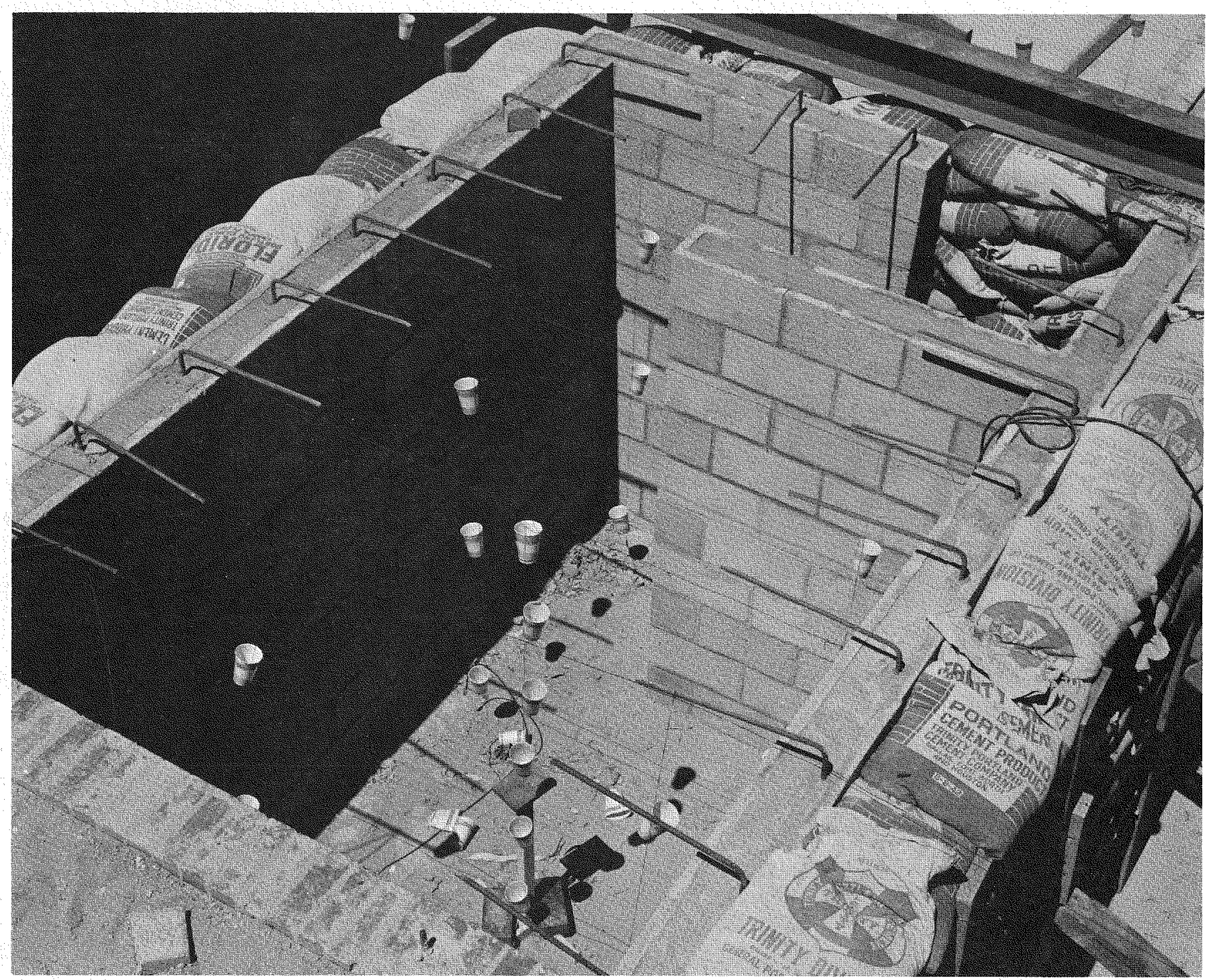

Fig. 1.2-Placement of sandbags around shelter walls. 


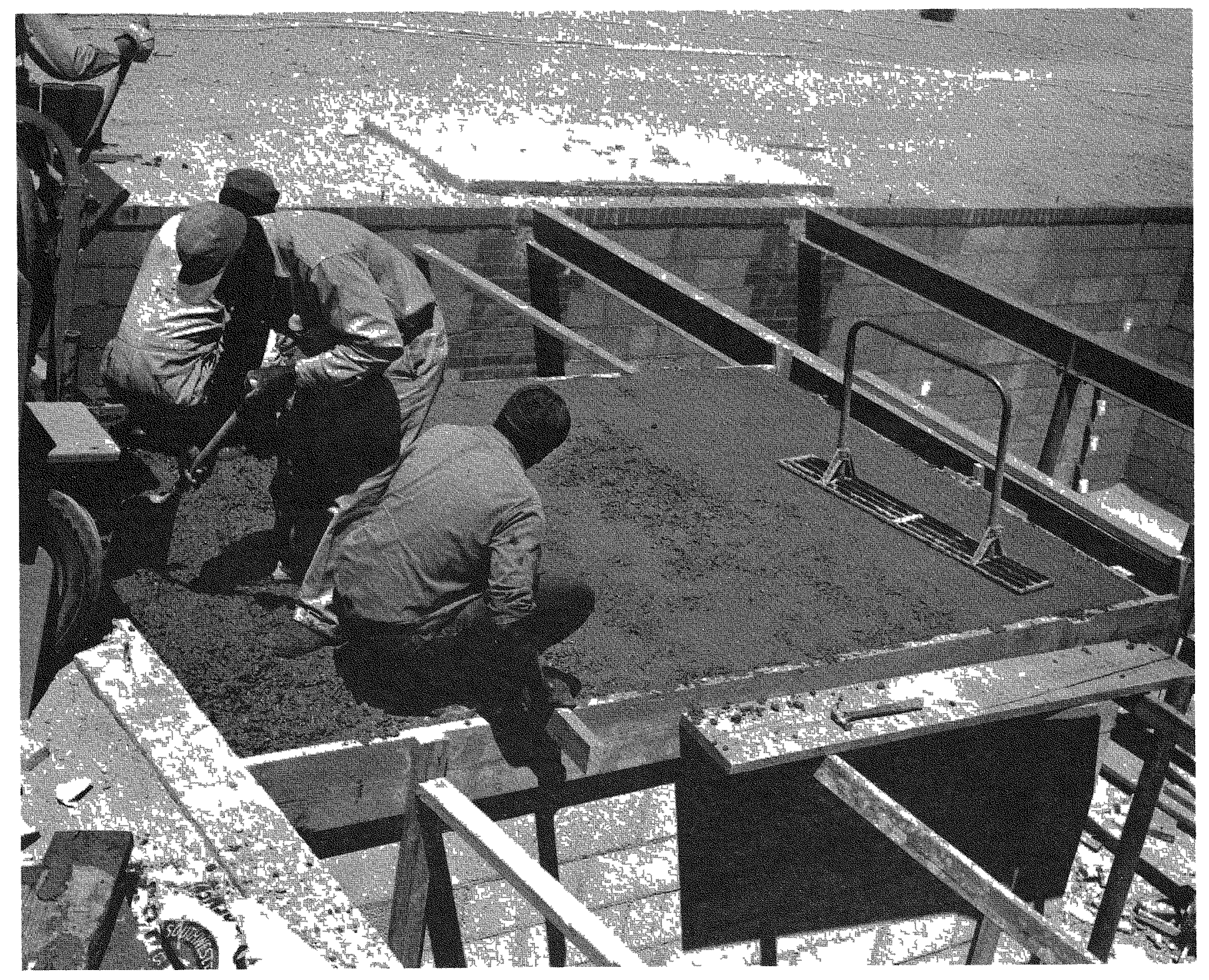

F1g. 1.3-Construction of shelter roof. 
Lightweight concrete planks were placed over the wood roof for additional measurements. Again the access opening was covered with an equivalent thickness of material. The density of the slabs was about $87 \mathrm{lb} / \mathrm{cu} \mathrm{ft}$, so that the mass thickness for the 4-in. layer was about $29 \mathrm{lb} / \mathrm{sq} \mathrm{ft}$ and that of the 8 -in. layer was $58 \mathrm{lb} / \mathrm{sq} \mathrm{ft}$.

\subsection{OBJECTIVES}

The general objective of the project was to acquire experimental information on the air-scattered radiation component from a plane source and to measure its attenuation through various structural components of a basement structure.

Specific experiments in sequence measured:

1. Air-scattered (skyshine) radiation in an open basement (the top of which was flush with the ground) from a simulated infiniteplane source.

2. Air-scattered radiation in an area surrounded by the shelter walls, located in one end of the open basement.

3. Same as No. 2 with sandbags around the outside of the shelter walls. The object was to measure only the skyshine component coming through the open top of the shelter.

4. Air-scattered radiation in a fully constructed shelter (without sandbags) in one end of the basement.

5. Radiation level in a basement containing a wood roof (the top flush with the ground) and in the fully constructed shelter in one end of the basement.

6. Radiation level in a basement with 4 in. of concrete planks (the top flush with ground level) over the wood roof, and in the fully constructed shelter in one end of the basement.

7. Radiation level in a basement with $8 \mathrm{in.} \mathrm{of} \mathrm{concrete} \mathrm{planks}$ (the top flush with ground level) over the wood roof, and in the fully constructed shelter in one end of the basement.

Data from these experiments were compared with other experimental data and with engineering calculations.

The results are useful for many air-scattering and shielding problems and apply directly to designing or evaluating fallout shelters in basements.

\section{REFERENCES}

1. J. A. Auxier, J. O. Buchanan, C. Eisenhauer, and H. E. Menker, Experimental Evaluation of the Radiation Afforded by Residential Structures Against Distributed Sources, Report CEX-58. 1, January 1959. 
2. J. F. Batter, Jr., A. L. Kaplan, and E. T. Clarke, An Experimental Evaluation of the Radiation Protection Afforded by a Large Modern Concrete Office Building, Report CEX-59.1, January 1960.

3. T. D. Strickler and J. A. Auxier, Experimental Evaluation of the Radiation Protection Afforded by Typical Oak Ridge Homes Against Distributed Sources, Report CEX59.13, April 1960.

4. H. Borella, Z. Burson, and J. Jacovitch, Evaluation of the Fallout Protection Afforded by Brookhaven National Laboratory Medical Research Center, Report CEX-60. 1, February 1961.

5. Z. G. Burson, Experimental Evaluation of the Fallout Radiation Protection Provided by Selected Structures in the Los Angeles Area, Report CEX-61.4, February 1963.

6. Z. G. Burson, Experimental Radiation Measurements in Conventional Structures, Report, CEX-59.7B, Part I, to be published.

7. Z. G. Burson, Experimental Radiation Measurements in Conventional Structures, Report CEX-59.7B, Part II, Comparison of Measurements in Above-Ground and BelowGround Structures from Simulated and Actual Fallout Radiation, January 1964.

8. L. V. Spencer, Structure Shielding Against Fallout Radiation from Nuclear Weapons, NBS Monograph 42 (National Bureau of Standards, Washington 25, D. C.), June 1962.

9. Engineering Manual: Design and Review of Structures for Protection from Fallout Gamma Radiation, Office of Civil Defense, revised October 1, 1961.

10. E. T. Clarke, et al., Measurement of Attenuation in Existing Structures of Radiation from Simulated Fallout, Report TO-B 59-4, Technical Operations, Inc., April 1959. 


\section{Chapter 2}

\section{DESCRIPTION OF EXPERIMENTAL METHOD}

\section{1 GENERAL DESCRIPTION}

A finite, idealized, plane source of radiation was simulated by pumping a ${ }^{60}$ Co source through a length of tubing evenly placed around the basement structure. The gamma-ray exposure* inside the structure was measured by integrating air-filled ionization chambers.

The source-pumping system used for this project has been used in other similar experiments and is thoroughly described in other reports. $1-2$

The system consisted of a remotely controlled hydraulicpumping unit which used water to move a stainless-steel-encapsulated radioactive source from its shield through the tubing and back into the shield. Movable, magnetic indicators attached to the tubing and connected to lights on the control panel enabled the operator to know the location of the source capsule at all times. The source was started, stopped, or reversed from the console located in a laboratory trailer $500 \mathrm{ft}$ from the pumping system. A hand pump provided an emergency mechanism for returning the source capsule to its shield.

\subsection{SOURCES AND INSTRUMENTATION}

Two ${ }^{60}$ Co sources of approximately 15 and 260 curies of activity were used in this project. They were encapsulated in magnetic, stainless-steel containers. Calibrations were performed by pumping a source into position $10 \mathrm{ft}$ above ground and measuring the exposure rate $10 \mathrm{ft}$ away by NBS-calibrated Victoreen condenser $r$-chambers. Detailed calibration information is presented in Ref. 2. The exact strengths of the sources at the time of the experiment are indicated in Table 3.1; the values were obtained from

* "Exposure" as defined in ICRU Report 10a, NBS Handbook 84, page $6(1962)$. 
standard decay curves. A photograph and drawing of the 260-curie 60 Co source appear in Fig. 2.1.

The radiation detectors used in this experiment include integrating ionization chambers with associated charger-readers. The chambers were of two types: 0 to 200-mr Victoreen model 362 pocket ionization chambers, and 0 to $10-\mathrm{mr}$ Victoreen model 239 stray-radiation chambers. Victoreen model 287 minometers were used for charging and reading the detectors. (See Fig. 2.2.)

The response of the chambers was reasonably flat for photon energies ranging from $100 \mathrm{kev}$ to $1.25 \mathrm{Mev}\left({ }^{60} \mathrm{Co}\right)$ and was about $20 \%$ low at 40 to $50 \mathrm{kev}$. Directional and energy response curves are available in the literature. $1-3$ The response of the low-range chambers was isotropic except in the direction of the ends, where they read $7 \%$ low.

\subsection{EXPERIMENTAL TECHNIQUE}

To simulate a uniformly distributed plane source, the
${ }^{60} \mathrm{Co}$ source capsule was pumped at constant speed through tubing that had been distributed with constant spacing over the area concerned. Since the integrating detectors showed the total exposure, a uniformly contaminated field was simulated by pumping the source so that it spent the same time per unit area over the entire area on which the tubing was laid.

The tubing was placed 6 ft apart out to about 50 or 60 ft from the center of the structure. The first line of tubing was $3 \mathrm{ft}$ from the edge. (See Fig. 2.3.) Figure 2.4 shows a sample tubing distribution. The exact area covered by the tubing was determined for each measurement with an area source and is listed in Table 3. 1 . The tubing was placed such that the source usually traveled perpendicular to a line from the source to the center of the basement to minimize errors caused by source anisotropy. Directional calibration of the sources showed effective source strengths along the long axis to be about $50 \%$ of that normal to the long axis (Ref. 2 ).

Because of limitation of available tubing, area sources could not be simulated beyond $60 \mathrm{ft}$ from the center of the structure. To enable the experimenters to estimate the skyshine contribution from beyond this area, measurements were made from a simulated ring source. Calculations 4 show that a radius of about $300 \mathrm{ft}$ for this ring source would produce the correct relative angular distribution. The same calculations show that the angular distribution is a slowly varying function of source-detector separation distance. A radius

( Text continued on page 14) 


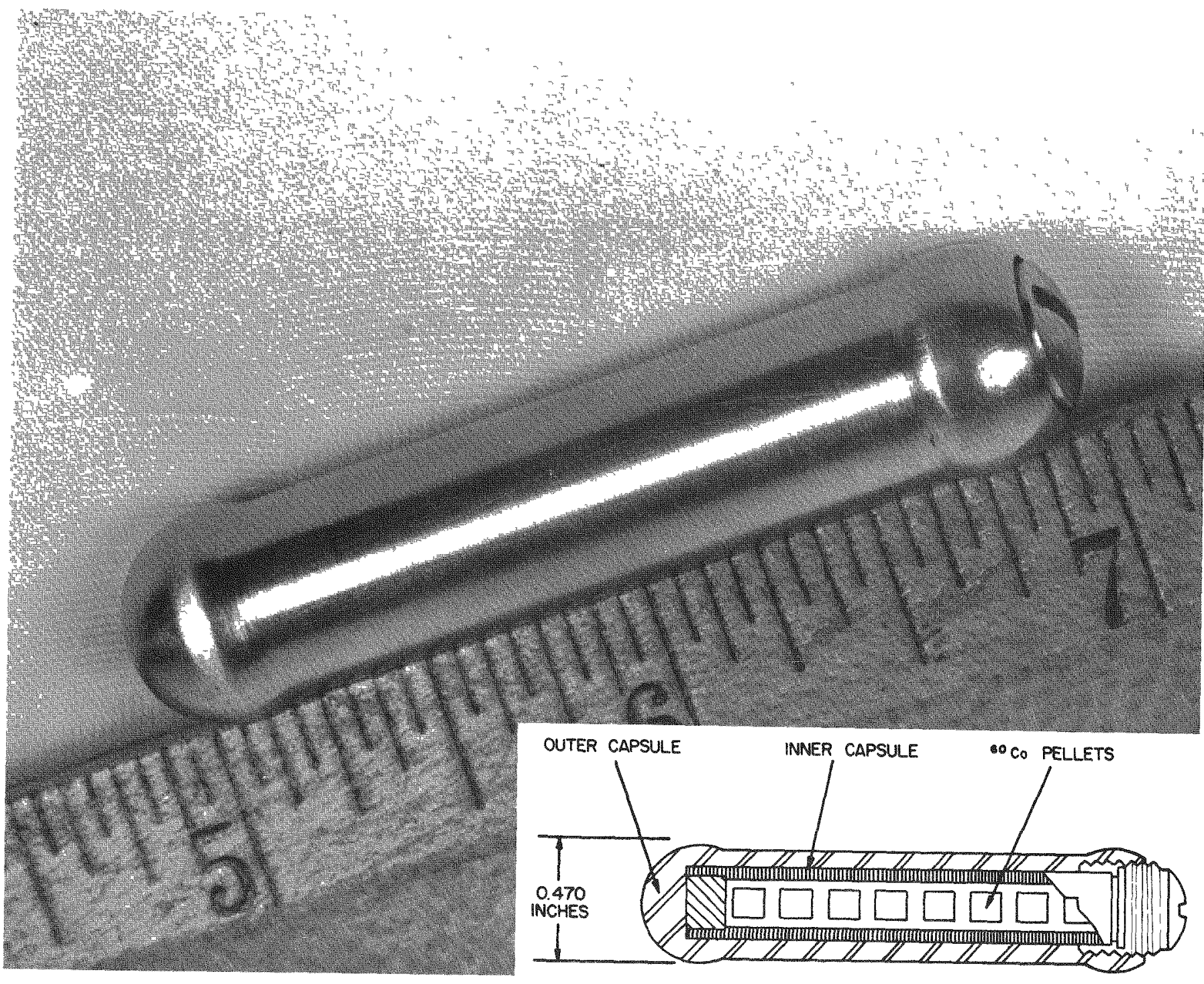

Fig. 2.1-260-curie ${ }^{60} \mathrm{Co}$ source, photo and detail drawing. 


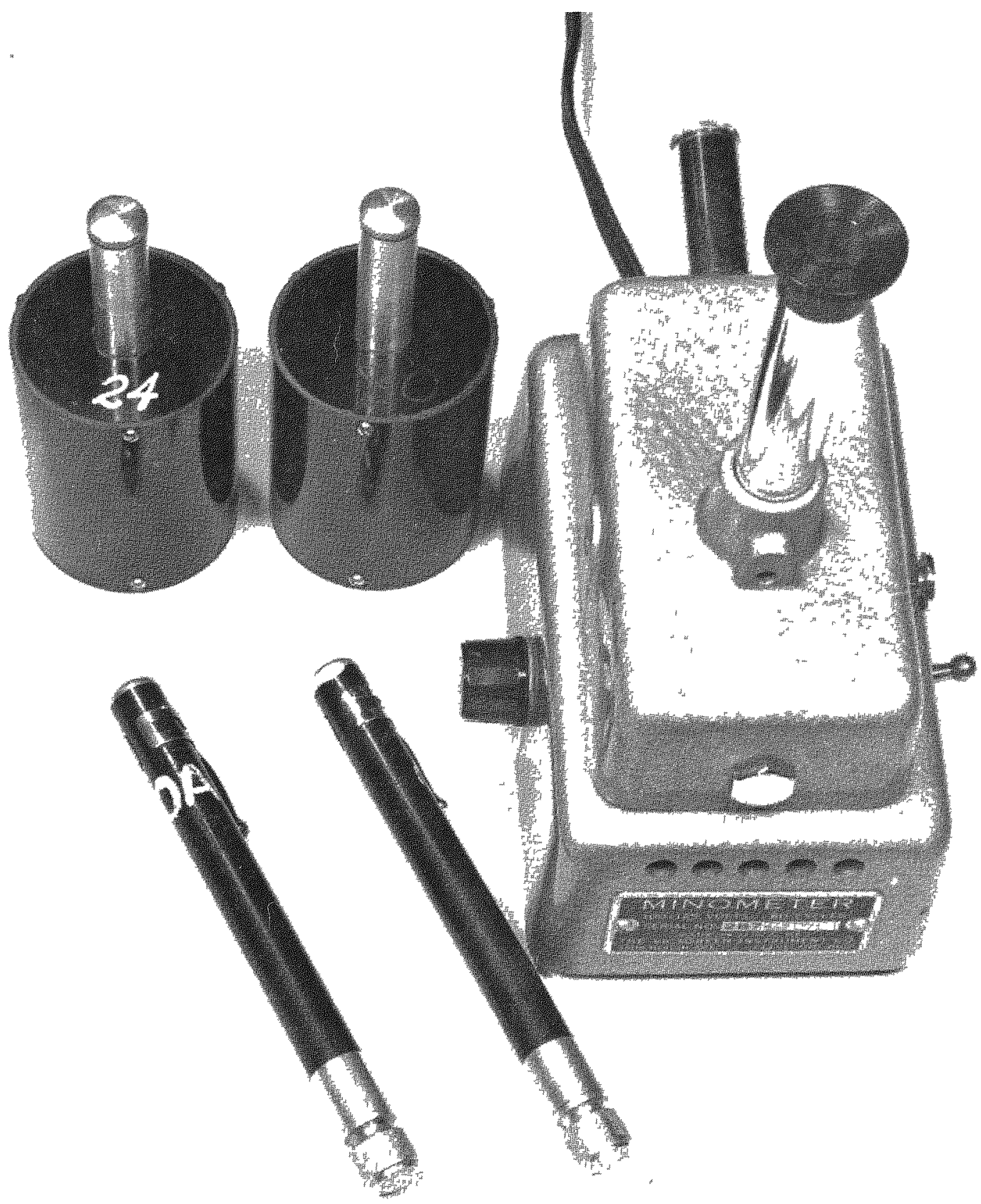

Fig. 2.2-Ionization chambers and charger-reader. 

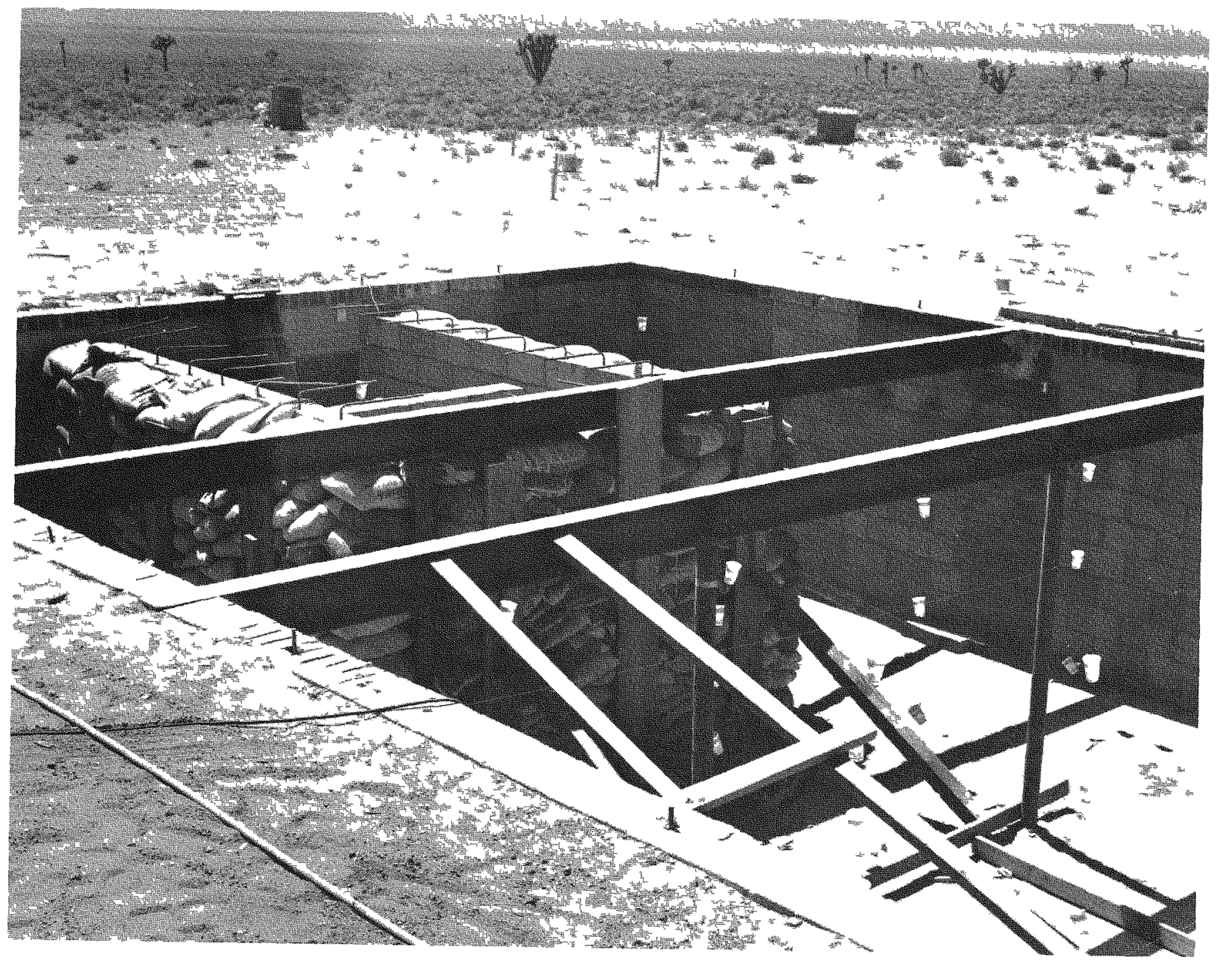

Fig. 2.3-Tubing layout around open basement. 


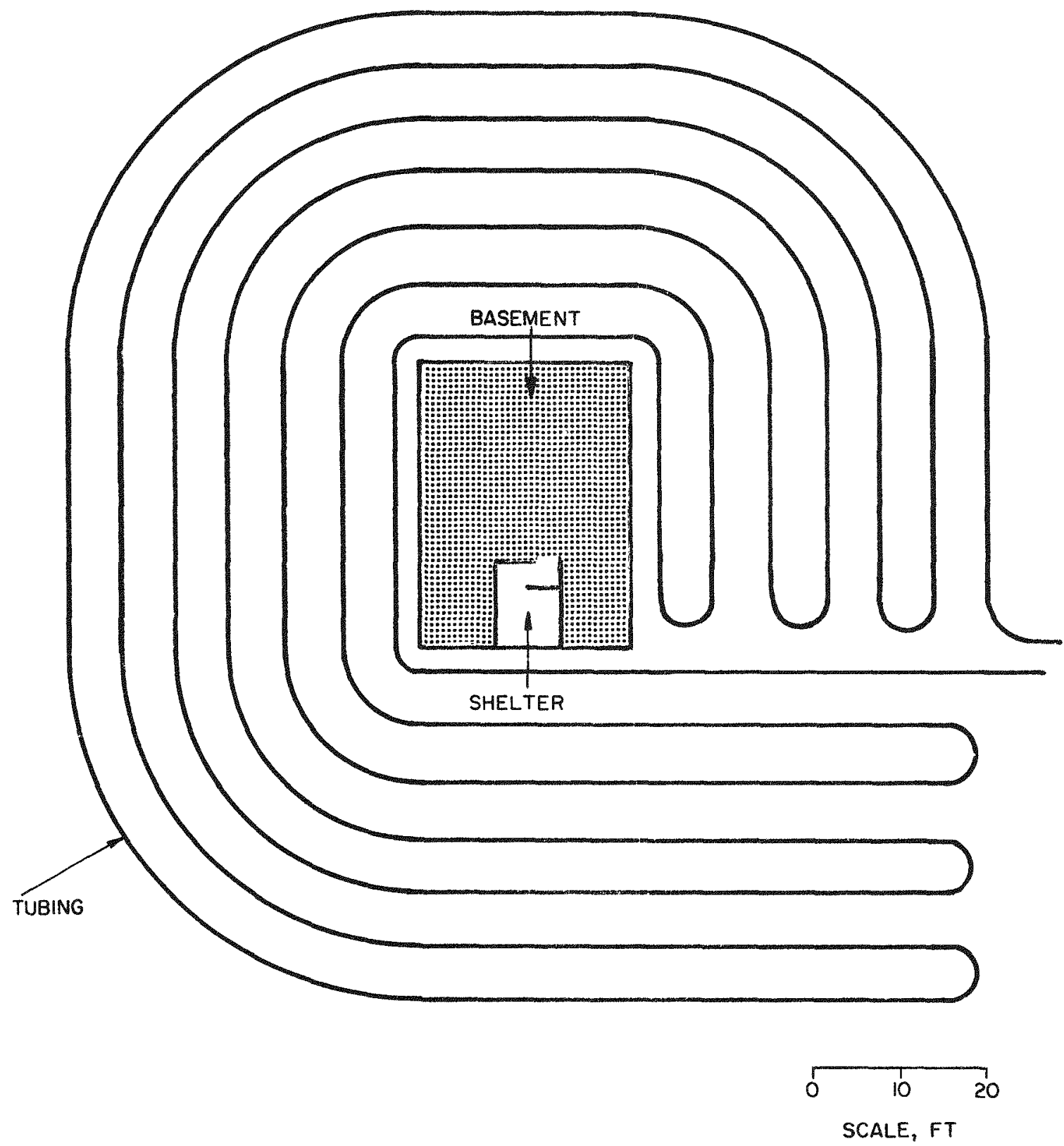

Fig. 2.4-Sample of tubing distribution around basement. 
of $127 \mathrm{ft}$ from the center of the basement was chosen because of the limitation of source activities and detector sensitivity and to correspond to previous measurements.

Measurements were also made with the tubing distributed $2 \mathrm{ft}$ apart on the roof of the basement (Fig. 2.5).

As the photographs indicate, the immediate area surrounding the structure was smoothed and graded before measurements were made. Also, after the wood roof was built and after each layer of concrete was placed on the roof, the ground was graded flush with the top of the roof. This assured the experimenters that only airscattered photons reached the structure components.

At each location several dosimeters were placed in paper cups attached to string hung from wires (Fig. 2.3). The time of exposure varied from a few minutes to several hours.

After each phase of construction the following procedures were observed during a specific exposure:

1. Polyethylene tubing was distributed over the desired area according to a predetermined plan.

2. Dosimeters were charged and positioned while a dummy source capsule was pumped through the tubing to assure that the tubing had not been damaged.

3. After the area was cleared of all personnel, a radioactive source capsule was used and the experimental run was made. At the end of the exposure, the source was secured in its shield, dosimeters were read, and readings were recorded.

\section{REFERENCES}

1. Z. G. Burson, Experimental Radiation Measurements in Conventional Structures, Report CEX-59.7B, Part I, Radiation Measurements in Two 2-story and Three 1-story Typical Residential Structures Before and After Modification, to be published.

2. Z. G. Burson, R. L. Summers, and J. T. Brashears, Mobile Radiological Measurement Unit: Description and Operating Information. Report CEX-63.11, February 1965.

3. F. W. Sanders et al., "A Simple Method of Minimizing the Energy Dependence of Pocket Ionization Chambers," Health Physics, Vol. 2, 308-09, 1960.

4. L. V. Spencer, Structure Shielding Against Fallout Radiation from Nuclear Weapons, NBS Monograph 42 (National Bureau of Standards, Washington 25, D. C.), June 1962. 


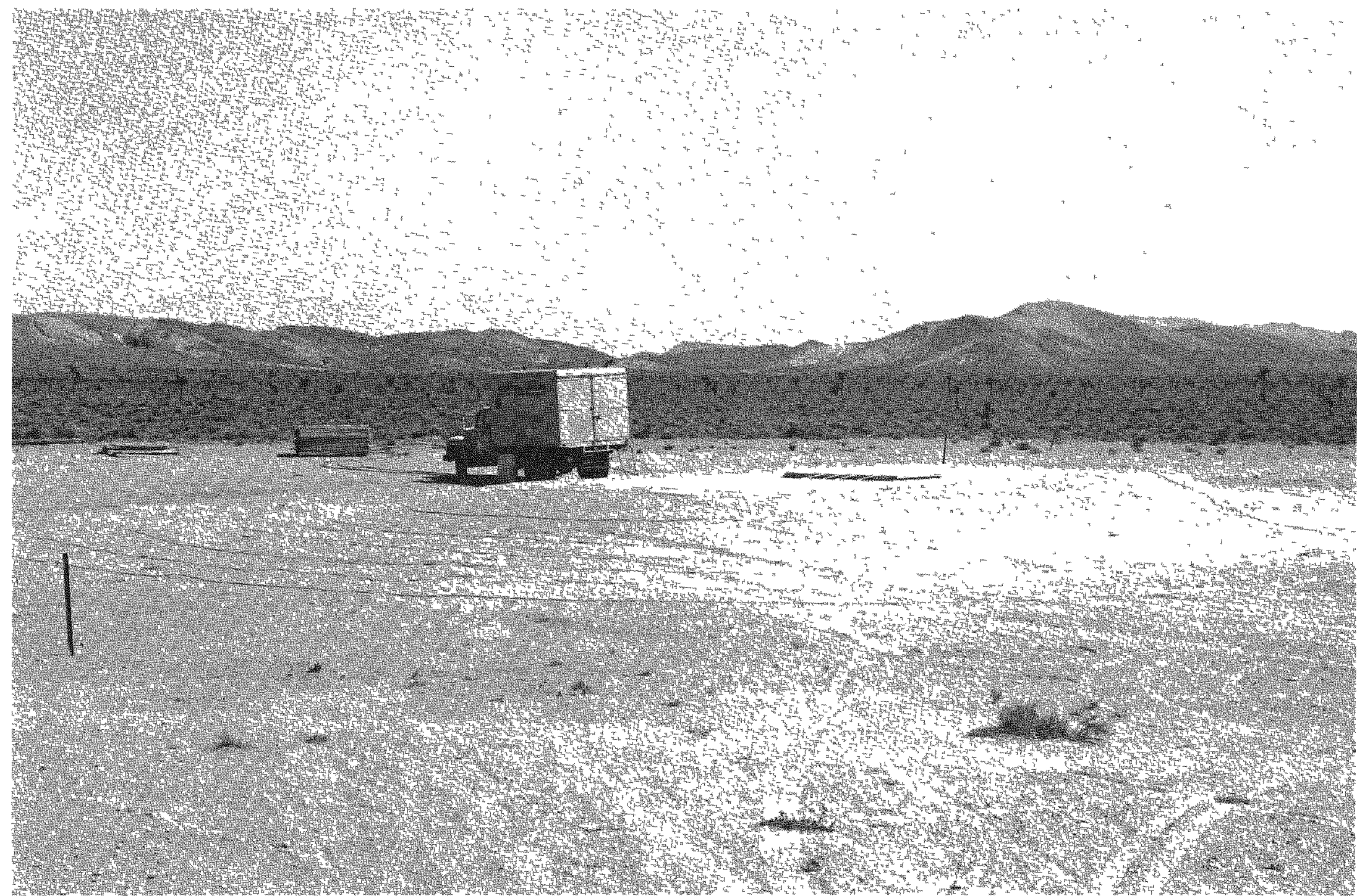

Fig. 2.5- Tubing distribution on basement roof and ground surrounding basement. 


\section{Chapter 3}

\section{PRESENTATION OF DATA}

The dosimeter readings at each point were corrected for background, temperature and pressure, and calibration. These corrected readings were then normalized to milliroentgens per hour per millicurie per square foot for the simulated area sources and to milliroentgens per hour per curie per foot of circumference for the simulated ring sources.

The area source data were normalized by multiplying the corrected readings ( $D_{c}$ in milliroentgens) by the total area ( $A$ in square feet over which the tubing was distributed) and dividing by the exposure time ( $\mathrm{T}$ in hours) and by the source strength ( $\mathrm{S}$ in millicuries). Thus

$$
\text { Normalized exposure rate, } \mathrm{mr} / \mathrm{hr} \text { per } \mathrm{mc} / \mathrm{sq} \mathrm{ft}=\frac{\mathrm{D}_{\mathrm{C}} \times \mathrm{A}}{\mathrm{T} \times \mathrm{S}}
$$

The resulting exposure rate at a particular point is the same as it would be if the same area were contaminated by $60 \mathrm{Co}$ to a source density of $1 \mathrm{mc} / \mathrm{sq} \mathrm{ft}$.

The ring source data were normalized as follows:

Normalized exposure rate, $\mathrm{mr} / \mathrm{hr}$ per $\mathrm{c} / \mathrm{ft}=\frac{\mathrm{D}_{\mathrm{c}} \times 2 \pi \mathrm{r}}{\mathrm{T} \times \mathrm{S}}$

where $r$ is the radius in feet and $S$ is the source strength in curies. Parameters for these normalizations are listed in Table 3. 1.

There were 25 detector positions in the bare basement. These positions are located on a floor plan in Fig. 3. 1. Readings were made at 1,3 , and $5 \mathrm{ft}$ above the basement floor at all positions. Additional data were taken at 2, 4, and $6 \mathrm{ft}$ heights at diagonal positions. After the shelter walls were erected, detector positions were renumbered. The positions were the same outside the shelter with additional positions inside. These position numbers are identified in Fig. 3.2 and were used for all other phases of construction. 
TABLE 3.1 - INFORMATION USED IN CORRECTING AND NORMALIZING DATA

\begin{tabular}{|c|c|c|c|c|c|c|c|}
\hline $\begin{array}{c}\text { Run } \\
\text { number }\end{array}$ & $\begin{array}{c}\text { Source } \\
\text { type }\end{array}$ & $\begin{array}{c}\text { Exposure } \\
\text { time, } \\
\text { hours }\end{array}$ & $\begin{array}{c}\text { Average } \\
\text { temp., } \\
{ }^{\circ} \mathrm{C}\end{array}$ & $\begin{array}{c}\text { Average } \\
\text { pressure, } \\
\text { mm Hg }\end{array}$ & $\begin{array}{l}\text { Area, } \\
\text { sqft }\end{array}$ & $\begin{array}{c}\text { Circumference, } \\
\mathrm{ft}\end{array}$ & $\begin{array}{r}\text { Source } \\
\text { Activity, } \\
\text { curies }\end{array}$ \\
\hline \multicolumn{8}{|c|}{ Bare Basement } \\
\hline 1 & Ground area & 0.254 & 23 & 654 & 11,150 & & 264 \\
\hline 2 & 127-ft radius & 0.775 & 20 & 658 & & 798 & 264 \\
\hline \multicolumn{8}{|c|}{ Shelter Walls Only } \\
\hline 3 & Ground area & 0.386 & 21 & 658 & 11,150 & & 264 \\
\hline 4 & $127-\mathrm{ft}$ radius & 1. 066 & 20 & 654 & & 798 & 264 \\
\hline \multicolumn{8}{|c|}{ Sandbags Around Outside Walls of Shelter } \\
\hline 5 & Ground area & 0.385 & 21 & 661 & 11,150 & & 263 \\
\hline 6 & $127-\mathrm{ft}$ radius & 1.452 & 23 & 662 & & 798 & 263 \\
\hline \multicolumn{8}{|c|}{ Roof Over Shelter } \\
\hline 7 & Ground area & $0.267^{*}$ & 22 & 653 & 11,150 & & 262 \\
\hline & & 1. $425 * *$ & 22 & 653 & 11,150 & & 262 \\
\hline 8 & $127-\mathrm{ft}$ radius & $0.982 *$ & 25 & 660 & & 798 & 262 \\
\hline & & $3.472 \% *$ & 25 & 660 & & 798 & 262 \\
\hline \multicolumn{8}{|c|}{ Wood Roof Over Basement } \\
\hline 9 & Ground area & $0.391 *$ & 23 & 662 & 10,580 & & 261 \\
\hline & & $2.081 * *$ & 23 & 662 & 10,580 & & 261 \\
\hline 10 & Roof area & 0.0570 & 22 & 656 & 822 & & 15.7 \\
\hline \multicolumn{8}{|c|}{4 in. Concrete Over Basement } \\
\hline 11 & Ground area & $1.033 *$ & 17 & 658 & 11,110 & & 260 \\
\hline & & 4. $161 * *$ & 17 & 658 & 11,110 & & 260 \\
\hline 12 & Roof area & 0.0979 & 27 & 658 & 822 & & 15.7 \\
\hline \multicolumn{8}{|c|}{8 in. Concrete Over Basement } \\
\hline 13 & Ground area & 3.559 & 18 & 658 & 7,280 & & 259 \\
\hline 14 & Roof area & 0.147 & 18 & 659 & 822 & & 15.6 \\
\hline
\end{tabular}




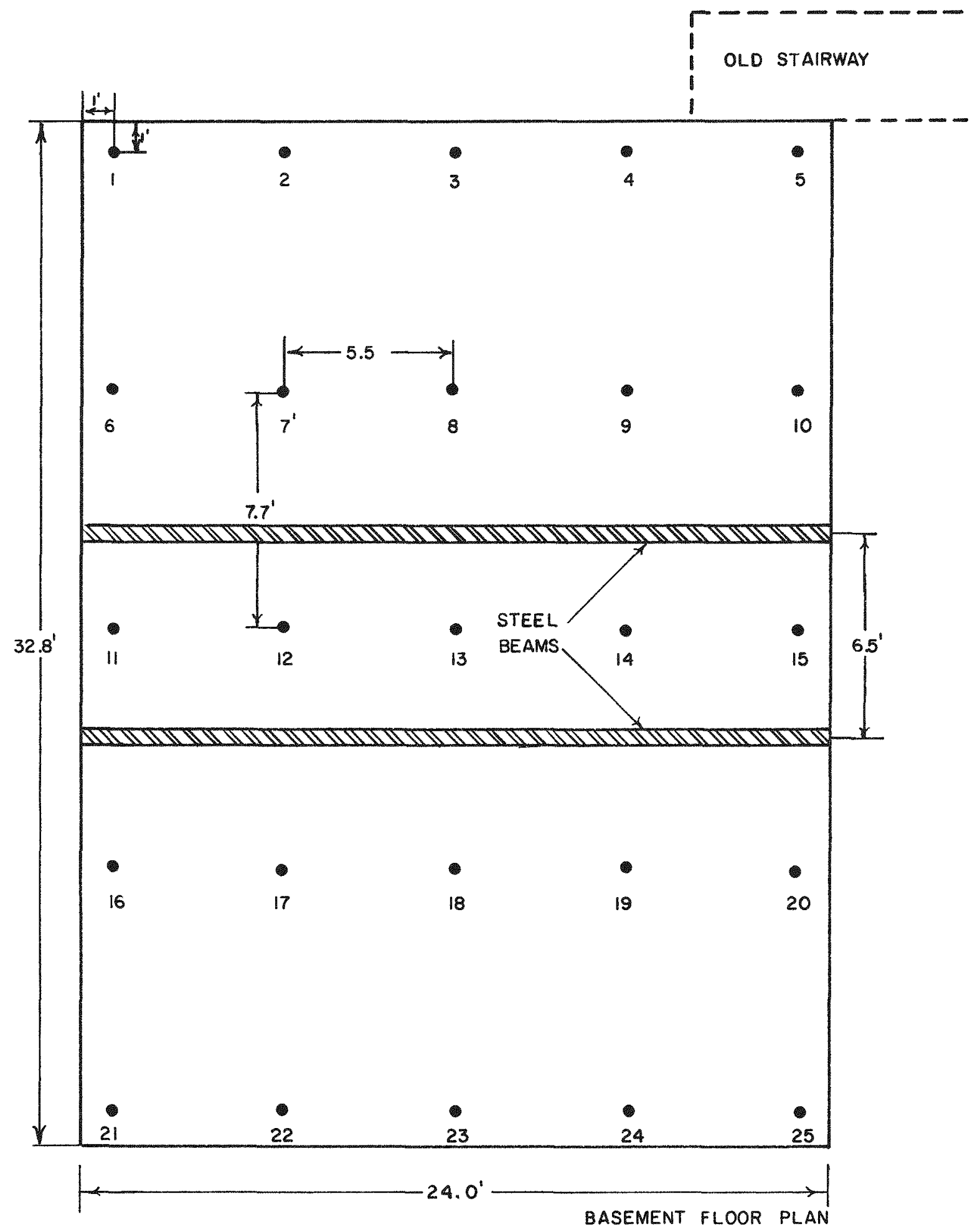

Fig. 3.1-Dosimeter positions for bare basement measurements. 


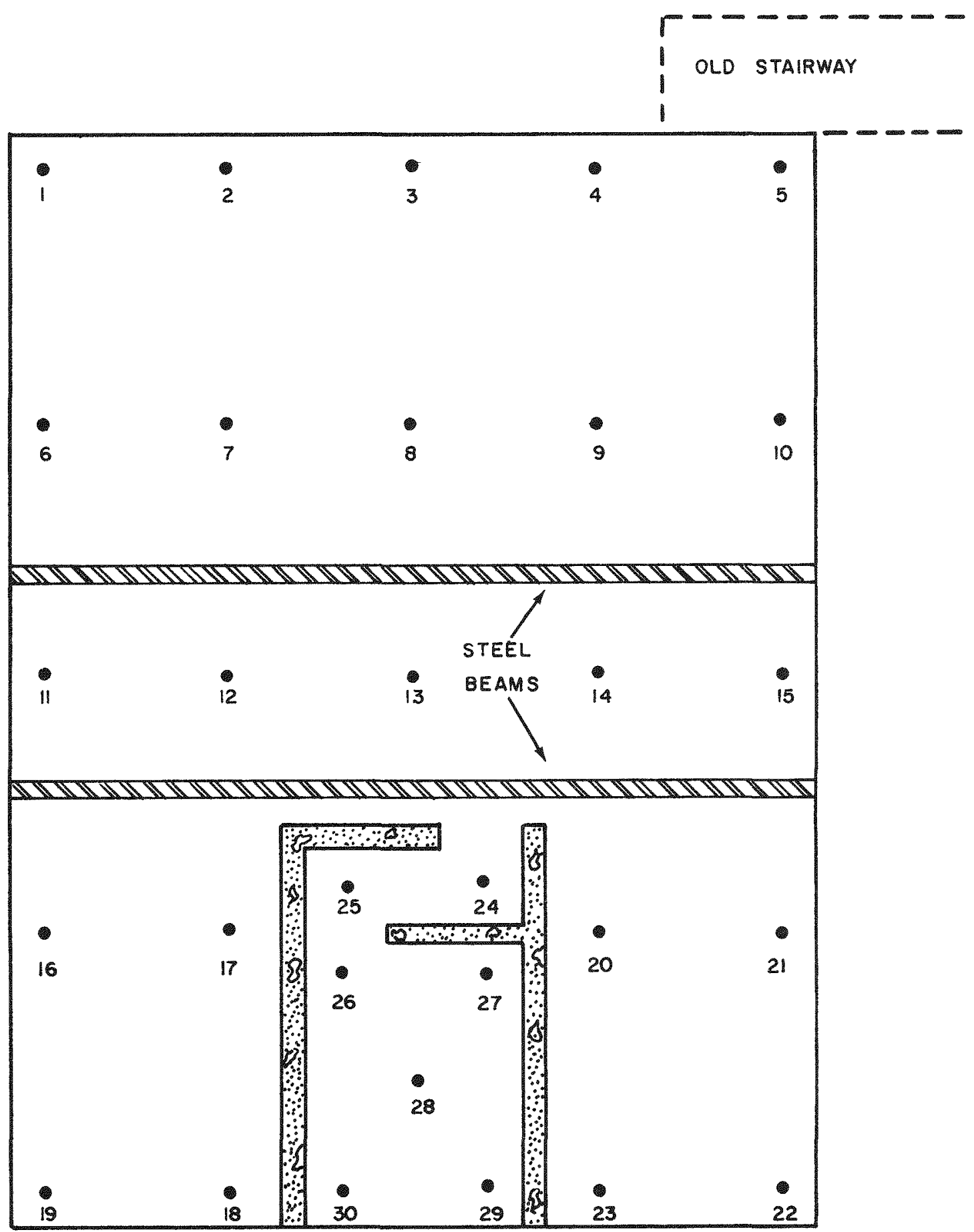

Fig. 3.2-Dosimeter positions for basement with shelter. 
The data are presented in seven tables. Table 3.2 contains data in the bare, open basement. Tables 3.3 through 3.8 include data for all other phases of the experiment. In addition, some of the data are presented graphically in Figs. 3. 3 through 3.13. Most of the data points inside the shelter were averaged from two dosimeter readings. The high-range chambers ( 0 to $200 \mathrm{mr}$ ) were used for readings outside the shelter from the simulated area source on the roof of the basement. The low-range chambers ( 0 to $10 \mathrm{mr}$ ) were used inside the shelter and for all other readings.

Exposure times were such that most of the chambers read at least $10 \%$ of full scale ( $1 \mathrm{mr}$ for the 0 to $10-\mathrm{mr}$ chambers). Because of the wide range of exposure rates to be measured, two readings were usually made. Even then, some chambers at the 6-ft height read off scale; blank spaces in the tables denote this. The exposure times were long for the 127-ft-radius ring-source measurements. Therefore, these measurements were discontinued after the roof was constructed over the shelter. 
TABLE 3.2 - EXPOSURE RATE IN BARE, OPEN BASEMENT

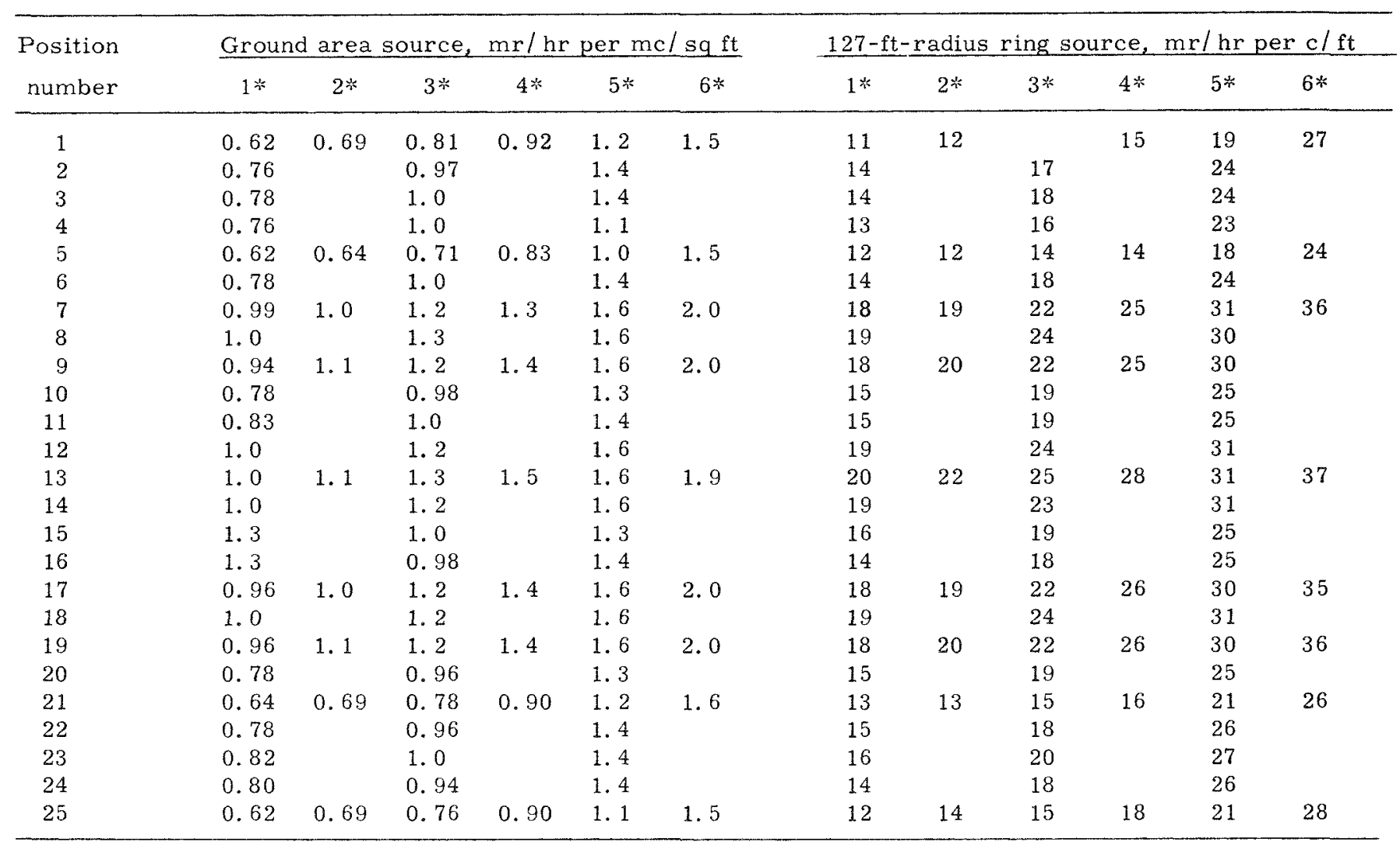

* Height in feet above basement floor. 
TABLE 3.3 - EXPOSURE RATES IN OPEN BASEMENT WITH ONLY THE SHELTER WALLS CONSTRUCTED

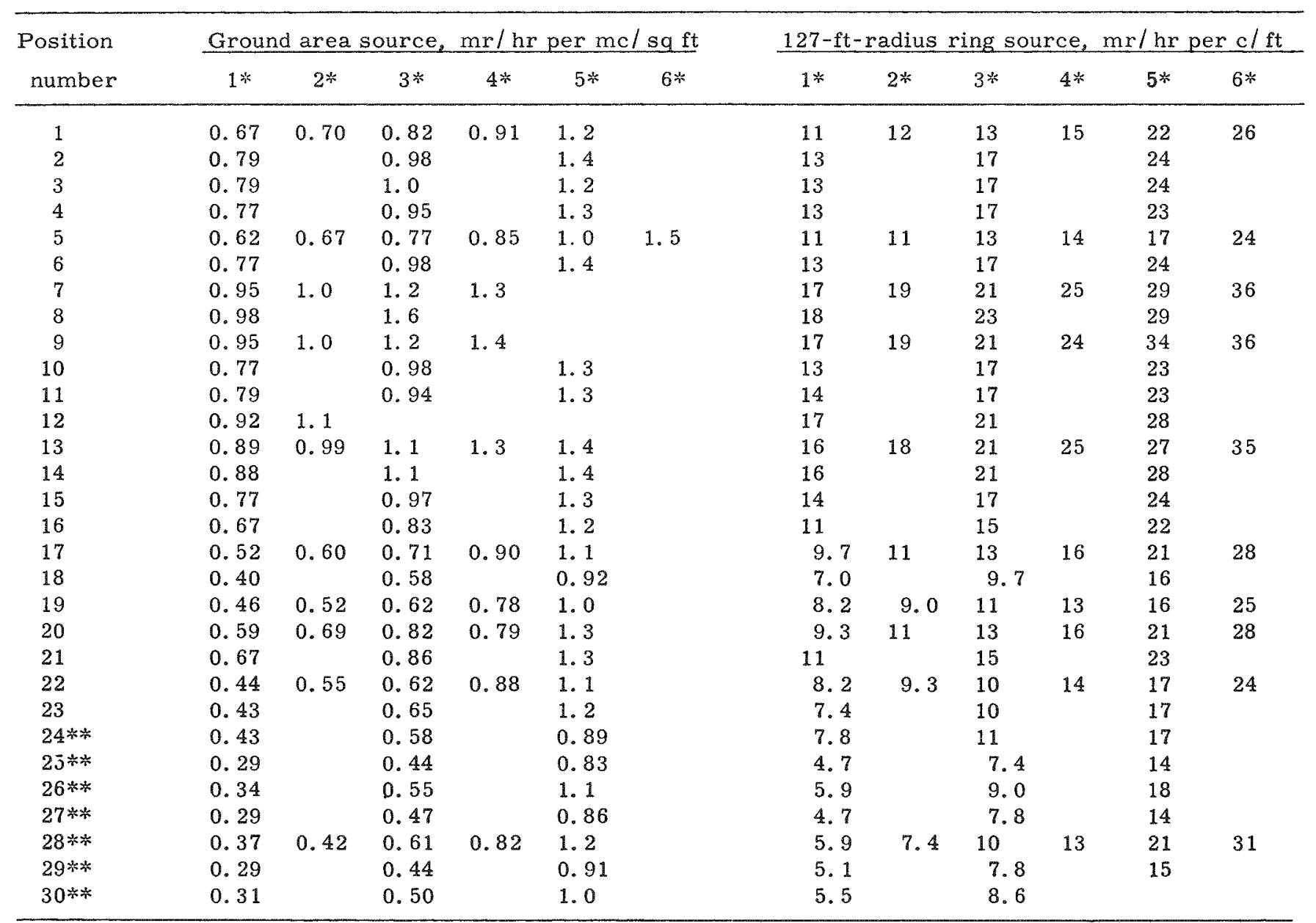

* Height in feet above basement floor.

$* *$ Inside shelter. 
TABLE 3. - EXPOSURE RATES IN OPEN BASEMENT WITH SANDBAGS AROUND SHELTER WALLS

\begin{tabular}{|c|c|c|c|c|c|c|c|c|c|c|c|c|}
\hline \multirow{2}{*}{$\begin{array}{l}\text { Position } \\
\text { number }\end{array}$} & \multicolumn{6}{|c|}{ Ground area source, $\mathrm{mr} / \mathrm{hr}$ per $\mathrm{mc} / \mathrm{sq} \mathrm{ft}$} & \multicolumn{6}{|c|}{ 127-ft-radius ring source, $\mathrm{mr} / \mathrm{hr}$ per c/ft } \\
\hline & $1 *$ & $2 *$ & $3 *$ & $4 *$ & $5 *$ & $6 *$ & $1 *$ & $2 *$ & $3 *$ & $4 *$ & $5 *$ & $6 *$ \\
\hline 1 & 0.64 & 0.67 & 0.77 & 0.90 & 1. 1 & & 11 & 12 & 14 & 16 & 20 & 27 \\
\hline 2 & 0.76 & & 0.94 & & 1.3 & & 13 & & 17 & & 24 & \\
\hline 3 & 0.80 & & 0.97 & & 1.3 & & 13 & & 17 & & 23 & \\
\hline 4 & 0.76 & & 0.92 & & 1. 3 & & 13 & & 16 & & 22 & \\
\hline 5 & 0.60 & 0.66 & 0.73 & 0.84 & 1.1 & & 10 & 11 & 12 & 14 & 17 & 22 \\
\hline 6 & 0.76 & & 0.97 & & 1.4 & & 14 & & 18 & & 25 & \\
\hline 7 & 0.92 & 1.0 & 1. 1 & 1.3 & & & 17 & 19 & 22 & 25 & & \\
\hline 8 & 0.97 & & 1.4 & & & & 18 & & 23 & & & \\
\hline 9 & 0.95 & 1.0 & 1.2 & 1.4 & & & 17 & 19 & 21 & 25 & & \\
\hline 10 & 0.79 & & 0.97 & & 1.4 & & 14 & & 18 & & 23 & \\
\hline 11 & 0.77 & & 0.95 & & 1.4 & & 14 & & 17 & & 24 & \\
\hline 12 & 0.88 & & 1.1 & & & & 16 & & 20 & & & \\
\hline 13 & 0.82 & 0.78 & 1. 1 & 1. 2 & 1.4 & & 15 & 16 & 19 & 24 & 26 & \\
\hline 14 & 0.83 & & 1.0 & & 1.4 & & 16 & & 20 & & 27 & \\
\hline 15 & 0.74 & & 0.9 & & 1.3 & & 14 & & 18 & & 25 & \\
\hline 19 & 0.42 & 0.45 & 0.57 & 0.71 & 0.92 & & 7.7 & 8.6 & 10 & 13 & 17 & 27 \\
\hline 22 & 0.40 & 0.52 & 0.60 & 0.81 & 1.1 & & 7.2 & 9.2 & 10 & 13 & 17 & 25 \\
\hline $24 \% *$ & 0.12 & & 0.21 & & 0.54 & & 2.3 & & 4.0 & & 10 & \\
\hline $25 * *$ & 0.24 & & 0.37 & & 0.74 & & 4.3 & & 6.9 & & 13 & \\
\hline $26 *$ & 0.28 & & 0.46 & & 0.98 & & 5.2 & & 8.3 & & 17 & \\
\hline $27+2$ & 0.28 & & 0.46 & & 0.82 & & 4.9 & & 7.7 & & 14 & \\
\hline $28 *$ & 0.30 & 0.41 & 0.58 & 0.81 & 1.2 & & 5.5 & 6.3 & 9.7 & 13 & 22 & \\
\hline $29 * *$ & 0.28 & & 0.43 & & 0.92 & & 4. 9 & & 7.5 & & 15 & \\
\hline $30 * *$ & 0.30 & & 0.45 & & 1.1 & & 5.2 & & 8.3 & & 17 & \\
\hline
\end{tabular}

NOTE There are no data at positions 16, 17, 18, 20, 21 and 23 because of sandbag placement and support. * Height in feet above basement floor.

** Inside shelter. 
TABLE 3.5 - EXPOSURE RATES IN BASEMENT WITH ROOF OVER SHELTER

\begin{tabular}{|c|c|c|c|c|c|c|c|c|c|c|c|c|}
\hline $\begin{array}{l}\text { Position } \\
\text { number }\end{array}$ & $1 *$ & $2 *$ & $3 *$ & $4 *$ & $5 *$ & $6 *$ & $1 *$ & $2 *$ & $3 *$ & $4 *$ & $5^{*}$ & $6 *$ \\
\hline 2 & 0.75 & & 0.92 & & 1. 4 & & 12 & & 17 & & 24 & \\
\hline 3 & 0.77 & & 0.97 & & 1.3 & & 13 & & 17 & & 24 & \\
\hline 4 & 0.68 & & 0.92 & & 1.3 & & 12 & & 17 & & 23 & \\
\hline 7 & 0.88 & 0.99 & 1.1 & 1.3 & 1.6 & 1.9 & 16 & 18 & 20 & 24 & 30 & 36 \\
\hline 8 & 0.92 & & 1. 2 & & 1.5 & & 17 & & 22 & & 29 & \\
\hline 9 & 0.86 & 0.99 & 1.1 & 1.3 & 1.5 & 1.8 & 16 & 19 & 21 & 25 & 29 & 35 \\
\hline 10 & 0.73 & & 0.92 & & 1.3 & & 14 & & 18 & & 24 & \\
\hline 11 & 0.75 & & 0.94 & & 1. 3 & & 14 & & 19 & & 24 & \\
\hline 12 & 0.83 & & 1.1 & & 1.4 & & 16 & & 18 & & 24 & \\
\hline 17 & 0.53 & 0.57 & 0.68 & 0.88 & 1.1 & 1.3 & 12 & 12 & 15 & 19 & 22 & 27 \\
\hline 18 & 0.37 & & 0.55 & & 0.88 & & 9.4 & & 13 & & 17 & \\
\hline 19 & 0.44 & 0.48 & 0.57 & 0.73 & 0.94 & 1.4 & 7.3 & 8. 2 & 9.2 & 13 & 17 & 24 \\
\hline 20 & 0.55 & 0.68 & 0.77 & 0.97 & 1. 2 & 1.5 & & 12 & 15 & 18 & 22 & 27 \\
\hline 21 & 0.70 & & 0.79 & & 1. 2 & & 12 & & 15 & & 24 & \\
\hline 22 & 0.42 & 0.53 & 0.57 & & 1. 1 & 1.4 & 9.0 & 10 & 12 & 15 & 20 & 25 \\
\hline 23 & 0.42 & & 0.53 & & 0.97 & & 9.0 & & 11 & & 18 & \\
\hline 24 & 0.32 & & 0.38 & & 0.42 & & 6.6 & & 7.9 & & 11 & \\
\hline 25 头冰 & 0.058 & & 0.079 & & 0.11 & & 1. 1 & & 1.7 & & 2.3 & \\
\hline $26^{*} x^{2}$ & 0.058 & & 0.079 & & 0.099 & & 1. 1 & & 1.6 & & 1. 9 & \\
\hline $27 * *$ & 0.042 & & 0.062 & & 0.087 & & 0.74 & & 1.2 & & 1.7 & \\
\hline $28 * *$ & 0.050 & 0.066 & 0.091 & & 0.099 & 0.099 & 0.74 & 1. 1 & 1.3 & 1. 6 & 1.8 & 1.7 \\
\hline
\end{tabular}

* Height in feet above basement floor.

* Inside shelter. 
TABLE 3.6 - EXPOSURE RATES IN BASEMENT WITH WOOD ROOF OVER BASEMENT

\begin{tabular}{|c|c|c|c|c|c|c|c|c|c|c|c|c|}
\hline \multirow{2}{*}{$\begin{array}{l}\text { Position } \\
\text { number }\end{array}$} & \multicolumn{6}{|c|}{ Ground area source, $\mathrm{mr} / \mathrm{hr}$ per $\mathrm{mc} / \mathrm{sqft}$} & \multicolumn{6}{|c|}{ Roof area source, $\mathrm{mr} / \mathrm{hr}$ per $\mathrm{mc} / \mathrm{sq} f$} \\
\hline & $1 *$ & $2 *$ & $3 *$ & $4 *$ & $5 *$ & $6 *$ & $1 *$ & $2 *$ & $3 *$ & $4 *$ & $5 *$ & $6 *$ \\
\hline 1 & 0.40 & & & & 0.88 & & 37 & & 47 & & 60 & \\
\hline 2 & 0.54 & & 0.65 & & 0.86 & & 41 & & 53 & & 71 & \\
\hline 3 & 0.57 & & & & 0.88 & & 48 & & 60 & & 81 & \\
\hline 4 & 0.52 & & 0.65 & & 0.82 & & & & 55 & & 70 & \\
\hline 5 & 0.42 & 0.48 & 0.49 & 0.57 & 0.66 & 0.86 & 35 & 38 & 41 & 49 & 60 & 70 \\
\hline 6 & 0.57 & & & & 0.86 & & 47 & & 57 & & 74 & \\
\hline 7 & 0.68 & 0.73 & 0.79 & & 0.97 & 1.1 & 52 & 60 & 66 & 78 & 85 & 100 \\
\hline 8 & 0.71 & & & & 1.1 & & 61 & & 74 & & 100 & \\
\hline 9 & 0.69 & 0.76 & 0.83 & 0.95 & & 1. 1 & 53 & 62 & 72 & 80 & 100 & 120 \\
\hline 10 & 0.58 & & & & 0.86 & & 47 & & 55 & & 71 & \\
\hline 11 & 0.62 & & 0.71 & & 0.82 & & 46 & & 51 & & 66 & \\
\hline 12 & 0.73 & & & & 0.96 & & 50 & & 63 & & 90 & \\
\hline 13 & 0.66 & & 0.74 & 0.82 & 0.85 & 0.95 & 50 & & 65 & 74 & 86 & 100 \\
\hline 14 & 0.71 & & & & 0.90 & & 50 & & 62 & & 81 & \\
\hline 15 & 0.55 & & & & 0.82 & & 46 & & 52 & & 74 & \\
\hline 16 & 0.47 & & & & 0.76 & & & & 47 & & 72 & \\
\hline 17 & 0.48 & 0.49 & 0.54 & 0.65 & 0.75 & 0.91 & 30 & 40 & 40 & 48 & 60 & 72 \\
\hline 18 & 0.34 & & & & 0.65 & & 21 & & 35 & & 52 & \\
\hline 19 & 0.35 & 0.40 & 0.48 & 0.75 & 0.68 & 0.88 & 27 & 31 & 38 & 47 & 52 & 66 \\
\hline 20 & 0.42 & 0.48 & 0.54 & 0.64 & 0.75 & 0.88 & 33 & & 47 & 53 & 68 & 85 \\
\hline 21 & 0.48 & & 0.59 & & 0.79 & & 37 & & 48 & & 63 & \\
\hline 22 & 0.34 & 0.38 & 0.45 & & 0.68 & 0.82 & 37 & 31 & 41 & 47 & 57 & 62 \\
\hline 23 & 0.33 & & 0.39 & & 0.62 & & 23 & & 35 & & 57 & \\
\hline 24 & 0.22 & & 0.24 & & 0.21 & & & & & & & \\
\hline $25 * *$ & 0.032 & & 0.051 & & 0.059 & & 8.4 & & 12 & & & \\
\hline $26 * *$ & 0.032 & & 0.045 & & 0.056 & & 9.4 & & 13 & & & \\
\hline $27 * *$ & 0.025 & & 0.043 & & 0.048 & & 7.3 & & 11 & & 12 & \\
\hline $28 * *$ & 0.027 & 0.035 & 0.040 & 0.051 & 0.053 & 0.051 & 8.7 & 11 & 12 & & & \\
\hline $29 * *$ & 0.041 & & 0.043 & & 0.048 & & 7.1 & & 9.8 & & 13 & \\
\hline $30 * *$ & 0.025 & & 0.035 & & 0.051 & & 7.3 & & 11 & & 12 & \\
\hline
\end{tabular}

* Height in feet above basement floor.

** Inside shelter. 
TABLE 3.7 - EXPOSURE RATES IN BASEMENT WITH WOOD ROOF AND 4 IN. OF CONCRETE OVER BASEMENT

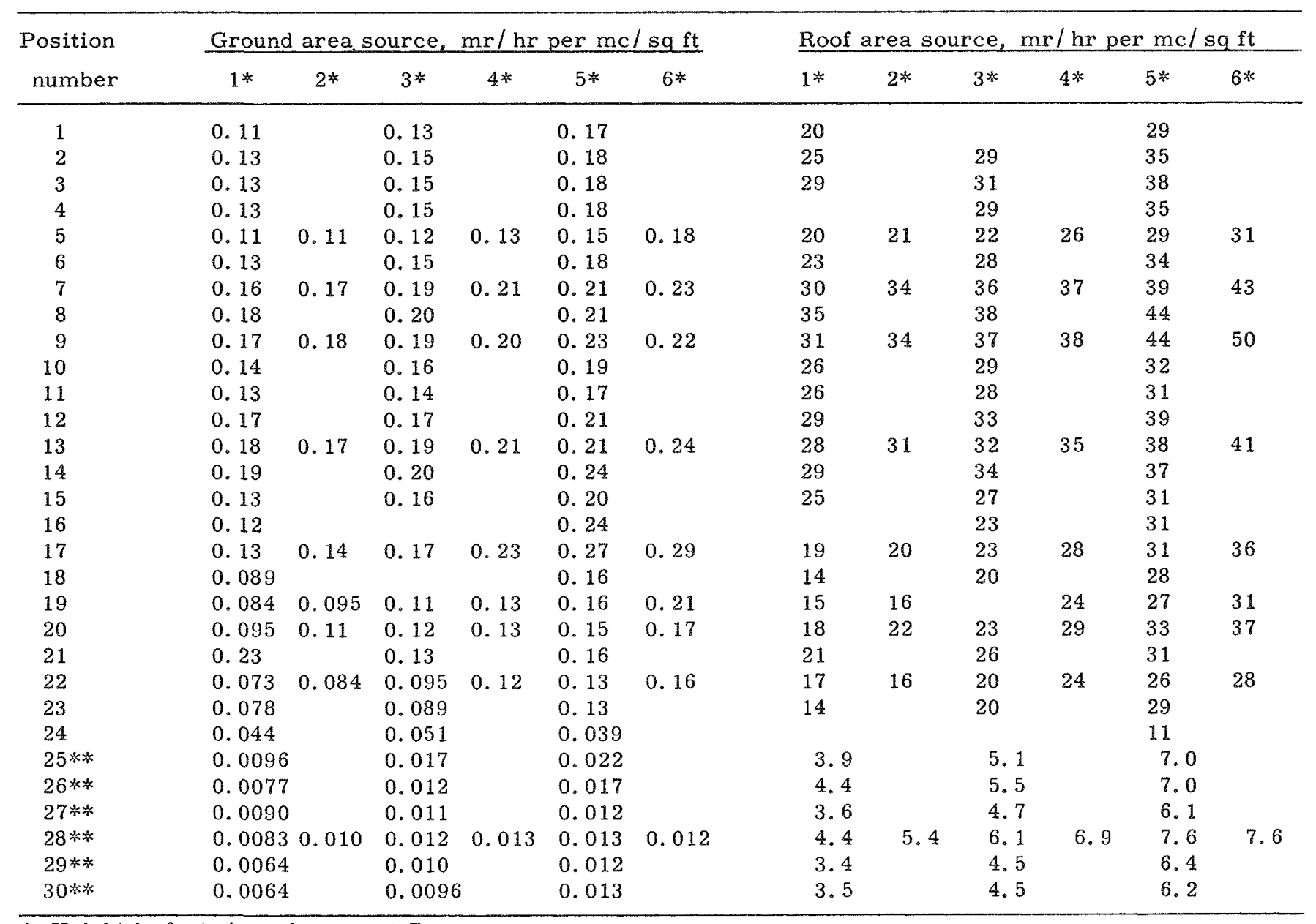

* Height in feet above basement floor.

** Inside shelter. 
TABLE 3.8 - EXPOSURE RATES IN BASEMENT WITH WOOD ROOF AND 8 IN. OF CONCRETE OVER BASEMENT

\begin{tabular}{|c|c|c|c|c|c|c|c|c|c|c|c|c|}
\hline \multirow{2}{*}{$\begin{array}{l}\text { Position } \\
\text { number }\end{array}$} & \multicolumn{6}{|c|}{ Ground area source, $\mathrm{mr} / \mathrm{hr}$ per $\mathrm{mc} / \mathrm{sq} \mathrm{ft}$} & \multicolumn{6}{|c|}{ Roof area source, $\mathrm{mr} / \mathrm{hr}$ per $\mathrm{c} / \mathrm{ft}$} \\
\hline & $1 *$ & $2 *$ & $3 *$ & $4 *$ & $5 *$ & 6 * & $1^{*}$ & $2 \%$ & $3 *$ & $4 *$ & $5 *$ & $6 *$ \\
\hline 1 & 0.034 & & 0.038 & & 0.076 & & 8.5 & & 9.9 & & 14 & \\
\hline 2 & 0.048 & & 0.058 & & 0.069 & & 9.4 & & 11 & & 13 & \\
\hline 3 & 0.054 & & 0.063 & & 0.066 & & 9.4 & & 13 & & 16 & \\
\hline 4 & 0.047 & & 0.059 & & 0.082 & & 9.4 & & 12 & & 14 & \\
\hline 5 & 0.031 & 0.032 & 0.034 & 0.041 & 0.058 & 0.11 & 6.6 & 7.5 & 8.0 & 9.4 & 10 & 14 \\
\hline 6 & 0.048 & & 0.053 & & 0.064 & & 9.9 & & 13 & & 14 & \\
\hline 7 & 0.066 & 0.067 & 0.079 & 0.081 & 0.082 & 0.069 & 14 & 14 & 15 & 15 & 16 & 17 \\
\hline 8 & 0.072 & & 0.086 & & 0.073 & & 15 & & 16 & & 19 & \\
\hline 9 & 0.061 & 0.067 & 0.081 & 0.092 & 0.10 & 0.086 & 14 & 14 & 17 & 16 & 19 & 19 \\
\hline 10 & 0.044 & & 0.050 & & 0.074 & & 10 & & 12 & & 14 & \\
\hline 11 & 0.046 & & 0.047 & & 0.058 & & 9.9 & & 10 & & 14 & \\
\hline 12 & 0.064 & & 0.071 & & 0.083 & & 11 & & 14 & & 17 & \\
\hline 13 & 0.064 & 0.071 & & 0.074 & 0.065 & 0.059 & 13 & 14 & 14 & 15 & 17 & 17 \\
\hline 14 & 0.063 & & 0.070 & & 0.072 & & 13 & & 14 & & 15 & \\
\hline 15 & 0.048 & & 0.047 & & 0.050 & & 9.4 & & 10 & & 13 & \\
\hline 16 & 0.038 & & & & & 0.057 & 9.9 & & 9.9 & & 14 & \\
\hline 17 & 0.039 & 0.044 & 0.051 & 0.062 & 0.067 & 0.065 & 6.6 & 8.5 & 9.4 & 11 & 14 & \\
\hline 18 & 0.023 & & & & 0.056 & & 5.2 & & 8.9 & & 11 & \\
\hline 19 & 0.023 & 0.025 & & 0.037 & 0.053 & 0.090 & 6.2 & 7.5 & 8.9 & 12 & 9.9 & 13 \\
\hline 20 & 0.038 & 0.048 & 0.055 & 0.066 & 0.070 & 0.066 & 8.9 & 8.9 & 10 & 12 & 14 & 14 \\
\hline 21 & 0.038 & & 0.048 & & 0.062 & & 8.9 & & 10 & & 14 & \\
\hline 22 & 0.023 & 0.026 & 0.027 & 0.043 & 0.060 & 0.097 & 8.5 & 8.0 & 9.4 & 9.9 & 11 & 13 \\
\hline 23 & 0.026 & & 0.035 & & 0.058 & & 5.7 & & 8.9 & & 11 & \\
\hline 24 & 0.022 & & 0.021 & & 0.014 & & 4.9 & & 4.8 & & 4.5 & \\
\hline $25 * *$ & 0.012 & & 0.014 & & 0.012 & & 1.5 & & 2.0 & & 2.8 & \\
\hline $26 * *$ & 0.011 & & 0.012 & & 0.012 & & 1.8 & & 2.3 & & 2.9 & \\
\hline $27 \%$ & 0.0099 & & 0.012 & & 0.0099 & & 1.4 & & 1. 9 & & 2.5 & \\
\hline $28 * *$ & 0.0089 & 0.012 & 0.013 & 0.012 & 0.012 & 0.0099 & 1.8 & 2.3 & 2.6 & 2.9 & 3.1 & 3.3 \\
\hline $29 * *$ & 0.0094 & & 0.013 & & 0.013 & & 1.4 & & 1.9 & & 2.7 & \\
\hline $30 * *$ & 0.0084 & & 0.0094 & & 0.014 & & 1.5 & & 2.0 & & 2.8 & \\
\hline
\end{tabular}

* Height in feet above basement floor.

** Inside shelter. 


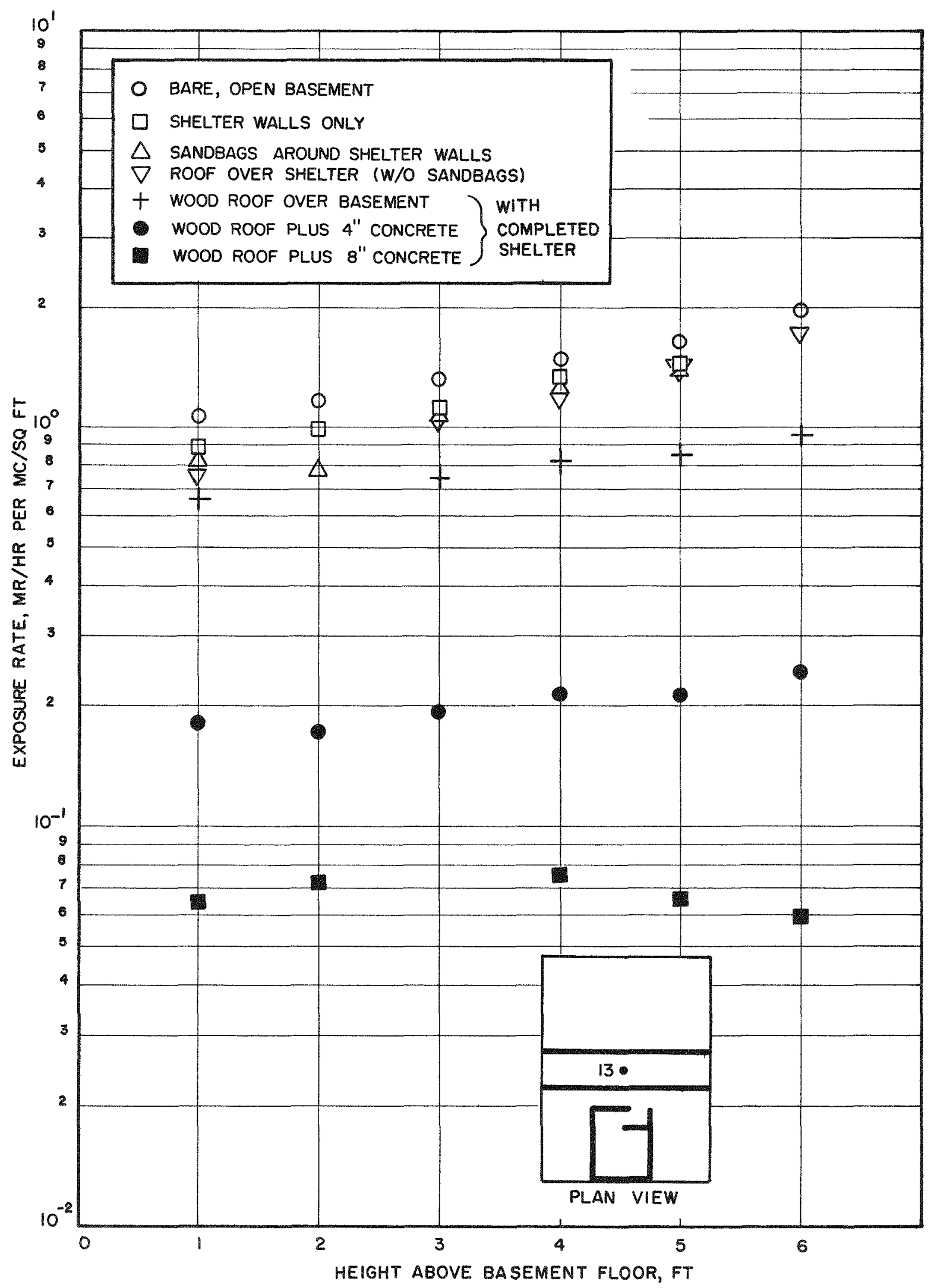

Fig. 3.3-Exposure rates at Position 13 (center) from simulated area source on ground for various stages of construction. 


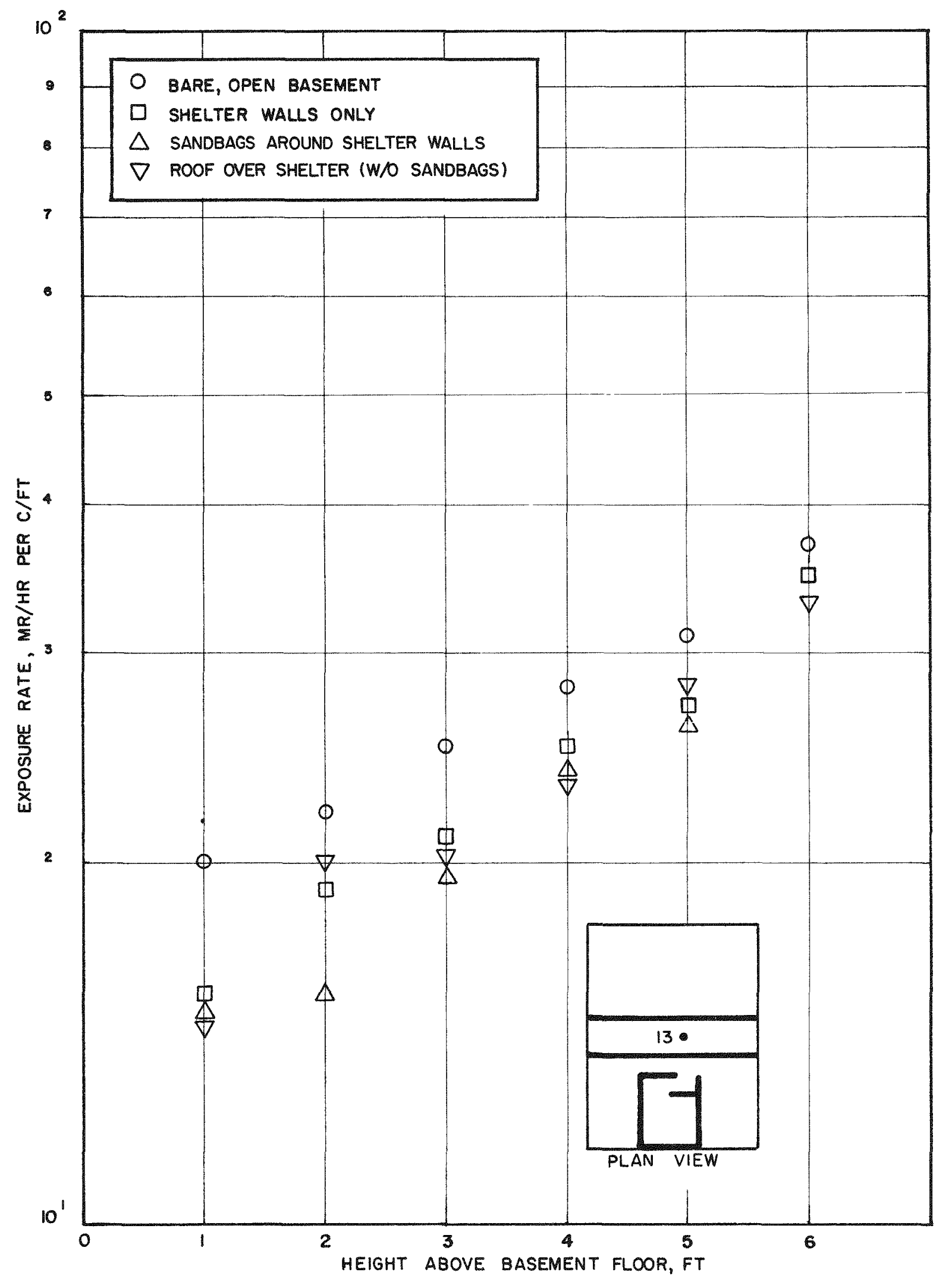

Fig. 3.4-Exposure rates at Position 13 (center) from a simulated ring source at 127 -ft radius for various stages of construction. 


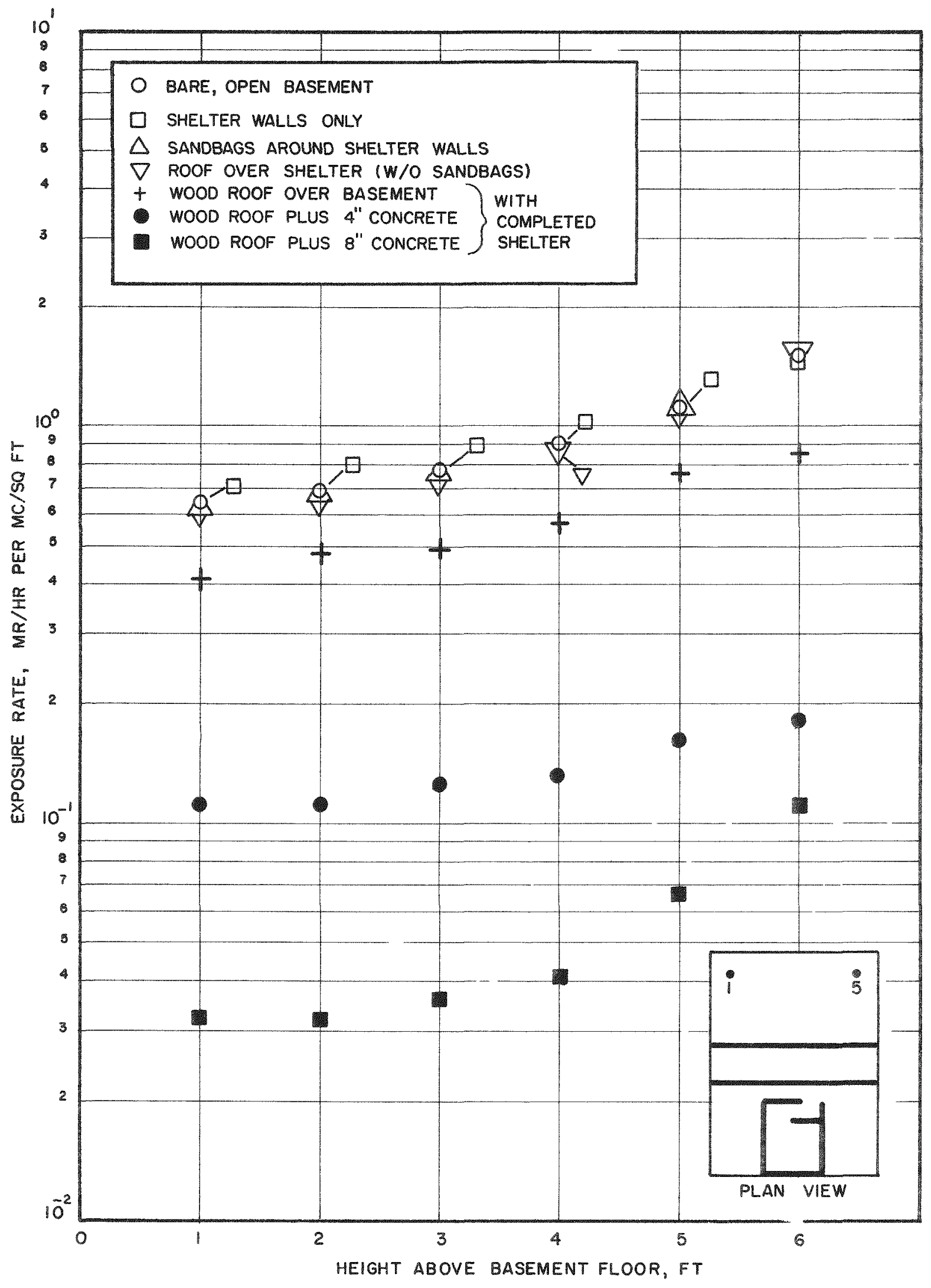

Fig. 3.5-Exposure rates at Positions 1 and 5 (averaged) from a simulated area source on the ground for various stages of construction. 


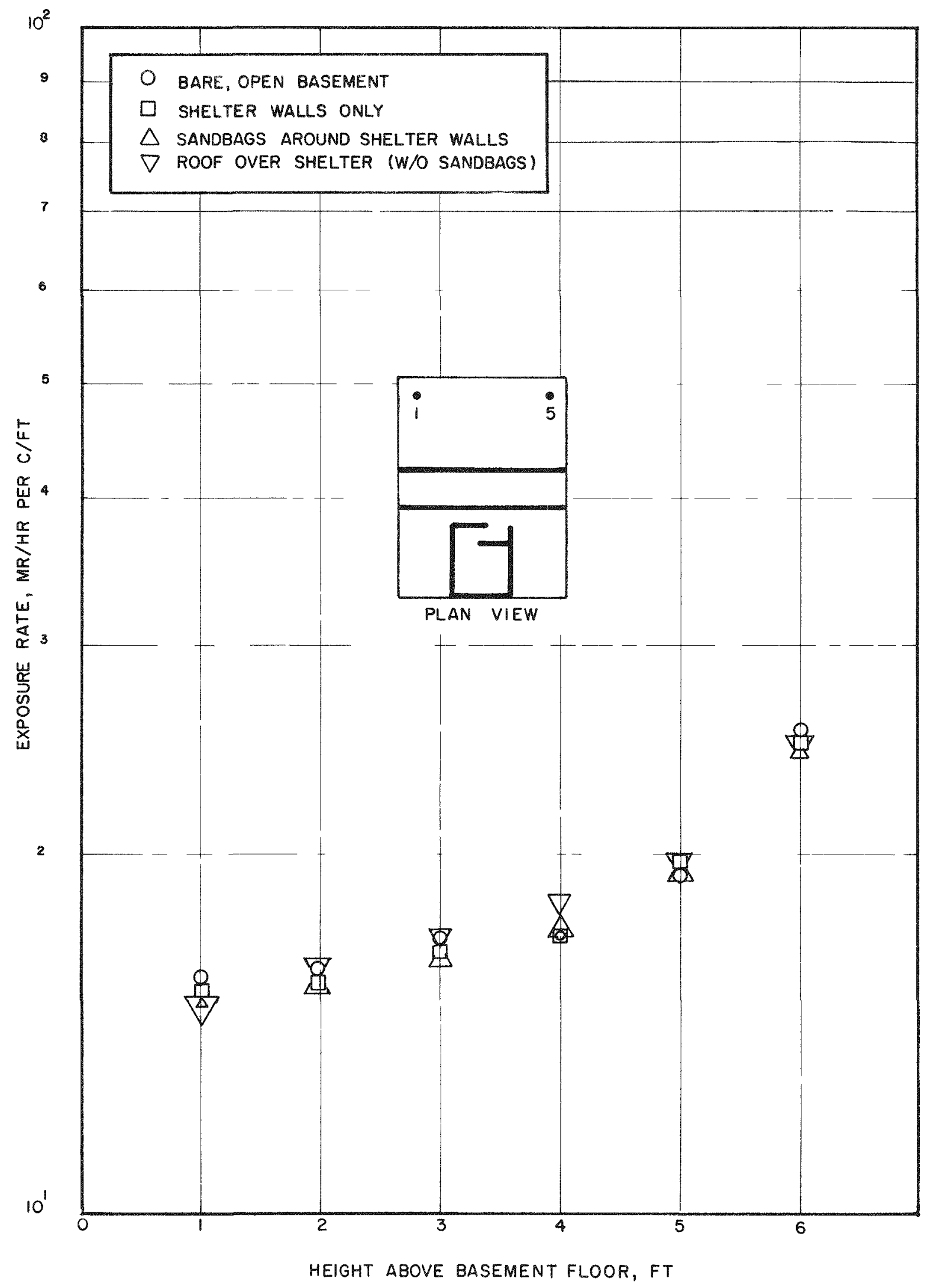

Fig. 3.6-Exposure rates at Positions 1 and 5 (averaged) from a simulated ring source at 127-ft radius for various stages of construction. 


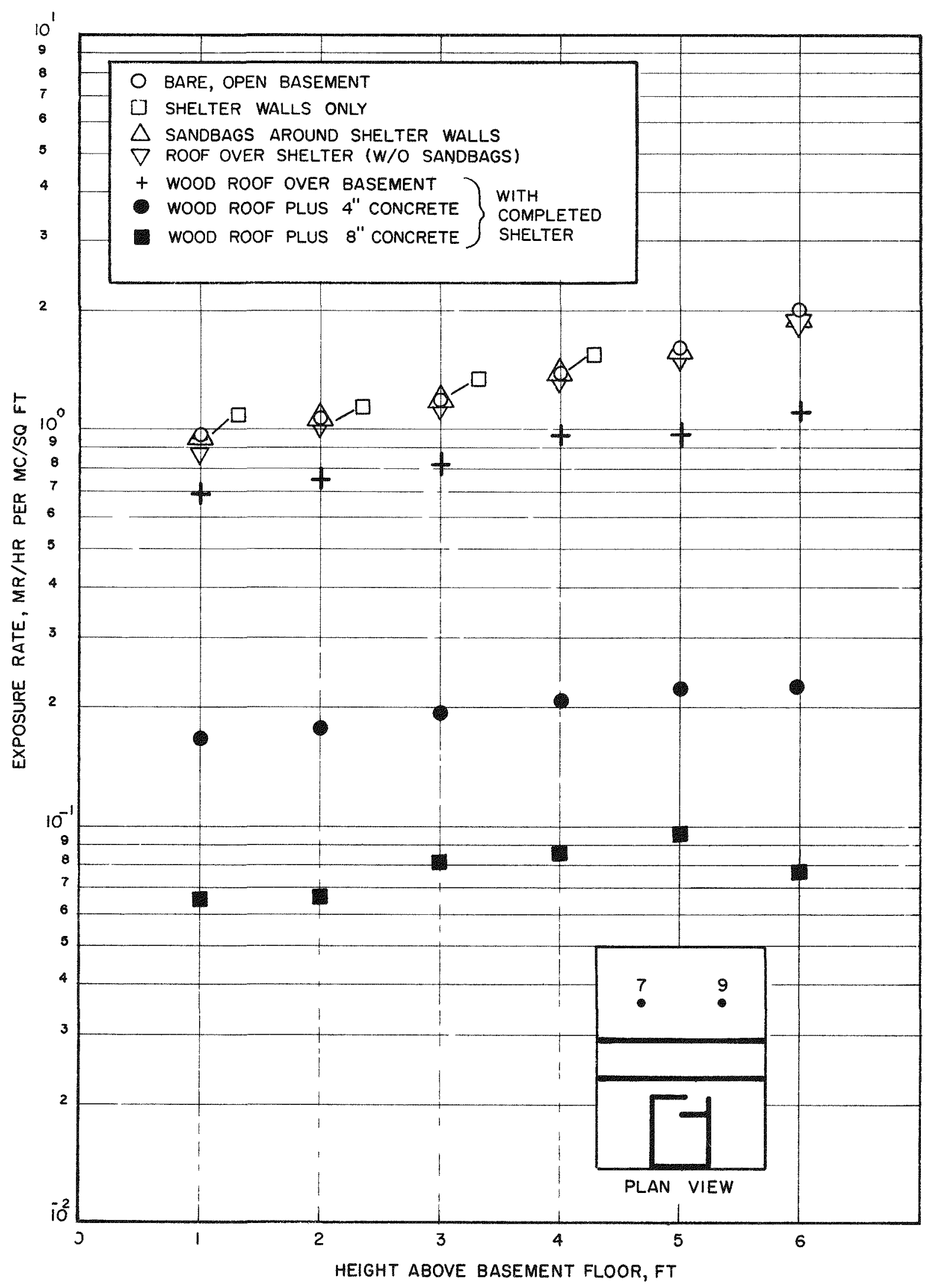

f1g. 3.7-Exposure rates at Positions 7 and 9 (averaged) from a simulated area source on the ground for $\checkmark$ arrous stages of coustruction. 


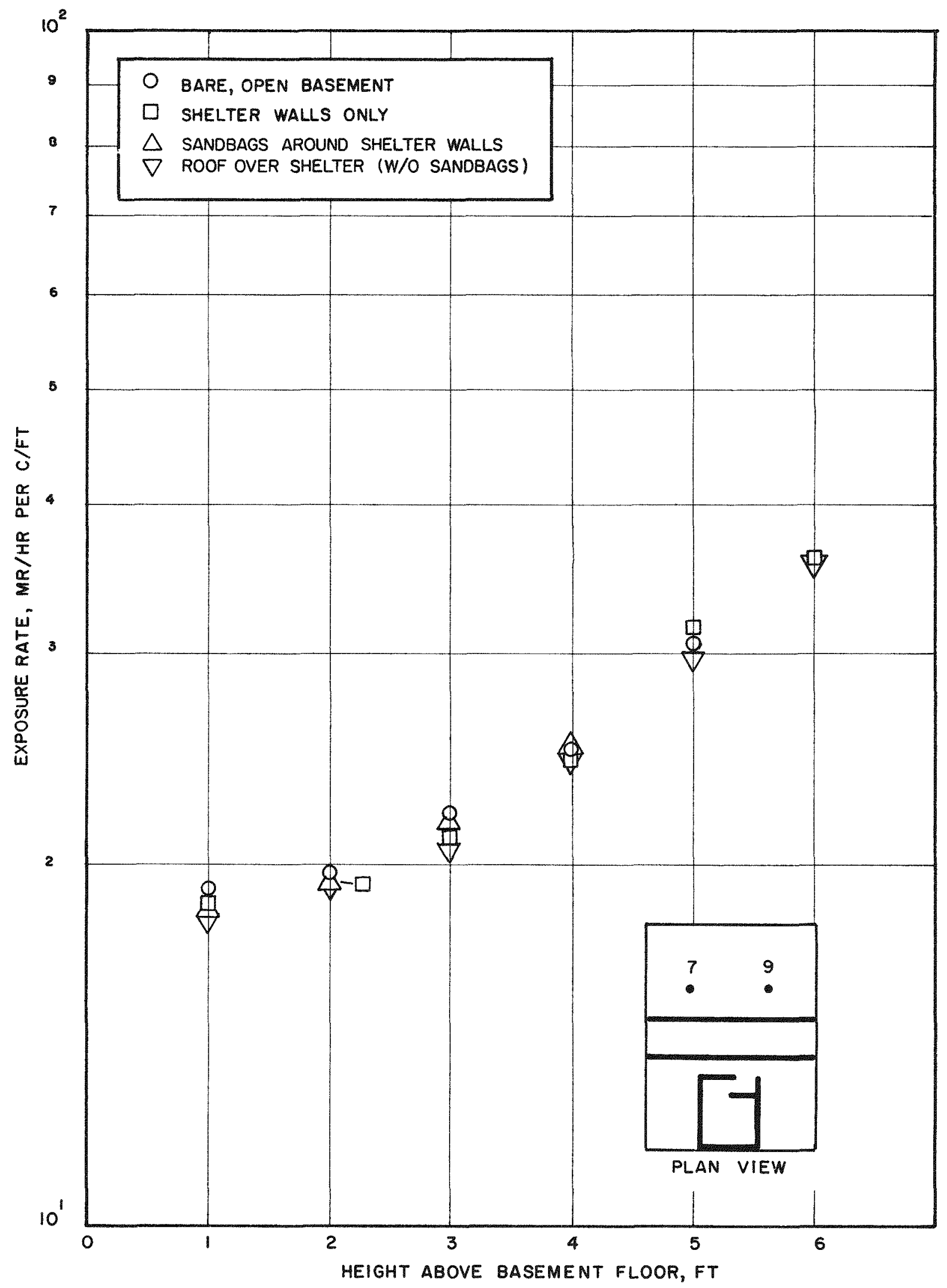

Fig. 3.8-Exposure rates at Positions 7 and 9 (averaged) from a simulated ring source at 127-ft radius for various stages of construction. 


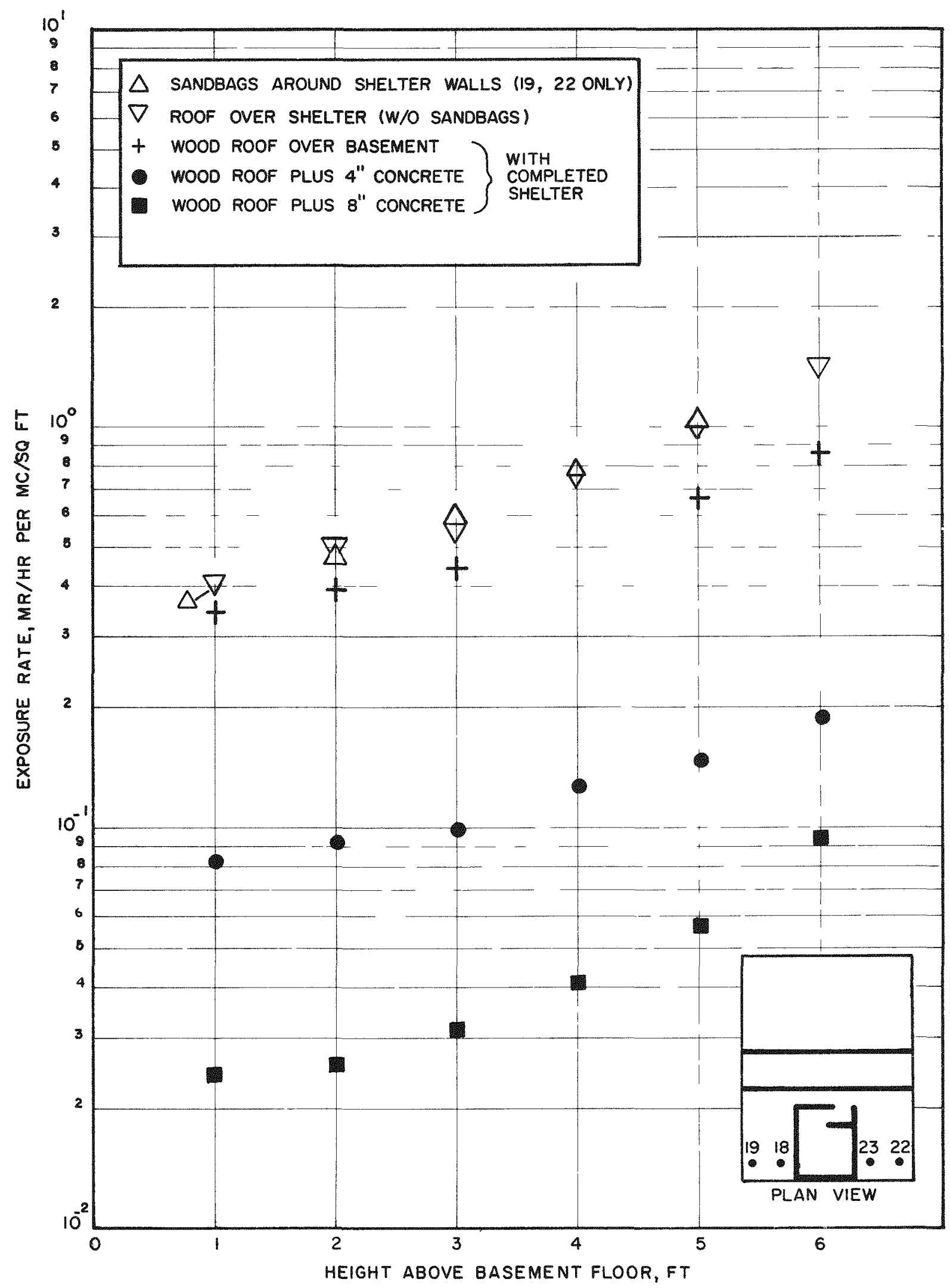

F1g. 3.9-Exposure rates at Positions 18, 19, 22, and 23 (averaged) from a simulated area source on the ground for various stages of construction. 


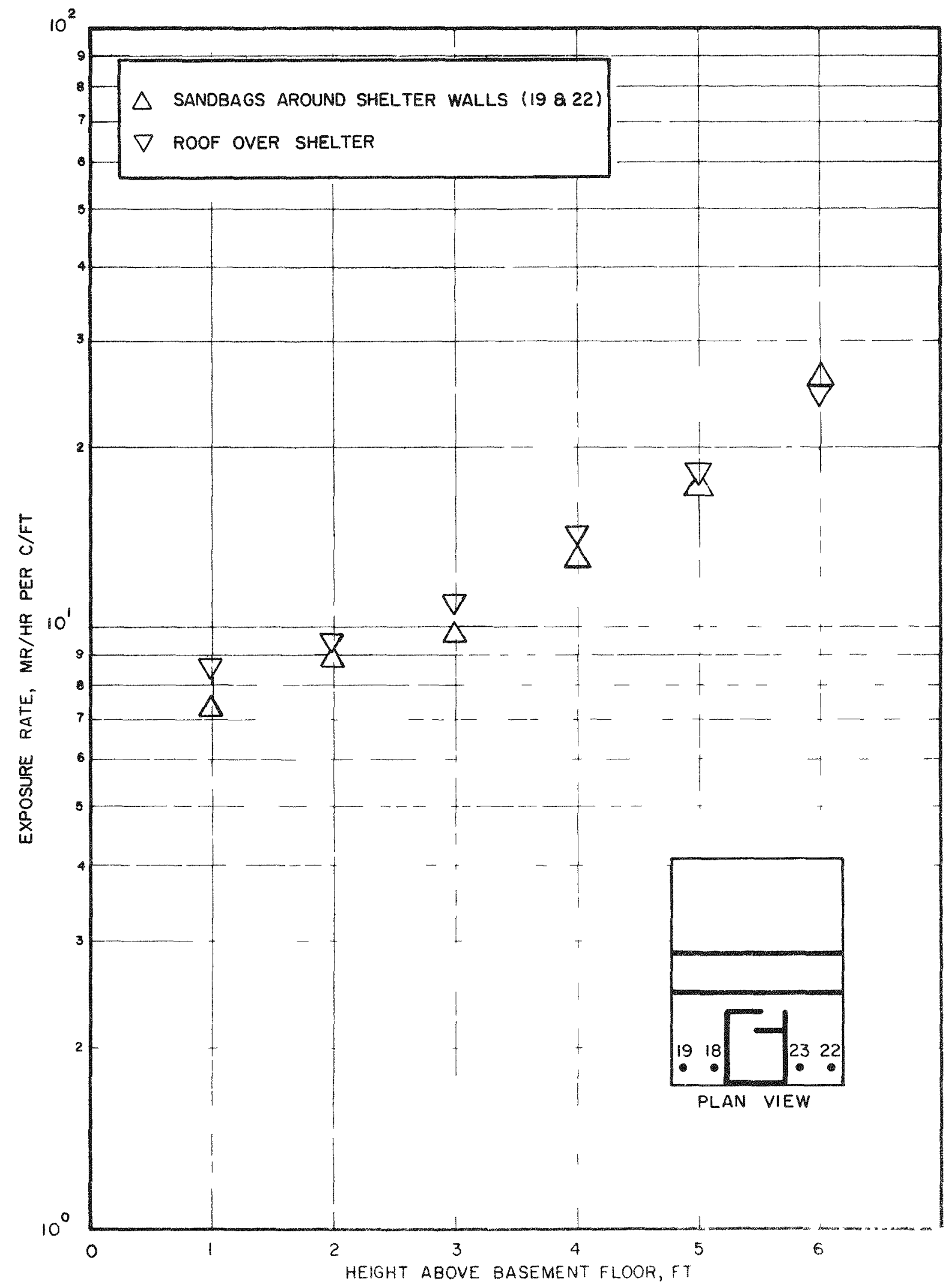

Fig. 3.10-Exposure rates at Positions 1 h. 1 . 22 and 21 (averaged) from a simul ited ing sonce it 127 -ft radius for varous stages of construction. 


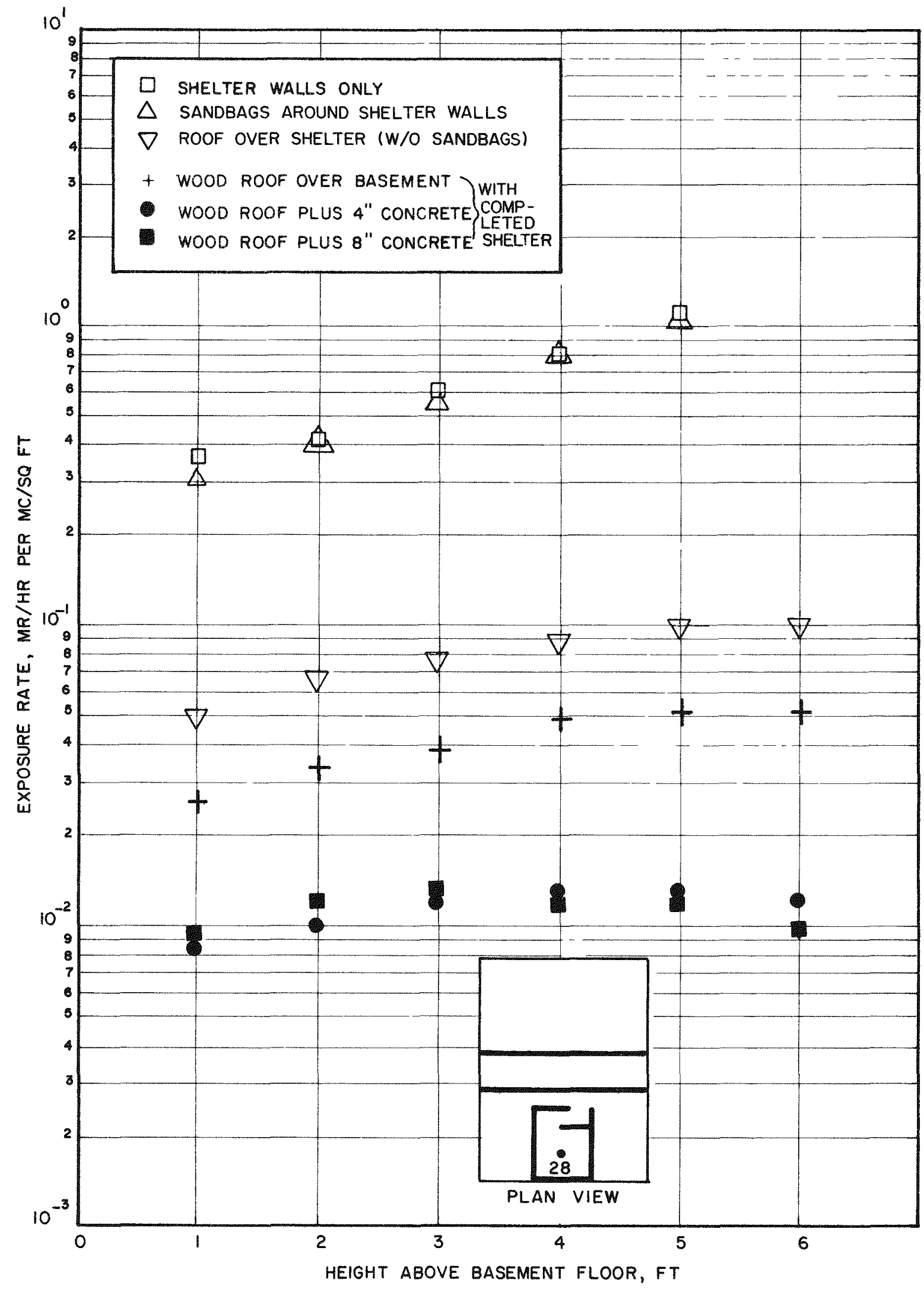

Fig. 3.11-Exposure rates at Position 28 from a simulated area source on the ground for various stages of construction. 


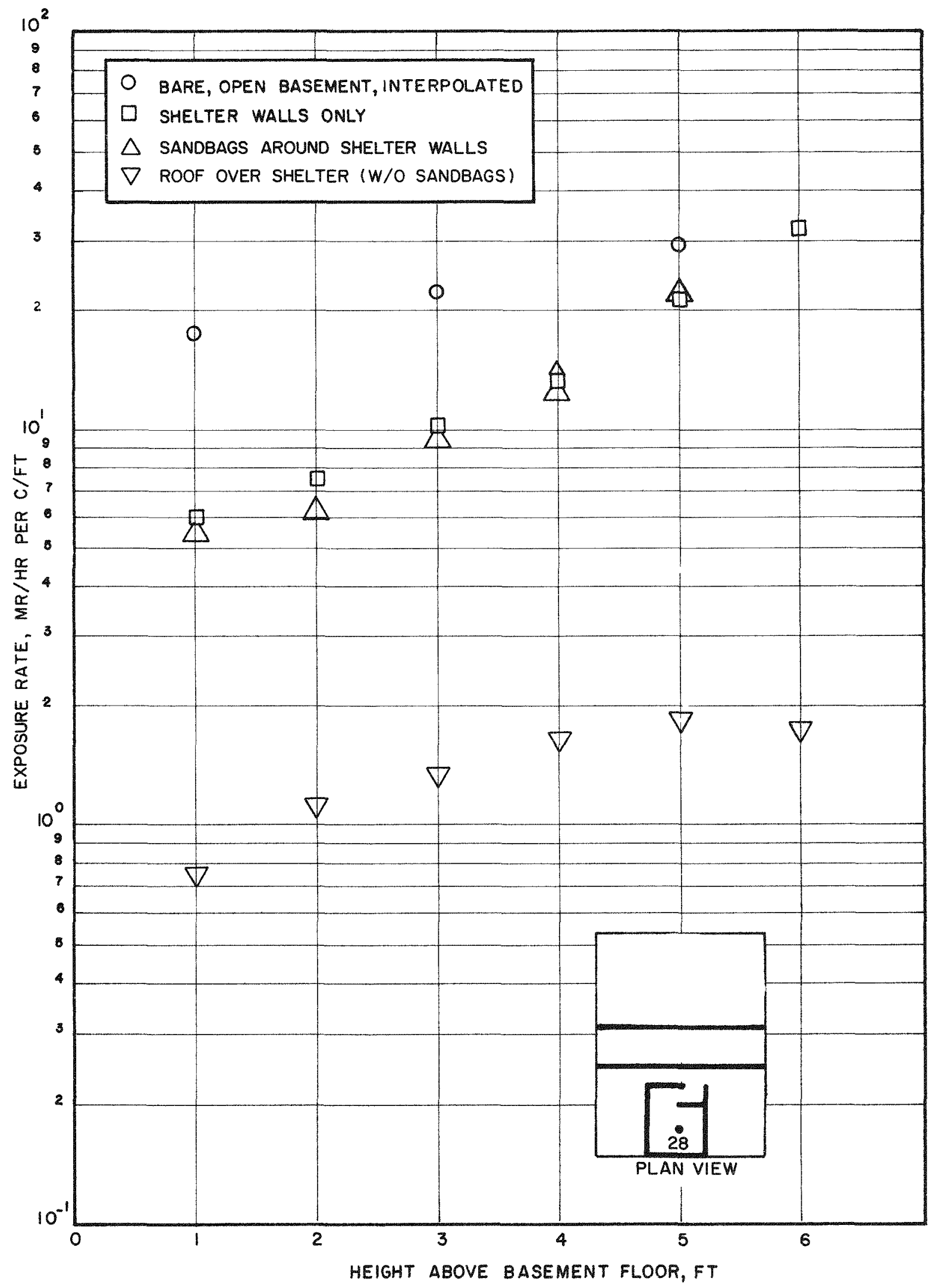

Fig. 3.12-Exposure rates at Position 28 from a simulated ring source at 127 - $\mathrm{ft}$ radius for various stages of construction. 


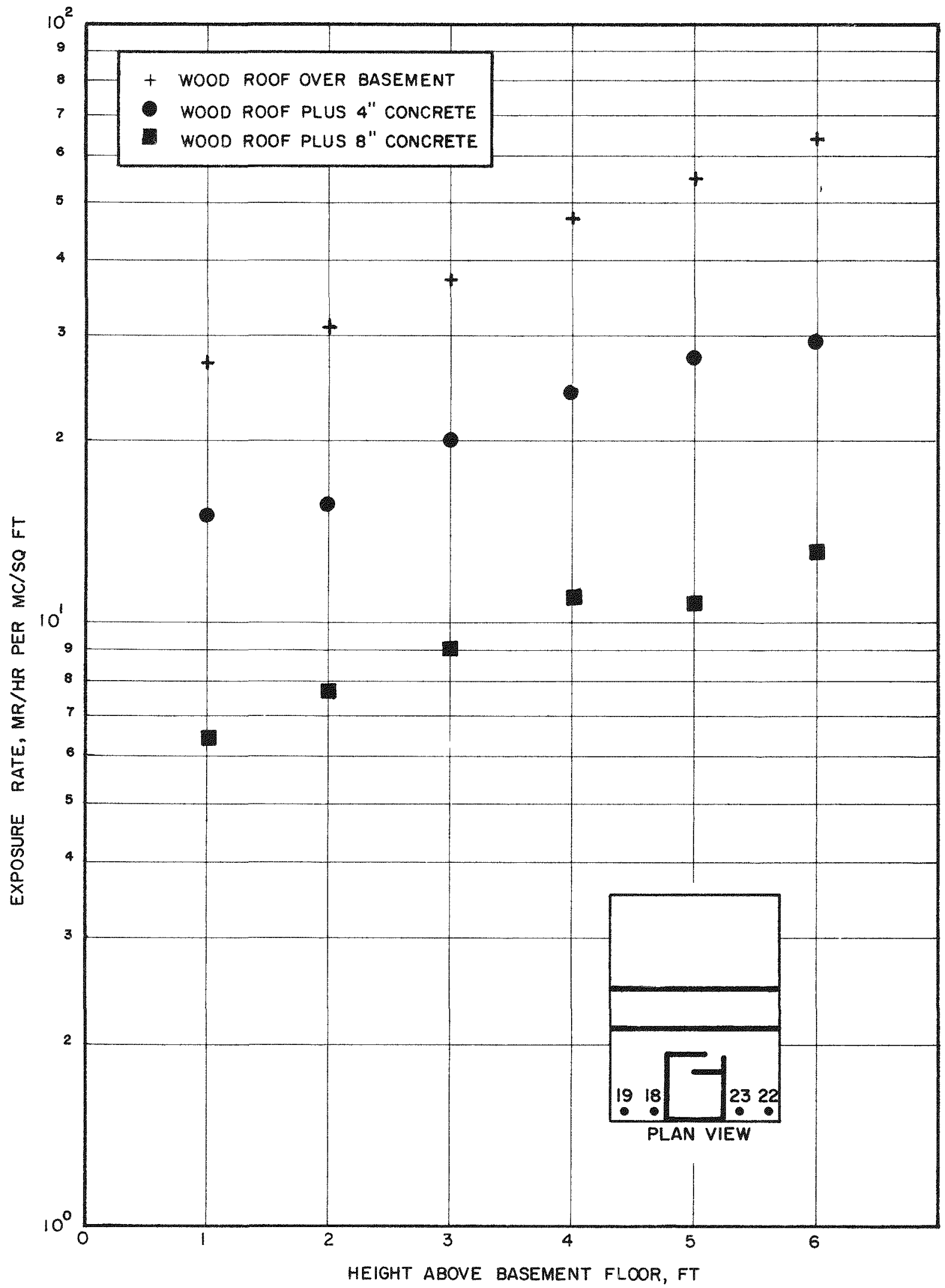

Fig. 3.13-Exposure rates at Positions 18, 19, 22, and 23 from a simulated area source on the roof over the basement. 


\section{Chapter 4}

\section{ANALYSIS}

Even though the experiment was directed toward practical application in real structures, the results lend themselves to comparison with calculations in elementary detector-source-medium arrangements.

The total scattered gamma radiation, $\mathrm{D}^{\mathrm{S}}$, at a detector in an infinite medium of air a distance, $d$, from an isotropic point source of radiation can be represented as:

$$
D^{S}=\frac{Q e^{-\mu d}}{d^{2}}[B(\mu d)-1]
$$

where $D^{S} \quad=$ the total scattered gamma radiation

Q = the specific gamma-ray constant: 14. $53 \times 10^{3} \mathrm{mr} / \mathrm{hr} 1 \mathrm{ft}$ from a 1 -curie ${ }^{60} \mathrm{Co}$ source

$\mathrm{d}=$ source-to-detector distance in feet

$\mu \quad=$ the total absorption coefficient for air

$\mathrm{B}(\mu \mathrm{d})=$ the buildup factor

Berger ${ }^{1}$ has expressed the buildup factor, $B(\mu \mathrm{d})$, for a 1.25 Mev isotropic point source in an infinite water medium as:

$$
\mathrm{B}(\mu \mathrm{d})=1+\mu \mathrm{d}\left[1.325 \mathrm{e}^{0.0314 \mu \mathrm{d}}-0.461 \mathrm{e}^{-0.244 \mu \mathrm{d}}\right]
$$

It is assumed the buildup factor for water (Equation 2) applies to air, with suitable density scaling.

Calculations have been generated for infinite, homogeneous media for many elementary detector-source-medium arrangements. ${ }^{2}$ Results indicate that these data can be used to predict exposure rates in actual structures, providing that these structures are considered suitable combinations of simple and ideal arrangements. 
To compare experimental data with calculations, the basement and shelter walls were assumed to act as a collimator for a portion of the detectors.

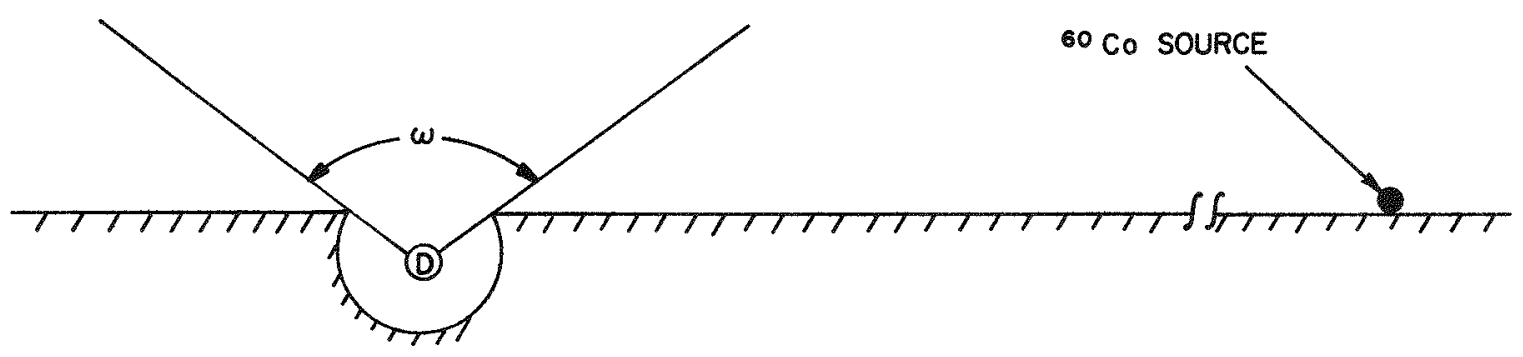

Fig. 4.1-Conical detector pointing $90^{\circ}$ away from the source-detector line, isotropic point ${ }^{60} \mathrm{Co}$ source, source and detector at the air-ground interface.

The detector response, $\mathrm{S}$, in Fig. 4.1 can be expressed

$$
\mathrm{S}=\mathrm{GK}_{\mathrm{a}} \mathrm{D}^{\mathrm{S}}
$$

where $\mathrm{G}$ is a directional-response correction factor to account for the collimation of the detector and $\mathrm{K}_{\mathrm{a}}$ is an interface correction factor to correct for the presence of the ground. Spencer ${ }^{2}$ has calculated several values of $\mathrm{G}$ for some simple, detector-source-medium arrangements. These are shown in Fig. 4.2. The values have been confirmed for ${ }^{60} \mathrm{Co}$ at short distances by $\mathrm{TO}^{3}$ and at $100 \mathrm{ft}$ by the author ${ }^{4}$.

The value of $\mathrm{K}_{\mathrm{a}}$ has been evaluated experimentally ${ }^{4}$ and has been found to be greater than 1.0 for short source-detector distances and less than 1.0 for long distances.

Calculations show that for a ring source of ${ }^{60} \mathrm{Co}$ at a $127-\mathrm{ft}$ radius the value of $S$ is $74.6 \mathrm{mr} / \mathrm{hr}$ per $\mathrm{c} / \mathrm{ft}$ of circumference when $G=0.5$ (solid-angle fraction, $\omega$, of 1.0 for a hemisphere) and the air density corresponds to experimental conditions at NTS. The value of $\mathrm{K}_{\mathrm{a}}$ was taken as 1.19 from Ref. 4 .

The exposure rate was calculated at Position 13, Positions 7, 9, 17 and 19 and Positions 1, 5, 21 and 25 in the bare, open basement from a ring source at a 127 -ft radius. The angular distribution of the 
skyshine radiation was assumed to follow Case 2 of Fig. 4.2 for

$\mathrm{d}=100 \mathrm{ft}$. Depending upon the height of the detector, the steel beams presented a $30 \mathrm{lb} / \mathrm{sq}$ ft vertical barrier or a $40 \mathrm{lb} / \mathrm{sq} \mathrm{ft}$ horizontal barrier. Barrier reduction factors for the beam were taken from Ref. 4.

For all off-center positions the direction of the radiation arriving at the detectors as well as the solid angle viewed by the detector was considered. For example, the exposure rate $6 \mathrm{ft}$ above the floor at Position 1 (corner) is considerably higher than the exposure rate $1 \mathrm{ft}$ above the floor at Position 13 (center) even though the solid angle viewed by detectors at these two positions is about the same. This is because of the large contribution of low-angle scattered photons coming from a nearly horizontal direction toward Position 1.

Calculations of the exposure rate at Positions 24 and 28 inside the shelter for the phase consisting of sandbags around the shelter walls were performed in like manner. Data and calculations are listed in Table 4.1 and presented in graphical form in Figs. 4.3 through 4.6.

Exposure rates at the same positions were also calculated from the simulated area source on the ground around the basement. These data are also listed in Table 4.1. The angular distribution of the skyshine radiation was assumed to follow Case 2 of Fig. 4.2 for $\mathrm{d}=3 \mathrm{ft}$. The area source effectively covered an area on the ground equivalent to the difference between two circular areas with radii of 16.2 and $61.7 \mathrm{ft}$; the center of the circular areas was the center of the basement. Integration of Equation 3 shows that if this area were covered with ${ }^{60} \mathrm{Co}$ to a source density of $1 \mathrm{mc} / \mathrm{sq} \mathrm{ft}$, the exposure rate would be $4.6 \mathrm{mr} / \mathrm{hr}$ in the center of the basement immediately below ground level $(\omega=1.0)$.

All the calculations were made using certain assumptions. For example: the cumulative angular distribution of the radiation in Case 2 of Fig. 4.2 is for a conical detector pointed $90^{\circ}$ from the sourcedetector line. For detectors in rectangular collimators, such as basements or shelters, it is generally assumed that Fig. 4.2 applies, providing the solid angle viewed by the detector of the scattering medium (in this case, air) is the same as for the conical collimator. Errors are small if the detector is in the center and the length-towidth ratio is not large.

For off-center positions, calculations are more involved. One must consider suitable combinations of "centered detectors" in fictional rectangular structures. This procedure was used for all calculations except those for Position 13. Additional small errors were

( Text continued on page 48) 


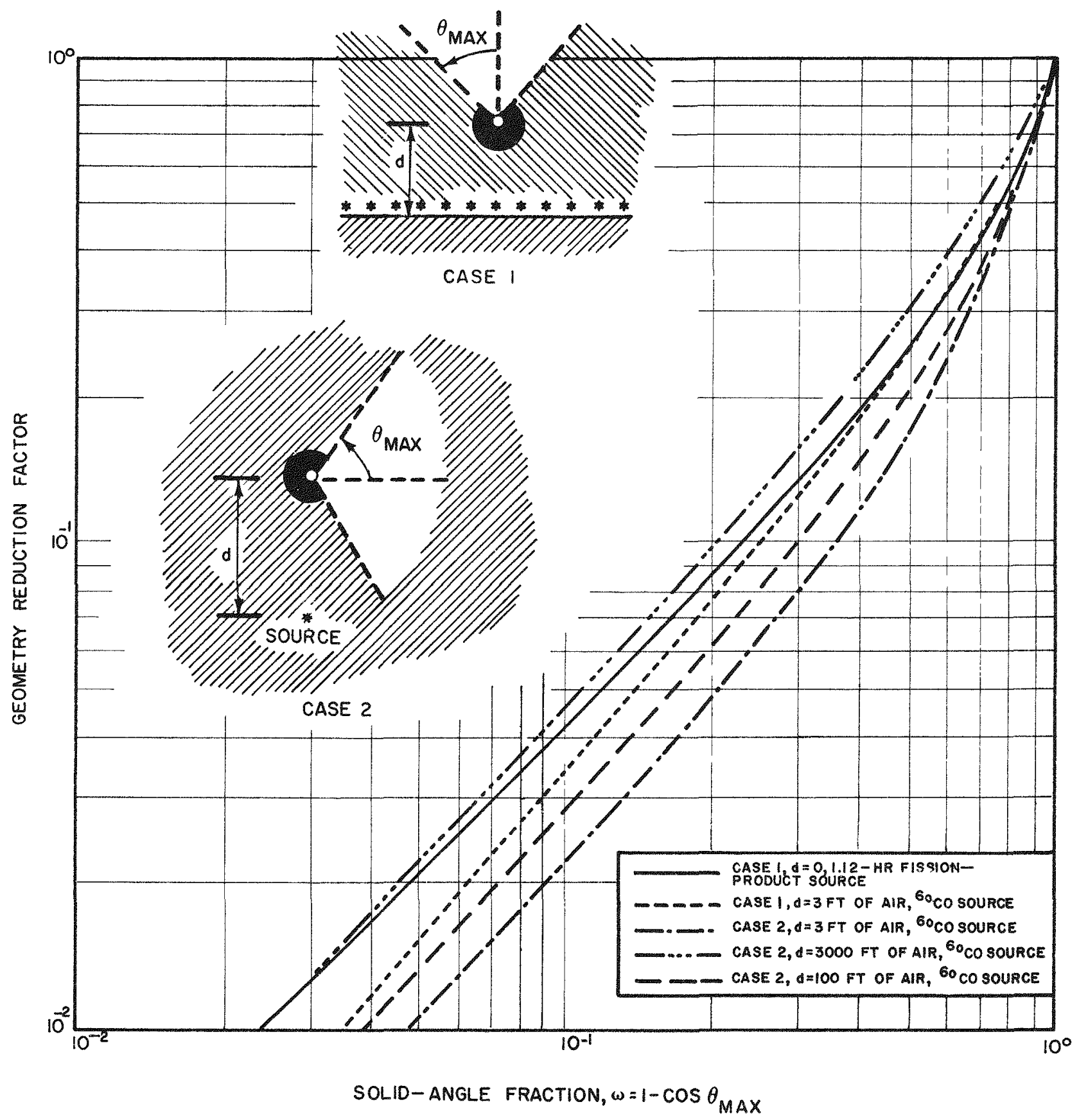

Fig. 4.2-Simple detector-source-medium arrangements. 
TABLE 4. 1 - CALCULATED AND MEASURED EXPOSURE RATES IN OPEN BASEMENT

\begin{tabular}{|c|c|c|c|c|c|}
\hline \multirow{2}{*}{$\begin{array}{l}\text { Position } \\
\text { number }\end{array}$} & \multirow{2}{*}{$\begin{array}{l}\text { Height, } \\
\text { ft }\end{array}$} & \multicolumn{2}{|c|}{ 127-ft-radius ring source, $\mathrm{mr} / \mathrm{hr}$ per $\mathrm{c} / \mathrm{ft}$} & \multicolumn{2}{|c|}{ Area source, $\mathrm{mr} / \mathrm{hr}$ per $\mathrm{mc} / \mathrm{sq} \mathrm{ft}$} \\
\hline & & Measured & Calculated & Measured & Calculated \\
\hline & \multicolumn{5}{|c|}{ Bare, Open Basement } \\
\hline $13 *$ & 1 & 20 & 20 & 1. 0 & 1. 1 \\
\hline \multirow[t]{5}{*}{ (center) } & 2 & 22 & 23 & 1. 1 & 1. 2 \\
\hline & 3 & 25 & 27 & 1.3 & 1.6 \\
\hline & 4 & 28 & 30 & 1.5 & 1.8 \\
\hline & 5 & 31 & 35 & 1. 6 & 2.0 \\
\hline & 6 & 37 & 38 & 2.0 & 2.1 \\
\hline $7,9, *$ & 1 & 18 & 19 & 0.96 & 0.99 \\
\hline \multirow{5}{*}{17,19} & 2 & 20 & 21 & 1.0 & 1.1 \\
\hline & 3 & 22 & 25 & 1. 2 & 1.4 \\
\hline & 4 & 25 & 31 & 1.4 & 1.7 \\
\hline & 5 & 30 & 36 & 1. 6 & 2.0 \\
\hline & 6 & 36 & 45 & 2.0 & 2.6 \\
\hline $1,5 *$ & 1 & 12 & 10 & 0.63 & 0.58 \\
\hline 21,25 & 2 & 13 & 11 & 0.68 & 0.66 \\
\hline \multirow[t]{5}{*}{ (corner) } & 3 & 15 & 13 & 0.77 & 0.76 \\
\hline & 4 & 16 & 15 & 0.89 & 0.86 \\
\hline & 5 & 20 & 18 & 1. 1 & 0.97 \\
\hline & 6 & 26 & 24 & 1.5 & 1.3 \\
\hline & \multicolumn{5}{|c|}{ Shelter Walls Surrounded By Sandbags } \\
\hline \multirow[t]{6}{*}{$28 * * *$} & 1 & 5.5 & 4.3 & 0.30 & 0.21 \\
\hline & 2 & 6.3 & 6.2 & 0.41 & 0.29 \\
\hline & 3 & 9.7 & 8.7 & 0.58 & 0.42 \\
\hline & 4 & 13 & 13 & 0.81 & 0.65 \\
\hline & 5 & 22 & 22 & 1. 2 & 1.1 \\
\hline & 6 & 31 & 39 & & 2.2 \\
\hline \multirow[t]{5}{*}{$24 * *$} & 1 & 2.3 & 1.8 & 0.12 & 0.088 \\
\hline & 2 & & 2.5 & & 0.12 \\
\hline & 3 & 4.0 & 3.6 & 0.21 & 0.18 \\
\hline & 4 & & 5.7 & & 0.28 \\
\hline & 5 & 10 & 10 & 0.54 & 0.53 \\
\hline
\end{tabular}

* See Fig. 3.1

** See Fig. 3.2 


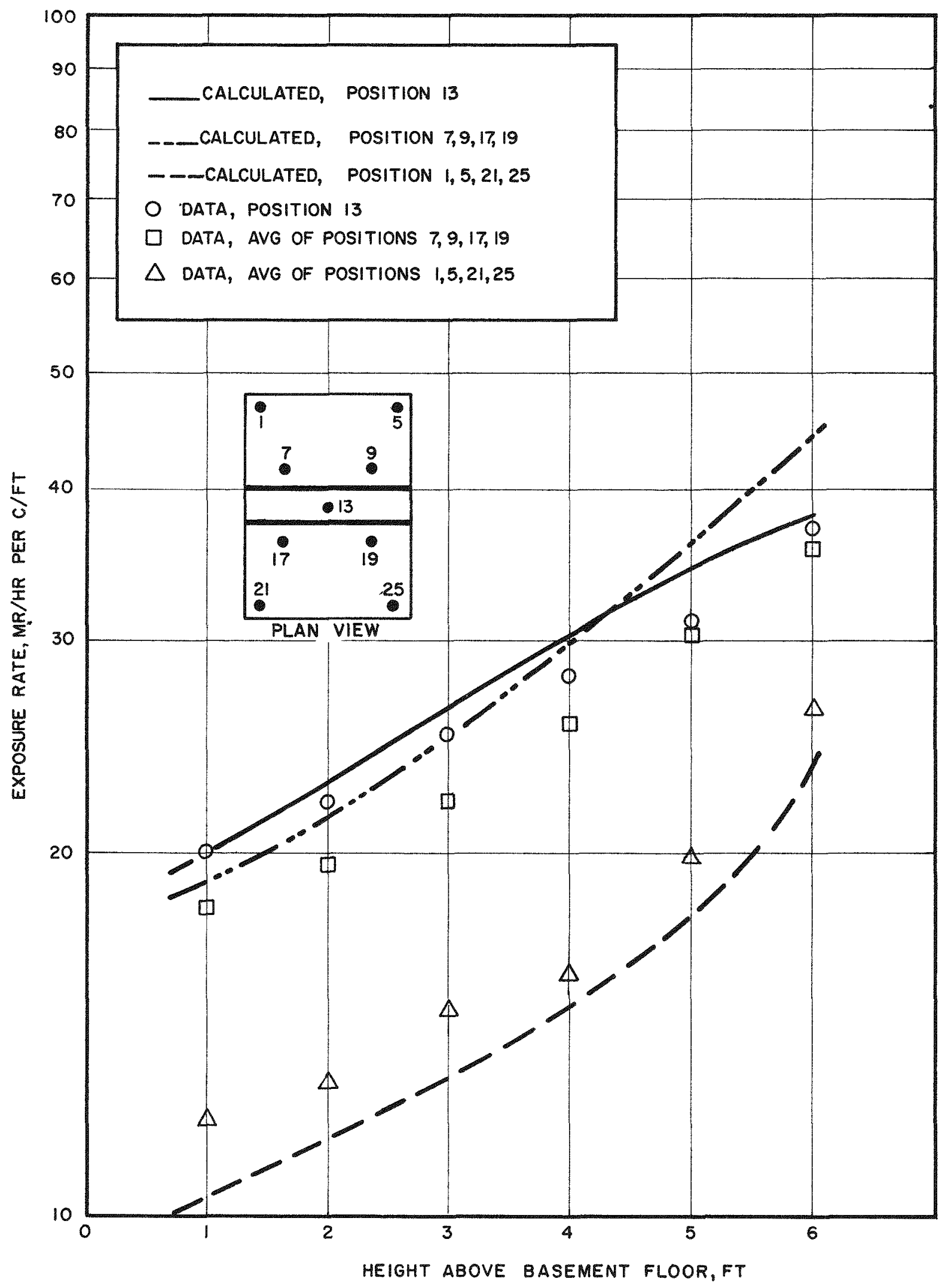

Fig. 4.3-Calculated and measured exposure rates in bare, open basement from a ring source of ${ }^{60} \mathrm{Co}$ at $127-\mathrm{ft}$ radius. 


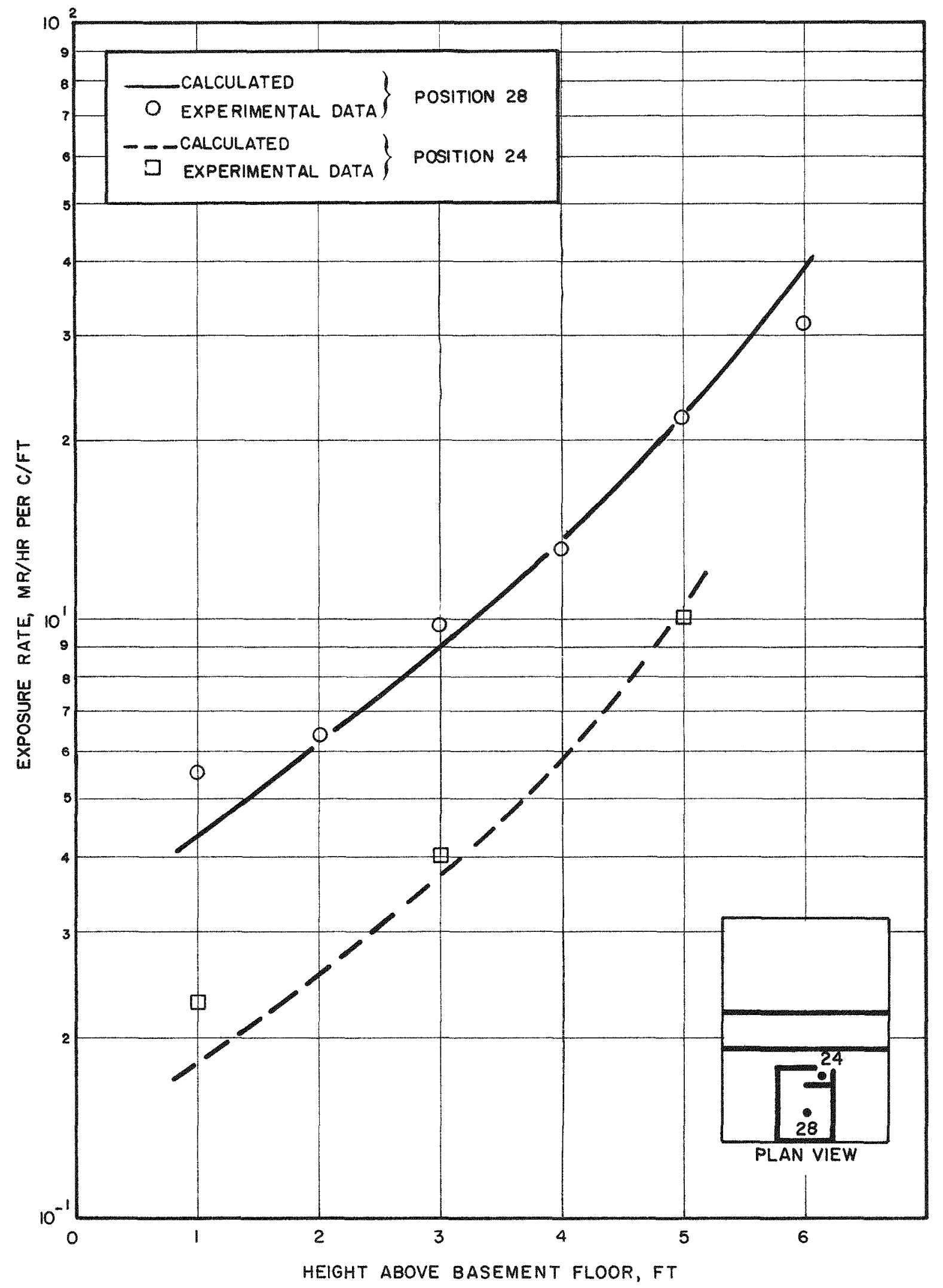

Fig. 4.4-Calculated and measured exposure rates in open shelter (with sandbags around shelter walls) from a ring source of ${ }^{60} \mathrm{Co}$ at 127 - $\mathrm{ft}$ radius. 


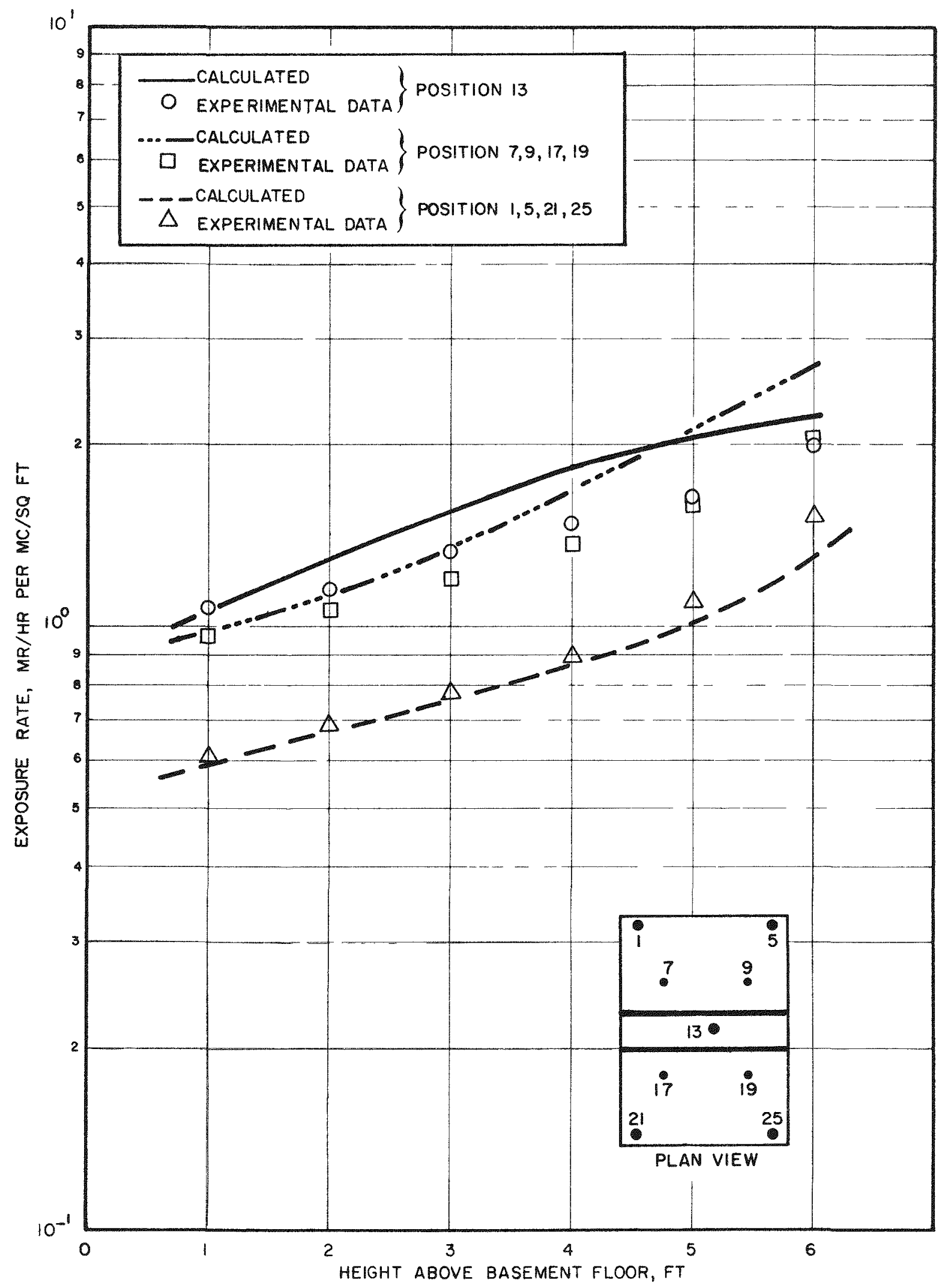

Fig. 4.5-Calculated and measured exposure rates in bare, open basement (without shelter) from an area source of ${ }^{60} \mathrm{Co}$ from basement edge to an effective radius of $60 \mathrm{ft}$. 


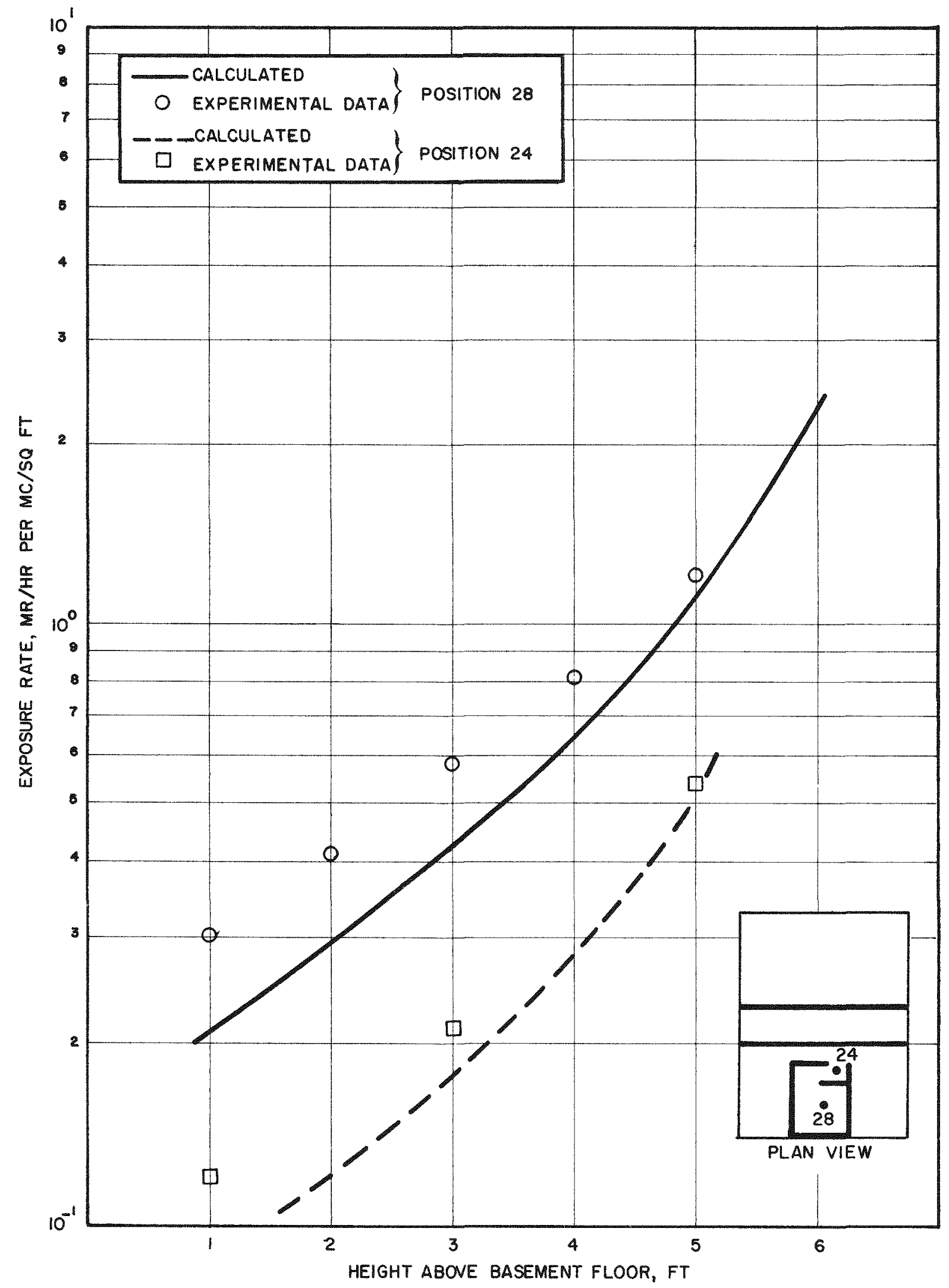

Fig. 4.6-Calculated and measured exposure rates in open shelter (with sandbags around shelter walls) from an are a source of ${ }^{60} \mathrm{Co}$ from basement edge to an effective radius of $60 \mathrm{ft}$. 
involved in assuming the position of the steel beams in relation to the detectors.

Calculations were compared with experimental data, shown in Figs. 4.3 through 4.6. The agreement is good, considering the exrors possible in experiments and in calculations. Most of the data are within $10 \%$ of calculations, with maximum separation of about $30 \%$.

No corrections were made for possible backscattering from walls or floor of the basement or shelter. Other experimental data 4 indicate that this correction would be small or negligible.

Calculations were made of the exposure rate at Positions 13 , 1 and 5, and 28 from a distributed source on the roof of the basement. Appropriate solid-angle fractions, $\omega$, were calculated and Fig. B. 45 of Spencer's monograph ${ }^{2}$ was used to obtain reduction factors* for a structure of this type. Again, for off-center positions, appropriate combinations of "centered detectors" in fictitious structures were assumed. The positions of the steel beams were also considered. The roof of the shelter was assumed to have a mass thickness of $65 \mathrm{lb} / \mathrm{sq} \mathrm{ft}$; the wood roof over the basement, $10 \mathrm{lb} / \mathrm{sq} \mathrm{ft}$; the wood roof plus $4 \mathrm{in}$. of concrete, $39 \mathrm{lb} / \mathrm{sq} \mathrm{ft}$; the wood roof plus $8 \mathrm{in}$. of concrete, $68 \mathrm{lb} / \mathrm{sq} \mathrm{ft}$; and the walls of the shelter, $80 \mathrm{lb} / \mathrm{sq} \mathrm{ft}$.

For Position 28, radiation penetrating the shelter walls and reaching the detector was considered. This portion was considered to be of two components, radiation passing through the wall and radiation scattered by the wall, according to the method suggested in the OCD Engineering Manual. 5

Experimental data and calculations are quantitatively compared in Table 4.2 and in Figs. 4.7 through 4.9 . The agreement is excellent, considering the magnitude of the errors possible in experiments and calculations. All data are within $10 \%$ of calculations except one data point which was about $30 \%$ high.

The skyshine contribution coming through the shelter walls would presumably be the difference between data taken with and without the sandbags around the shelter walls. The experimental data show that the difference is small, probably less than $10 \%$ of the exposure rate coming in through the open top of the shelter.

Calculation of the skyshine exposure rate penetrating the shelter walls yields an estimated value of about $0.6 \mathrm{mr} / \mathrm{hr}$ per c/ $\mathrm{ft}$ at the 3 -ft height of Position 28 from a ${ }^{60}$ Co ring source at a $127-\mathrm{ft}$

* Reduction factors in Fig. B. 45 of Ref. 2 refer to fractions of an exposure rate $3 \mathrm{ft}$ above a smooth, infinite-plane source of $60 \mathrm{Co}$. This exposure rate is $500 \mathrm{mr} / \mathrm{hr}$ for a source activity of $1 \mathrm{mc} / \mathrm{sq} \mathrm{ft}$.

( Text continued on page 53) 
TABLE 4.2 - CALCULATED AND MEASURED EXPOSURE RATES FROM AN AREA SOURCE ON THE BASEMENT ROOF

\begin{tabular}{|c|c|c|c|c|c|c|c|}
\hline \multirow{2}{*}{$\begin{array}{l}\text { Position } \\
\text { number }\end{array}$} & \multirow{2}{*}{$\begin{array}{l}\text { Height } \\
\mathrm{ft}\end{array}$} & \multicolumn{2}{|c|}{$\begin{array}{c}\text { Wood roof only } \\
\mathrm{mr} / \mathrm{hr} \text { per } \mathrm{mc} / \mathrm{sq} \mathrm{ft}\end{array}$} & \multicolumn{2}{|c|}{$\begin{array}{c}\text { Wood roof }+4^{\prime \prime} \text { concrete } \\
\mathrm{mr} / \mathrm{hr} \text { per } \mathrm{mc} / \mathrm{sq} \mathrm{ft}\end{array}$} & \multicolumn{2}{|c|}{$\begin{array}{c}\text { Wood roof }+8^{\prime \prime} \text { concrete } \\
\mathrm{mr} / \mathrm{hr} \text { per } \mathrm{mc} / \mathrm{sq} \mathrm{ft}\end{array}$} \\
\hline & & Measured & Calculated & Measured & Calculated & Measured & Calculated \\
\hline \multirow{6}{*}{$\begin{array}{l}13 \\
\text { (Center of } \\
\text { basement) }\end{array}$} & 1 & 50 & 49 & 28 & 26 & 13 & 11 \\
\hline & 2 & & 56 & 31 & 29 & 14 & 12 \\
\hline & 3 & 65 & 66 & 32 & 32 & 14 & 14 \\
\hline & 4 & 74 & 77 & 35 & 34 & 15 & 15 \\
\hline & 5 & 86 & 91 & 38 & 38 & 17 & 16 \\
\hline & 6 & 100 & 110 & 41 & 41 & 17 & 18 \\
\hline \multirow[t]{6}{*}{1,5} & 1 & 36 & 33 & 20 & 14 & 7.5 & 6.2 \\
\hline & 2 & 38 & 35 & 21 & 15 & 7.5 & 6.7 \\
\hline & 3 & 44 & 39 & 22 & 16 & 8.9 & 7.5 \\
\hline & 4 & 49 & 42 & 26 & 18 & 9.4 & 8.2 \\
\hline & 5 & 60 & 49 & 29 & 21 & 12 & 9.7 \\
\hline & 6 & 70 & 69 & 31 & 29 & 14 & 14 \\
\hline \multirow{6}{*}{$\begin{array}{l}\quad 28 \\
\text { (Center of } \\
\text { shelter) }\end{array}$} & 1 & 8.7 & 8.5 & 4.4 & 3.8 & 1.8 & 1.8 \\
\hline & 2 & 11 & 10 & 5.4 & 4.4 & 2.3 & 2.1 \\
\hline & 3 & 12 & 11 & 6.1 & 5.0 & 2. 6 & 2.4 \\
\hline & 4 & & 13 & 6.9 & 5.9 & 2.9 & 2.6 \\
\hline & 5 & $15 *$ & 14 & 7.6 & 6.6 & 3.1 & 2. 9 \\
\hline & 6 & & 15 & 7.6 & 7.2 & 3.3 & 3.2 \\
\hline
\end{tabular}

* Estimated from other positions. 


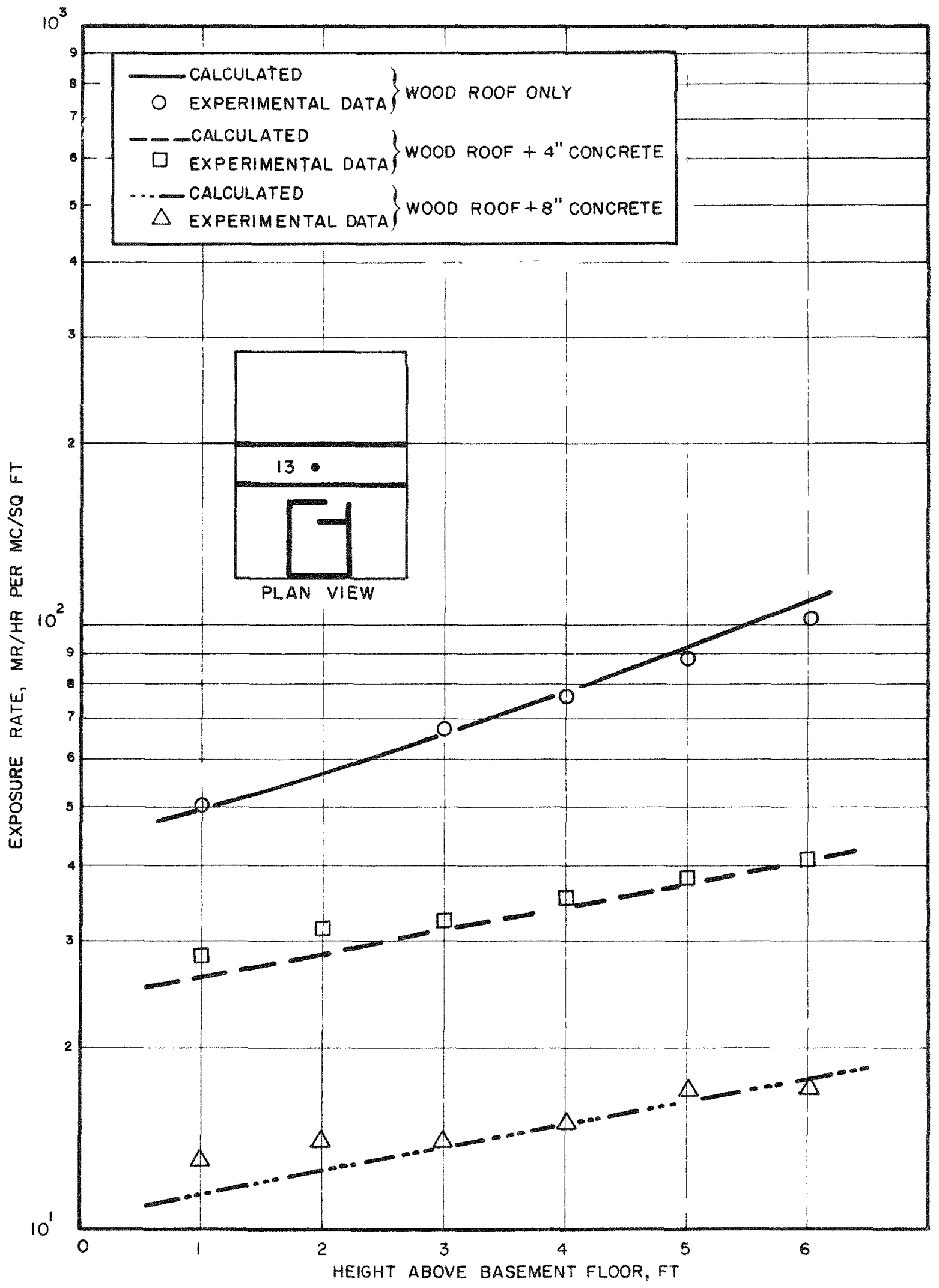

Fig. 4.7-Calculated and measured exposure rates at Position 13 (center) for an area source of ${ }^{60} \mathrm{Co}$ on top of the basement roof. 


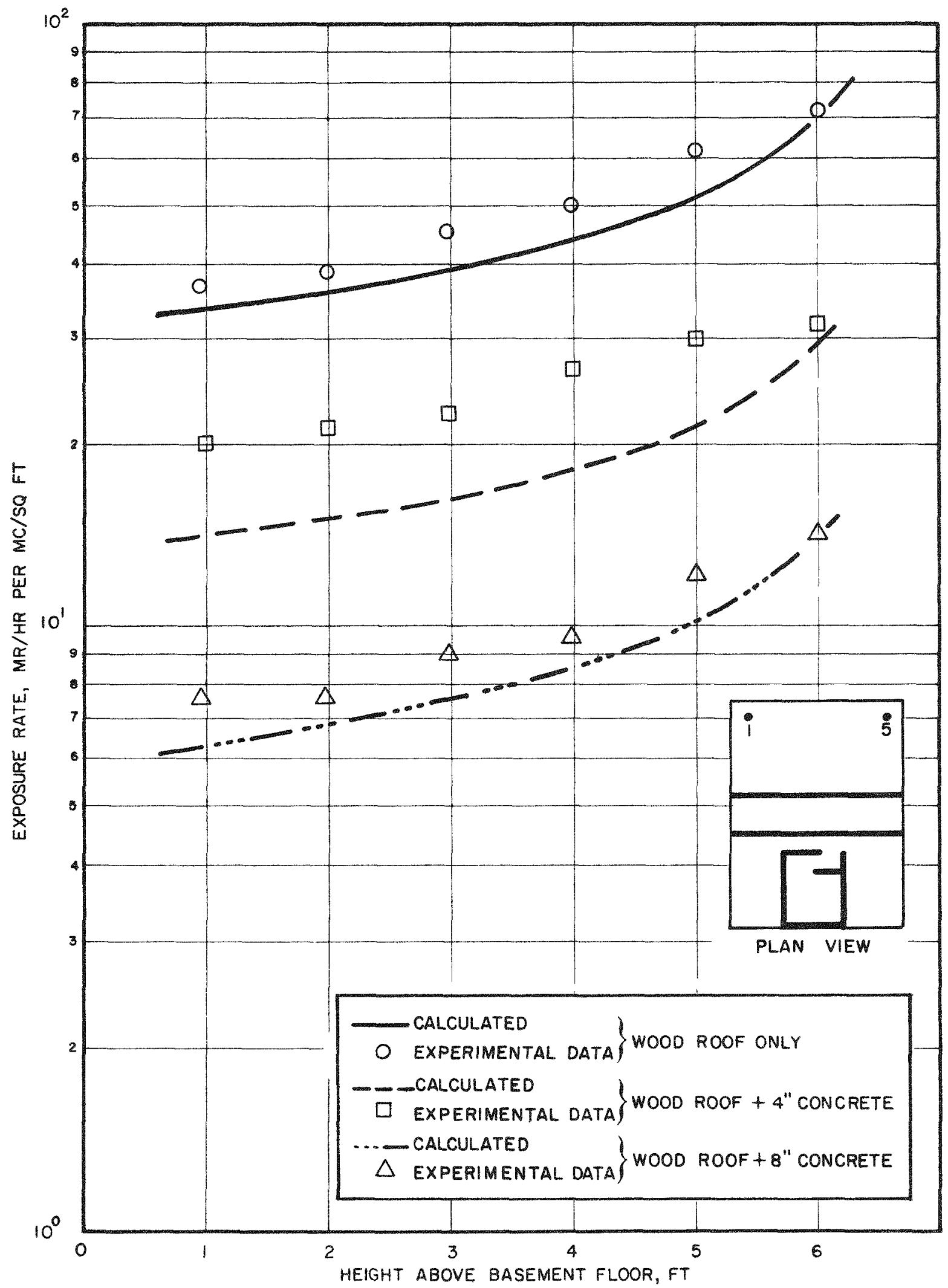

Fig. 4.8-Calculated and measured exposure rates at Positions 1 and 5 (corner) from an area source of ${ }^{60}$ Co on top of the basement roof. 


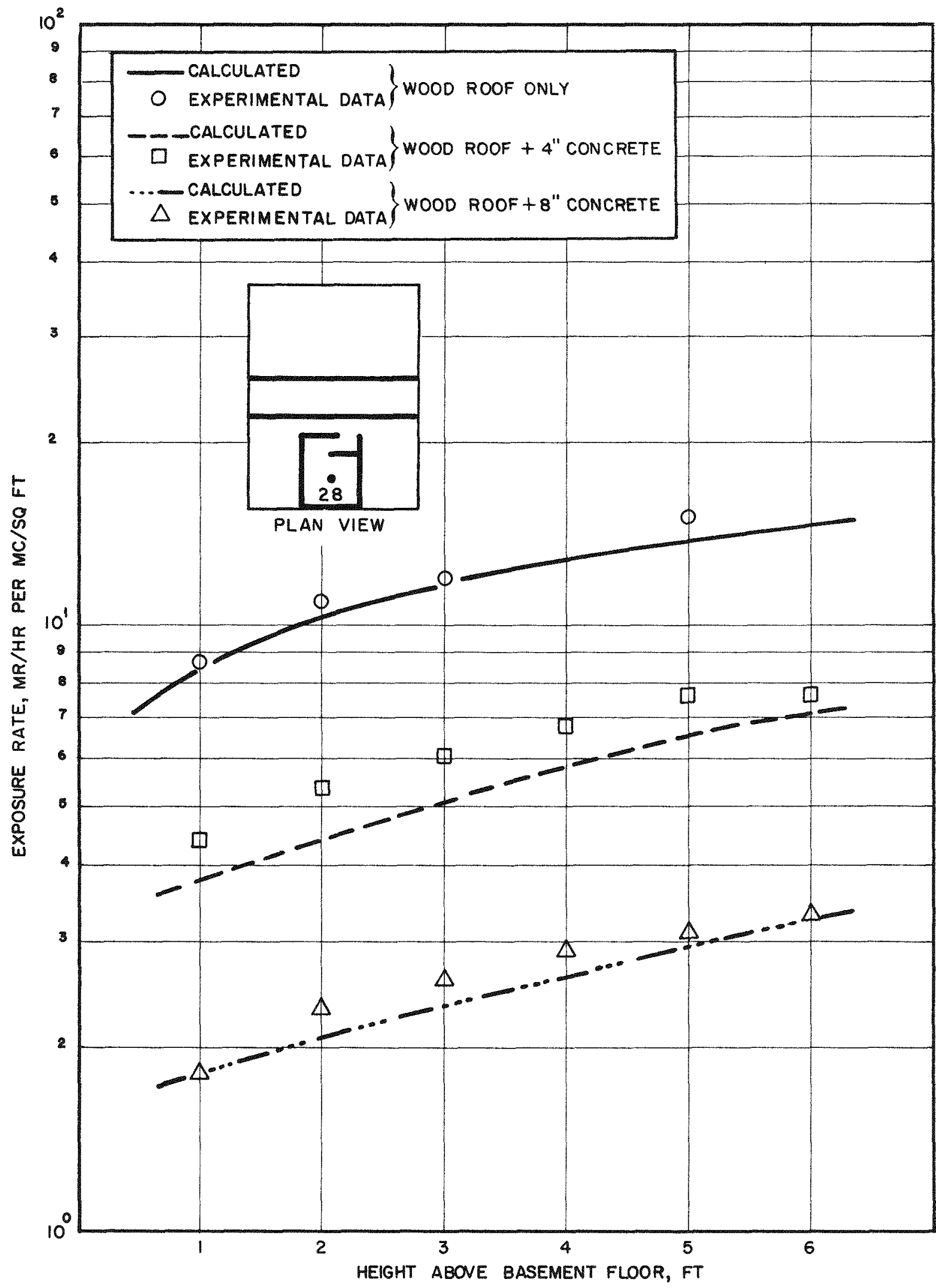

Fig. 4.9-Calculated and measured exposure rates at Position 28 (center of shelter) from an area source of ${ }^{60} \mathrm{Co}$ on top of the basement roof. 
radius. This value is about $7 \%$ of the calculated exposure rate coming in through the open top of the shelter. The estimate assumed an attenuation factor of 0.06 for the $80-1 \mathrm{~b} / \mathrm{sq} \mathrm{ft}$ vertical wall (Ref. 4).

The material attenuation provided by the shelter roof against skyshine radiation for the 3 - $\mathrm{ft}$ position is estimated to be 0.065 . This value was taken from Ref. 4, assuming a horizontal barrier thickness of $65 \mathrm{lb} / \mathrm{sq} \mathrm{ft}$ and a solid-angle fraction of 0.35 . If we apply this reduction to the calculated exposure rate coming through the open top $(8.73 \mathrm{mr} / \mathrm{hr}$ per $\mathrm{c} / \mathrm{ft}$ ) and add to it the estimated exposure rate penetrating the shelter walls, the resulting exposure rate is 1.17 $\mathrm{mr} / \mathrm{hr}$ per $\mathrm{c} / \mathrm{ft}$. This exposure rate corresponds to that measured from the 127-ft ring source after the shelter roof was constructed. The measured exposure rate was $1.3 \mathrm{mr} / \mathrm{hr}$ per c/ft. About half of this exposure rate is estimated to be coming through the shelter walls.

The tubing for the area source on the ground was placed $6 \mathrm{ft}$ apart, the first tubing being $3 \mathrm{ft}$ from the edge of the structure. In the case of the wood roof and concrete slabs over the basement, a portion of the radiation arriving at some of the detectors appeared to penetrate the ground and basement walls. For these cases the first tubing was $3 \mathrm{ft}$ from the outer edge, making a linear distance of $3 \mathrm{ft}$ of earth and $8 \mathrm{in.}$ of concrete to the inside of the basement. This ground penetration is especially noticeable in corner positions and inside the shelter.

In Figs. 3.5 and 3.9 the exposure rate rose sharply with height for the case of wood roof plus 8 in. concrete over the basement. Predictions were that the second layer of 4 -in. concrete slabs would reduce the exposure rate almost as much as the first layer did. It appeared to have done so at low heights but certainly not at the 5 -and 6 -ft heights, indicating the probability of ground penetration. In Fig. 3. 11 and Table 3.7 note that the addition of the second 4 -in. layer of concrete did not decrease the exposure rate inside the shelter at all, indicating that most of the exposure rate received was probably from ground penetration.

In a previous experiment, Technical Operations, $(\mathrm{TO})^{6}$ measured the exposure rate in the same open basement from simulated area sources on the ground outside. Figure 4.10 contains a comparison of one set of their measurements with those from this experiment. Because of the slightly larger area covered by TO's tubing and because the steel beams were not present during TO's measurements, their data are expected to be slightly higher than ours. The agreement is excellent. 


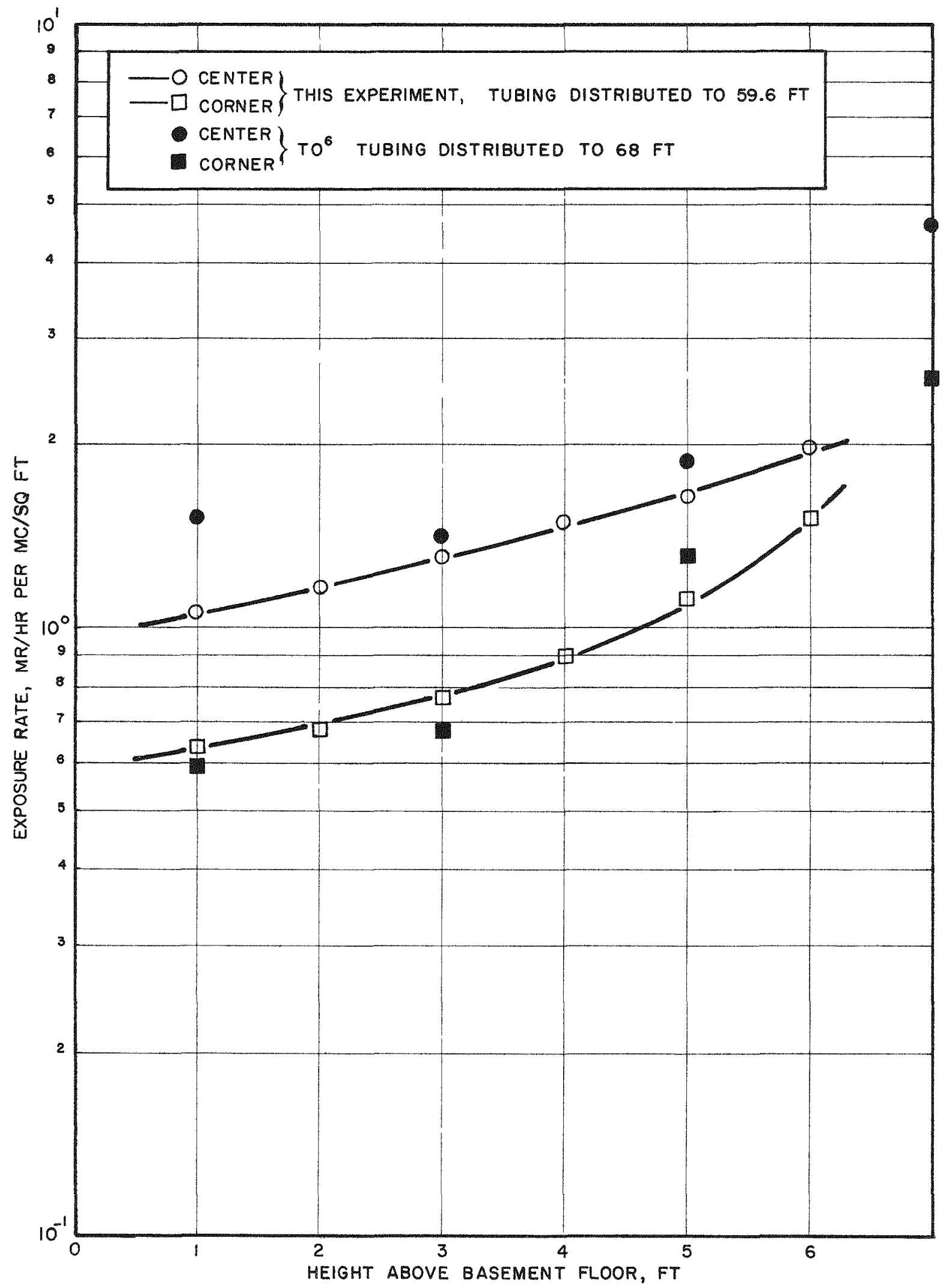

Fig. 4.10-Comparison of measurements made by $\mathrm{TO}^{6}$ and by this experiment in a bare, open basement. 
An earlier experiment ${ }^{7}$ measured the radiation level in a basement of a 2-story brick (2SB) house from simulated ring and area ${ }^{60} \mathrm{Co}$ sources on the ground outside. The $2 \mathrm{SB}$ basement was nearly the same size as the one studied here. It contained a shelter identical in size and location as the one in this study. Drawings of the wall and framing structure of the two basements are shown in Fig. 4. 11.

At the 2SB house, measurements were made in the basement before and after the shelter was built. These data for a ring source at a 127-ft radius are compared with data at corresponding positions in the open basement, shown in Fig. 4.12. Note that the exposure rate is slightly less in the 2SB basement proper than for the same positions in the open basement, and the exposure rates in the fully constructed shelter were about the same in both experiments; both agree well with calculations.

The fact that the exposure rates in the two basements are nearly the same is coincidental. The exposure rate in the open basement is entirely from skyshine radiation while the exposure rate in the basement of the 2SB house is mostly wall-scattered radiation. The relative contributions of skyshine and wall-scattered radiation are illustrated in Fig. 4.13. The basement in Fig. 4. 13 is a fictitious, square structure of infinitely high walls above ground. Calculations are based upon the method suggested in the OCD Engineering Manual ${ }^{5}$ with additional skyshine attenuation data from Ref. 4.

(References are on page 59.) 


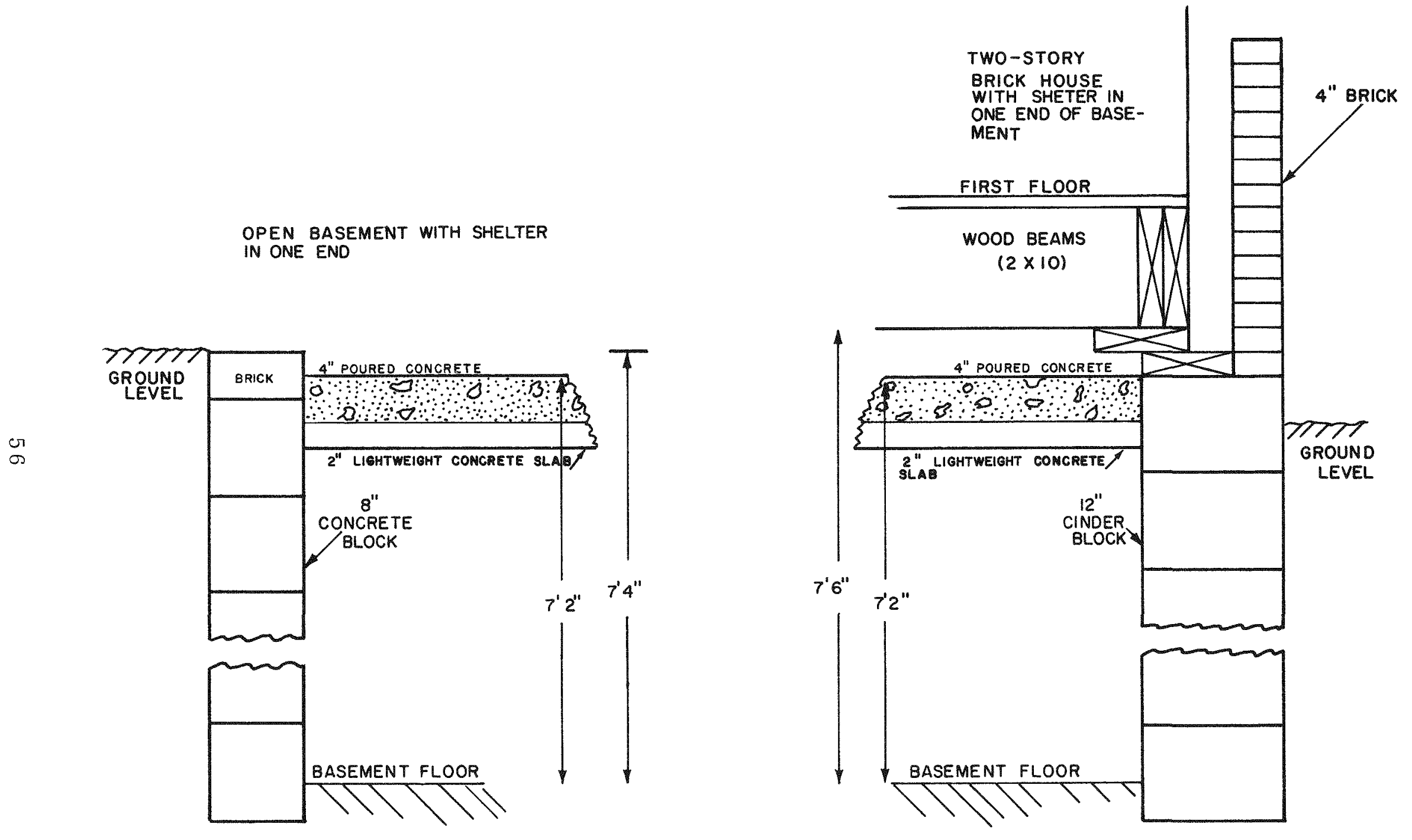

Fig. 4.11-Wall and framing structure of the open basement (this experiment) and the basement of 2SB house (USAEC Report CEX 59.7B, Part I). 


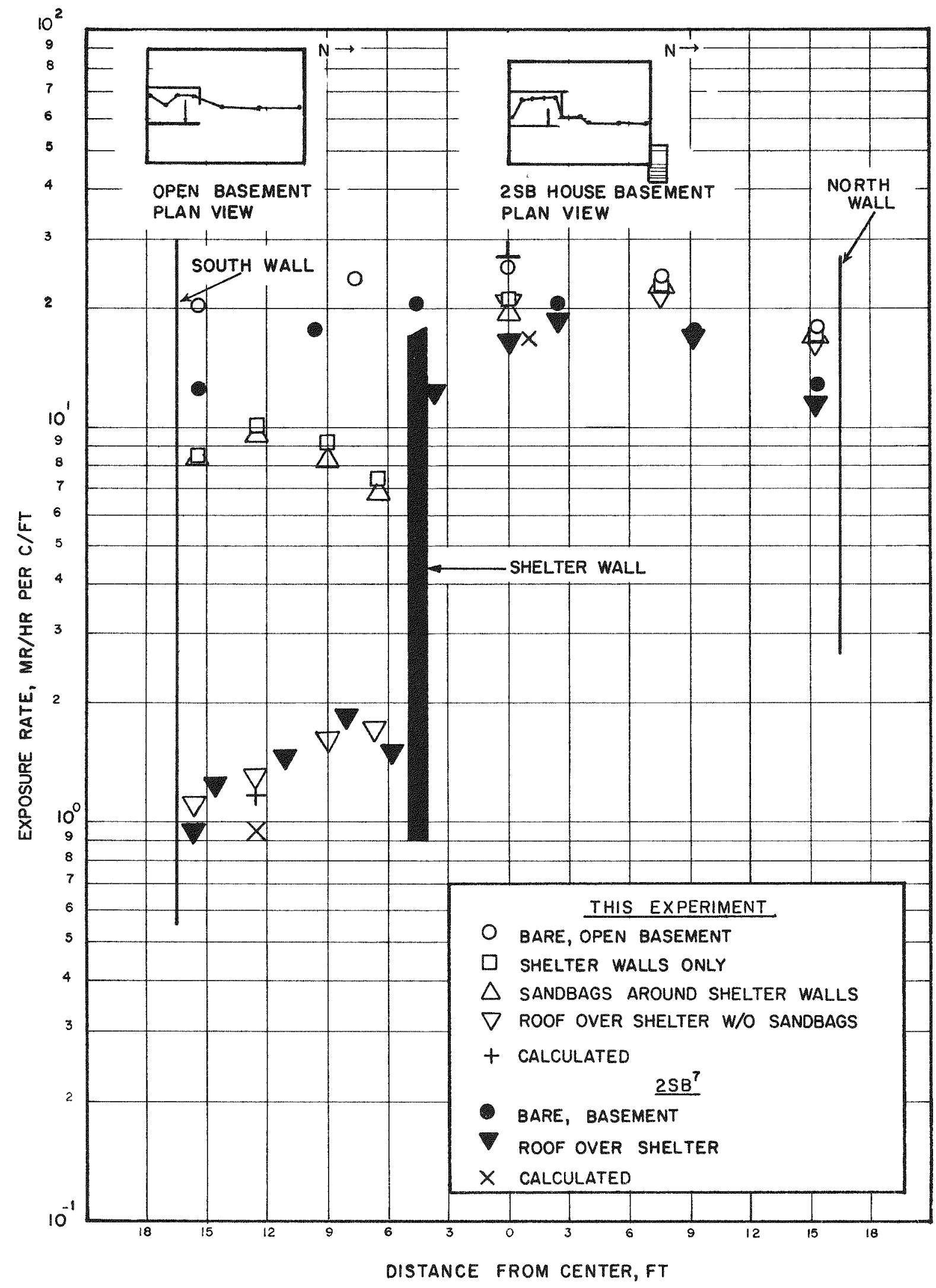

Fig. 4.12-Exposure rates in open basement and in $2 \mathrm{SB}$ house basement ${ }^{7}$ at $3 \mathrm{ft}$ above the floor from a ring source of ${ }^{60} \mathrm{Co}$ at a radius of $127 \mathrm{ft}$. 


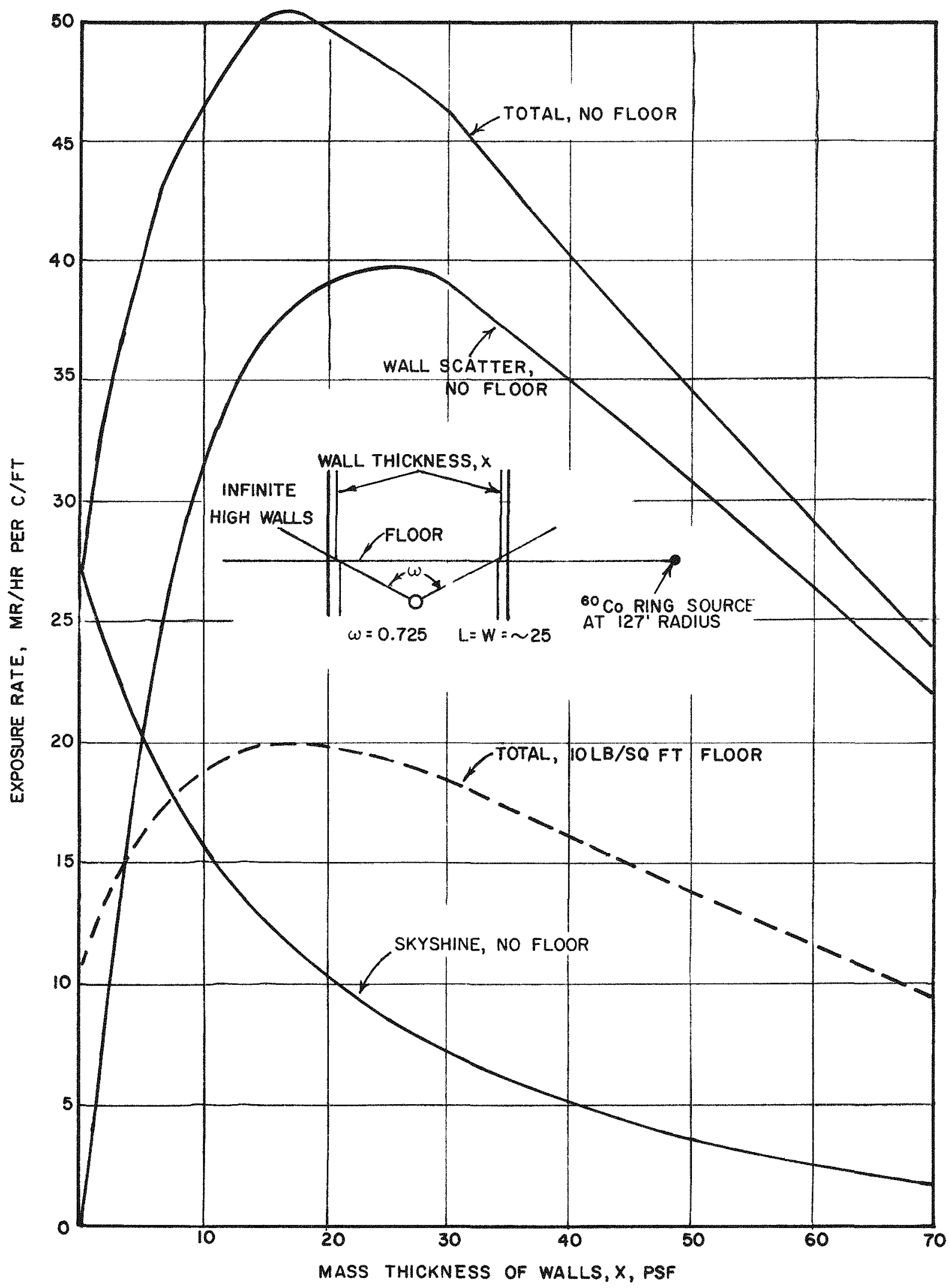

Fig. 4.13-Calculated exposure rates in a fictitious structure with infinite high, above-ground walls from a ring source of ${ }^{60} \mathrm{Co}$ at $127-\mathrm{ft}$ radius. 


\section{REFERENCES}

1. Martin J. Berger, "Calculation of Energy Dissipation by Gamma Radiation near the Interface between Two Media," Journal of Applied Physics, Vol. 28, No. 12, 1502-1508, December 1957.

2. L. V. Spencer, Structure Shielding Against Fallout Radiation from Nuclear. Weapons, NBS Monograph 42 (National Bureau of Standards, Washington 25, D. C.), June 1962.

3. Albert W. Starbird and John F. Batter, Angular Distribution of Skyshine Radiation at the Surface of a Plane of Fallout Contamination, Report TO-B 63-40 Technical Operations Research, March 1964.

4. Z. G. Burson, Attenuation of Skyshine Radiation from Co 60 and Cs 137 Sources of Vertical and Horizontal Barriers, Report CEX-63.3 to be published.

5. Engineering Manual: Design and Review of Structures for Protection from Fallout Gamma Radiation, Office of Civil Defense, revised October 1, 1961.

6. E. T. Clarke, J. F. Batter and A. L. Kaplan, Measurement of Attenuation in Existing Structures of Radiation from Simulated Fallout, Report TP-B 59-4 (Technical Operations Incorporated, Burlington, Massachusetts) April 27, 1959.

7. Z. G. Burson, Experimental Radiation Measurements in Conventional Structures, Report, CEX-59.7B, Part I, to be published. 


\section{Chapter 5}

\section{SUMMARY}

Measurements were made in a basement structure of the radiation from a simulated plane source of ${ }^{60} \mathrm{Co}$ on the ground outside. The measurements were made in a bare, open basement and after various stages of construction to study the air-scattered radiation contribution and its attenuation through structural components. The construction stages included: (1) building the walls of a shelter in the basement; (2) placing sandbags around the shelter walls; (3) removing the sandbags and constructing the shelter roof; (4) building a wood roof over the entire basement; (5) placing 4-in. concrete planks over the wood roof; and (6) placing a second layer of 4-in. concrete planks over the wood roof. In all cases the top of the materials (basement walls, wood roof or concrete planks) were flush with ground level. This assured that essentially all radiation reaching the detectors had been scattered at least once in the air.

The results are readily compared with calculations in elementary detector-source-medium arrangements. Experimental data from detectors in the bare, open basement agree excellently with calculations corrected for the presence of the ground; they also agree well with other experimental data.

Building the shelter walls reduced the exposure rate a factor of two at the 3-ft level in the center of the shelter both from the ring source at a 127-ft radius and from the area source on the ground around the basement. Adding sandbags around the shelter walls reduced the exposure very little, less than $10 \%$. Putting the roof over the shelter reduced the radiation level about a factor of eight. Calculations using experimentally determined attenuation factors for vertical and horizontal shields exposed only to skyshine radiation 1 agreed well with the above results.

Adding the wood roof and concrete planks over the entire basement further reduced the exposure rate inside the shelter from sources on the ground outside. However, a point was apparently 
reached where direct penetration through the ground and shelter walls became the dominant contribution. This ground penetration contribution was also noticed in corner positions outside the shelter. These results indicate the importance of considering the ground penetration contribution when predicting the fallout protection provided by a basement shelter.

Exposure rates measured in the basement and in the shelter from a simulated area source on the roof of the basement agreed excellently with calculations for the wood roof and both layers of concrete plank.

Results from this experiment were compared with data ${ }^{2}$ taken in a similar basement (and identical shelter) below a two-story brick house. The exposure rates at similar positions in the two structures were nearly the same. Computations indicate that the apparent agreement is probably coincidental. The exposure rates in the open basement were entirely from skyshine radiation. The additional radiation contribution provided by scattering from the walls of the two-story brick house apparently offset the skyshine attenuation provided by the walls and first floor.

The extent to which results obtained by using ${ }^{60} \mathrm{Co}$ can be applied to idealized fallout radiation has been discussed by Eisenhauer and implied by Spencer's ${ }^{4}$ extensive calculations. In most practical cases data from $60 \mathrm{Co}$ can be applied to a 1-hr fission spectrum by adding $10 \%$ to the mass thickness to obtain the same barrier reduction for the same source configuration.

The intent of the project was to study the relative skyshine contributions to various parts of the basement and to determine the attenuation provided by various structural components. The source configurations for these experiments met these objectives. Quantitatively, the results of this experiment for each source configuration compare well with calculations. Therefore, to apply these results to actual structures located in infinite radiation fields or in an actual fallout field, the theoretical calculations should be consulted.

In summary, the experimental data are consistent within themselves and compare well with calculations. The objectives were met and the experiment was conducted safely within the criteria established for the project. 
1. Z. G. Burson and R. L. Summers, Barrier Attenuation of Air-Scattered Gamma Radiation, CEX-63.3, to be published.

2. Z. G. Burson, Experimental Radiation Measurements in Conventional Structures. Report CEX-59.7B, Part I, to be published.

3. C. E. Eisenhauer, Analysis of Experiments on Light Residential Structures with Distributed Co ${ }^{60}$ Sources, Report NBS-6539, October 1959.

4. L. V. Spencer, Structure Shielding Against Fallout Radiation from Nuclear Weapons, NBS Monograph 42, June 1962. 
Appendix A

DETAIL DRAWINGS OF STRUCTURAL

COMPONENTS OF BASEMENT AND

SHELTER 


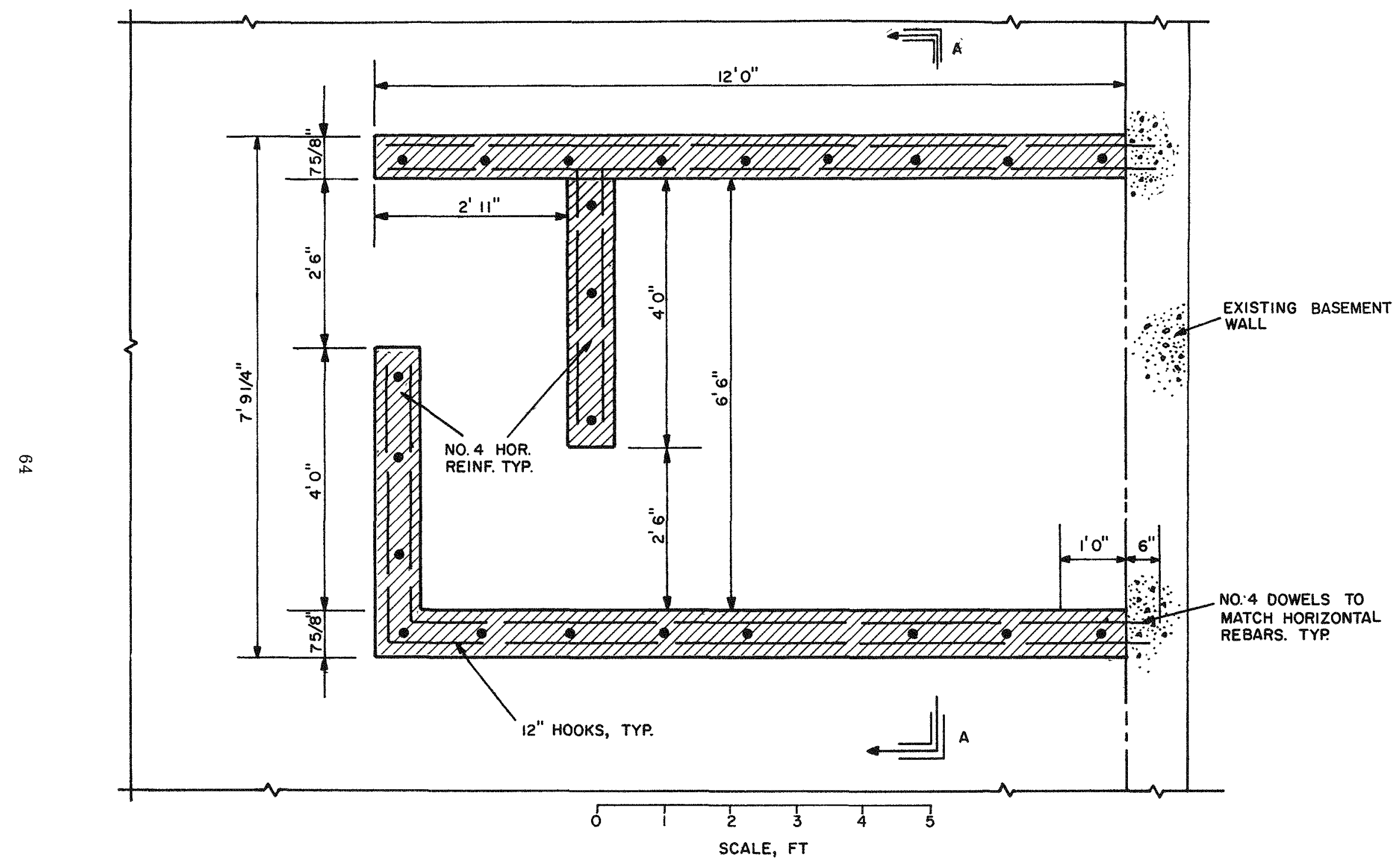

Fig. A.1-Floor plan of shelter. 


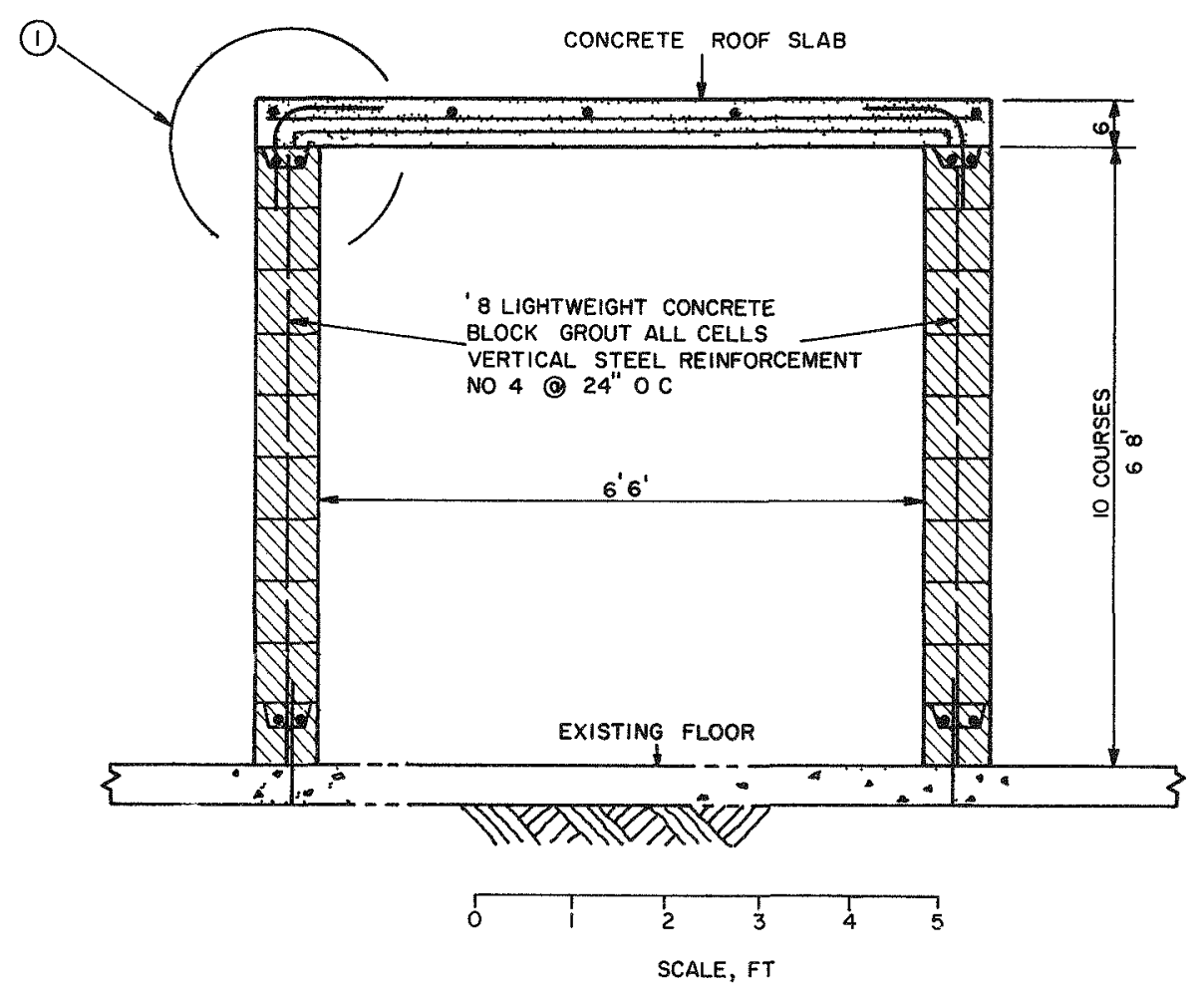

Tig. A 2-Typical section A of shelter

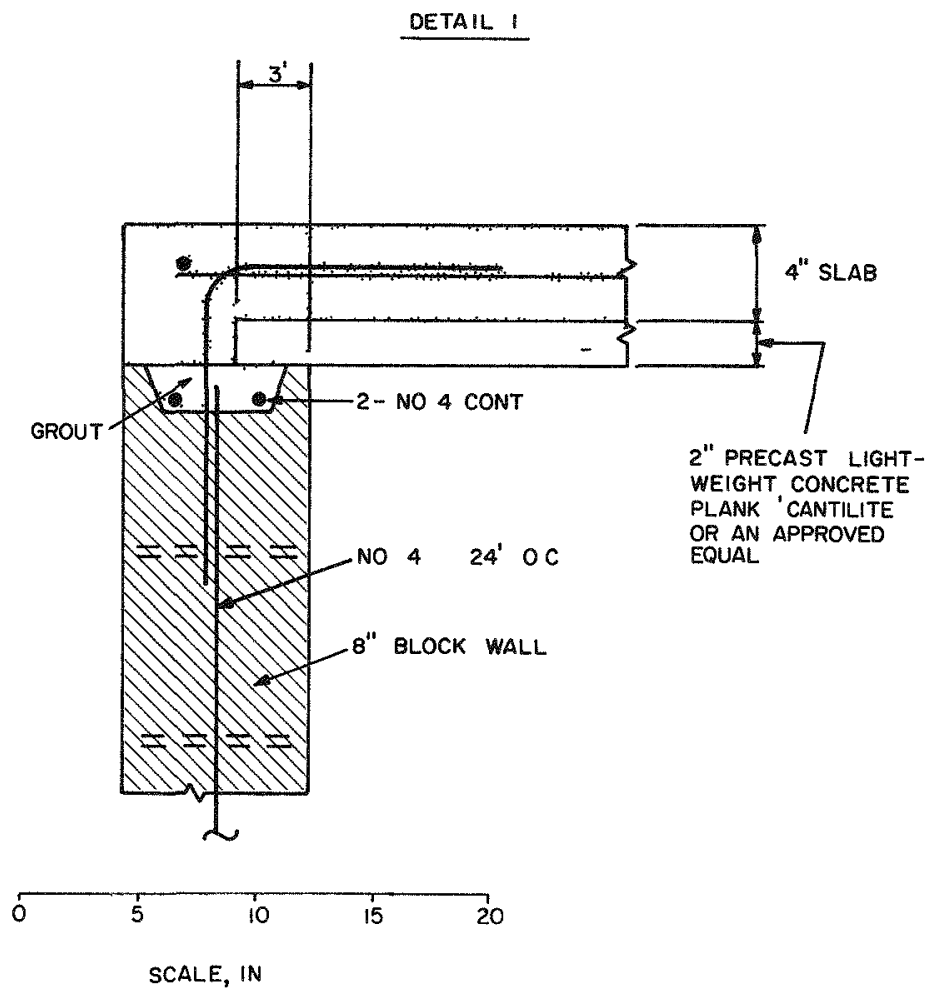

Fig A 3-Detall 1 of shelter 


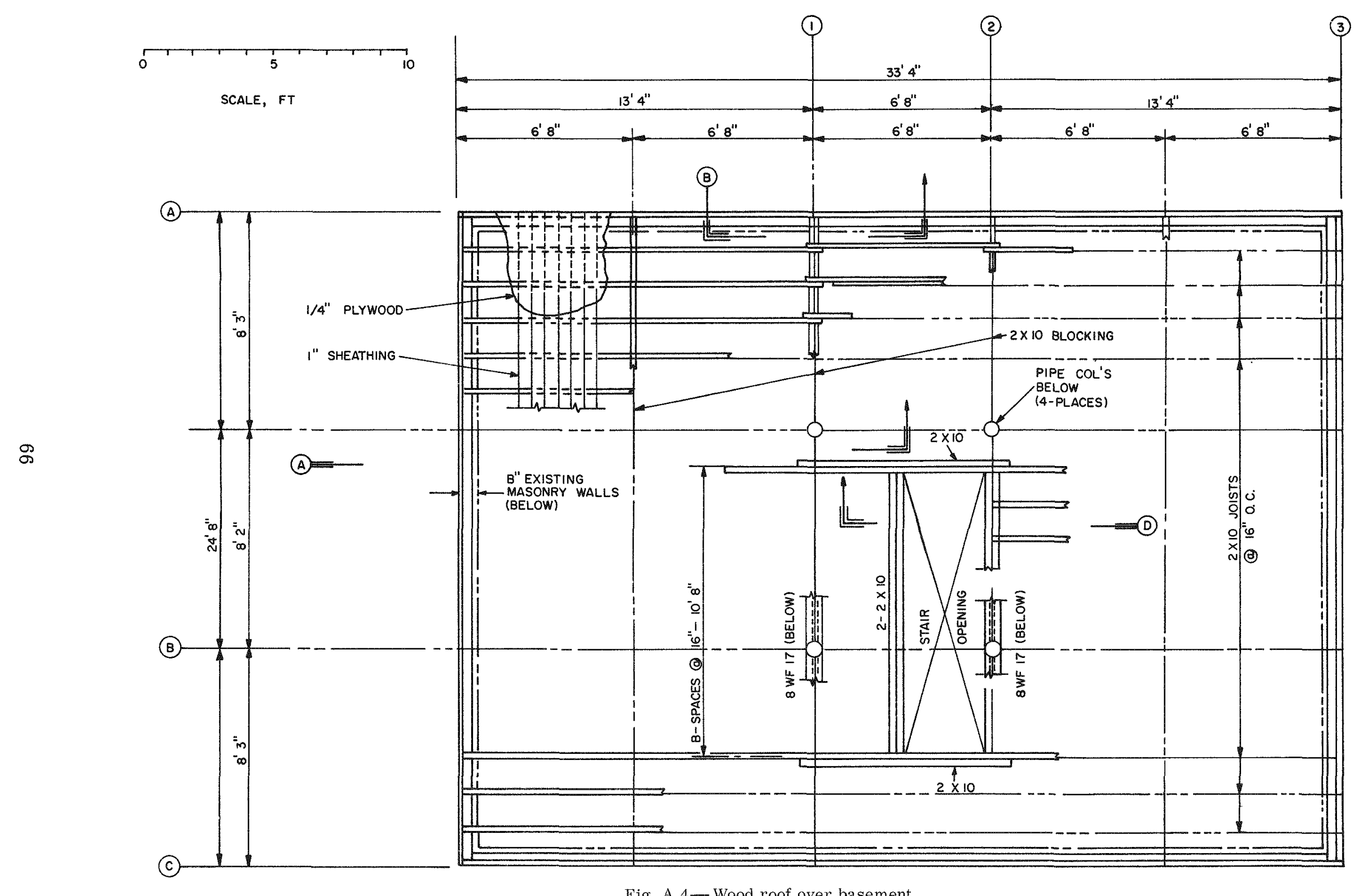

Fig. A.4-Wood roof over basement. 


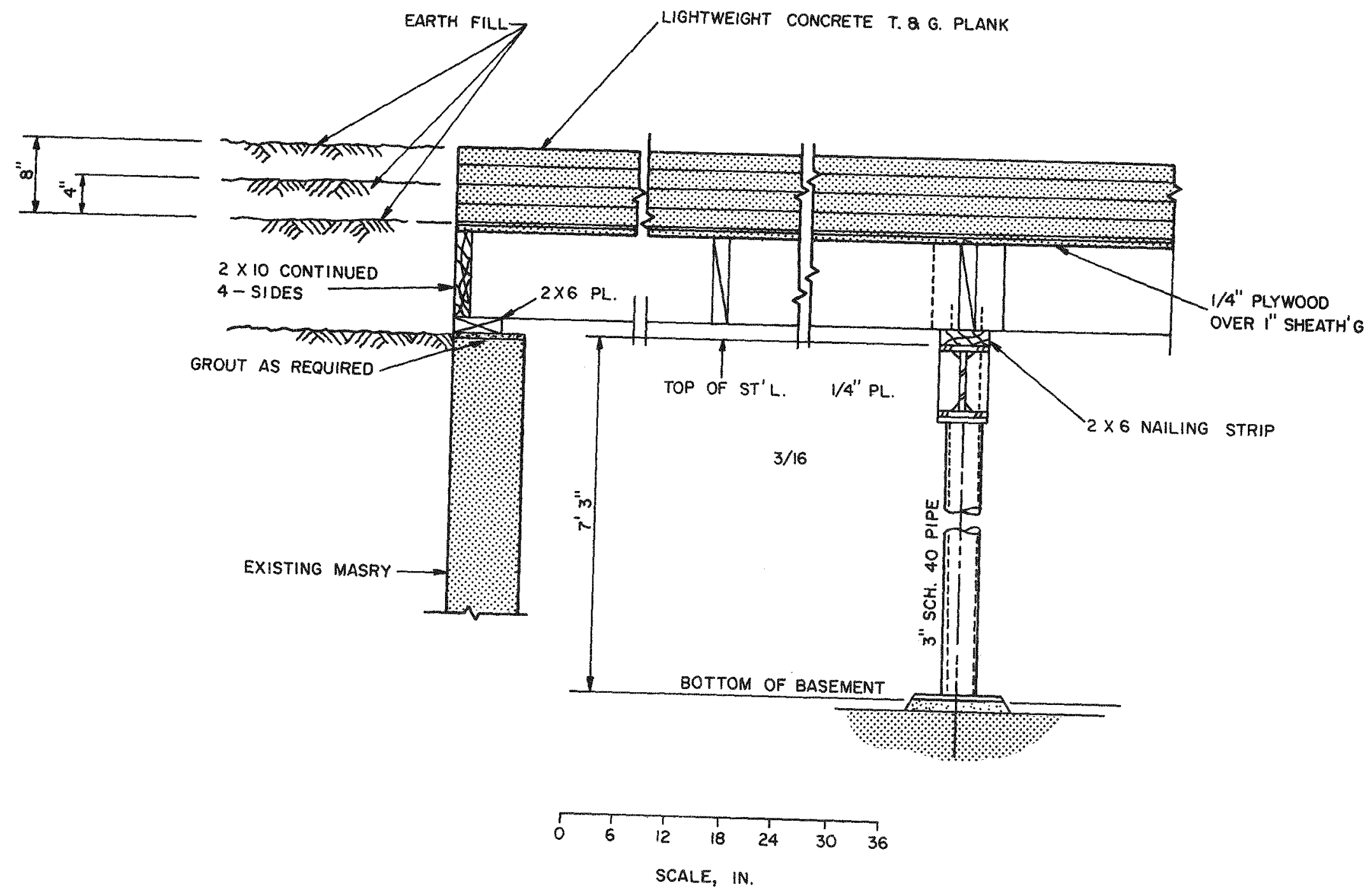

Fig. A.5-Section A of wood roof. 
SECTION B

$\infty$
SECTION C

BEAM POCKETS IN EXISTING WALLS

(c)

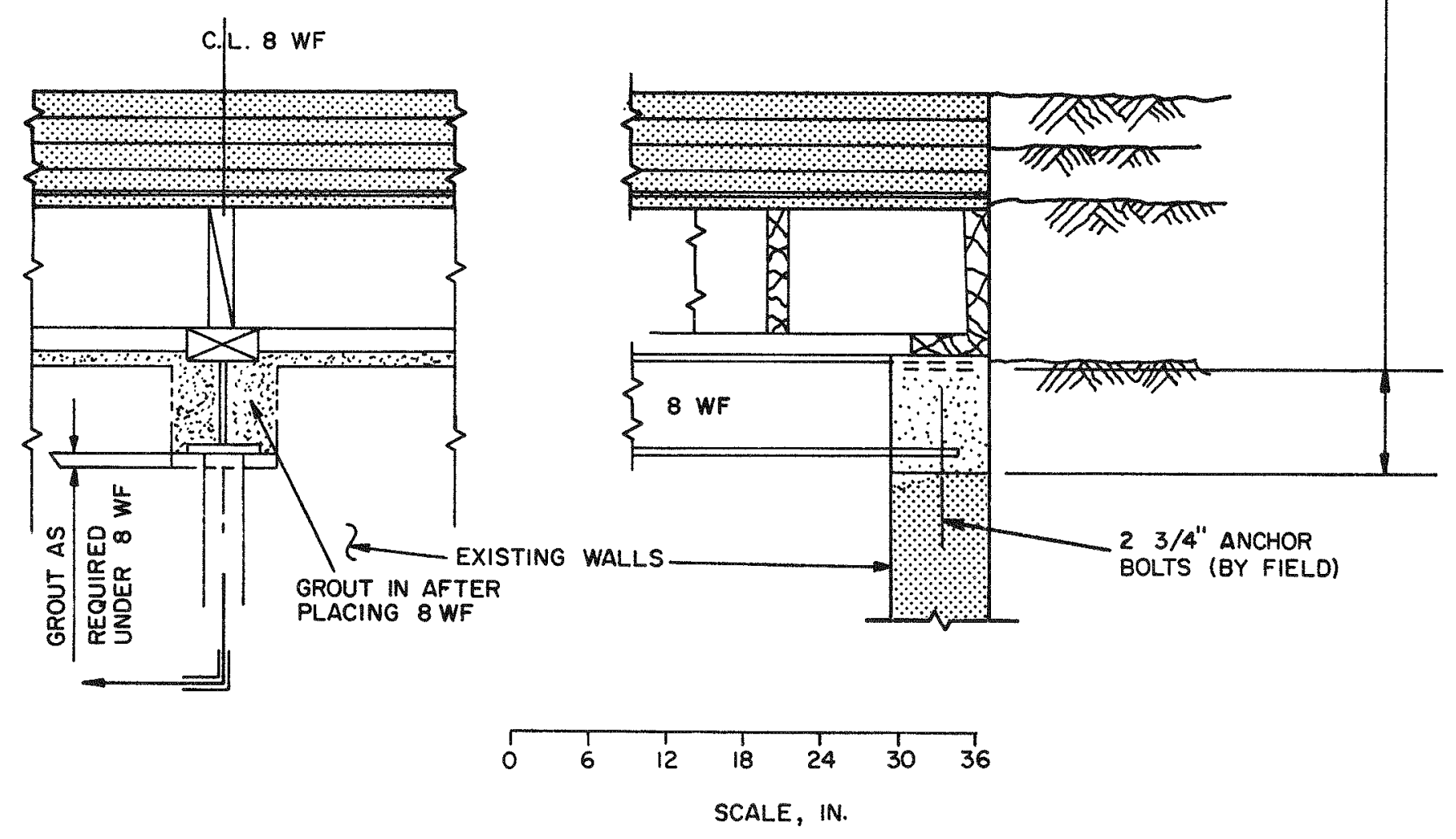

Fig. A.6-Sections B and C of wood roof. 


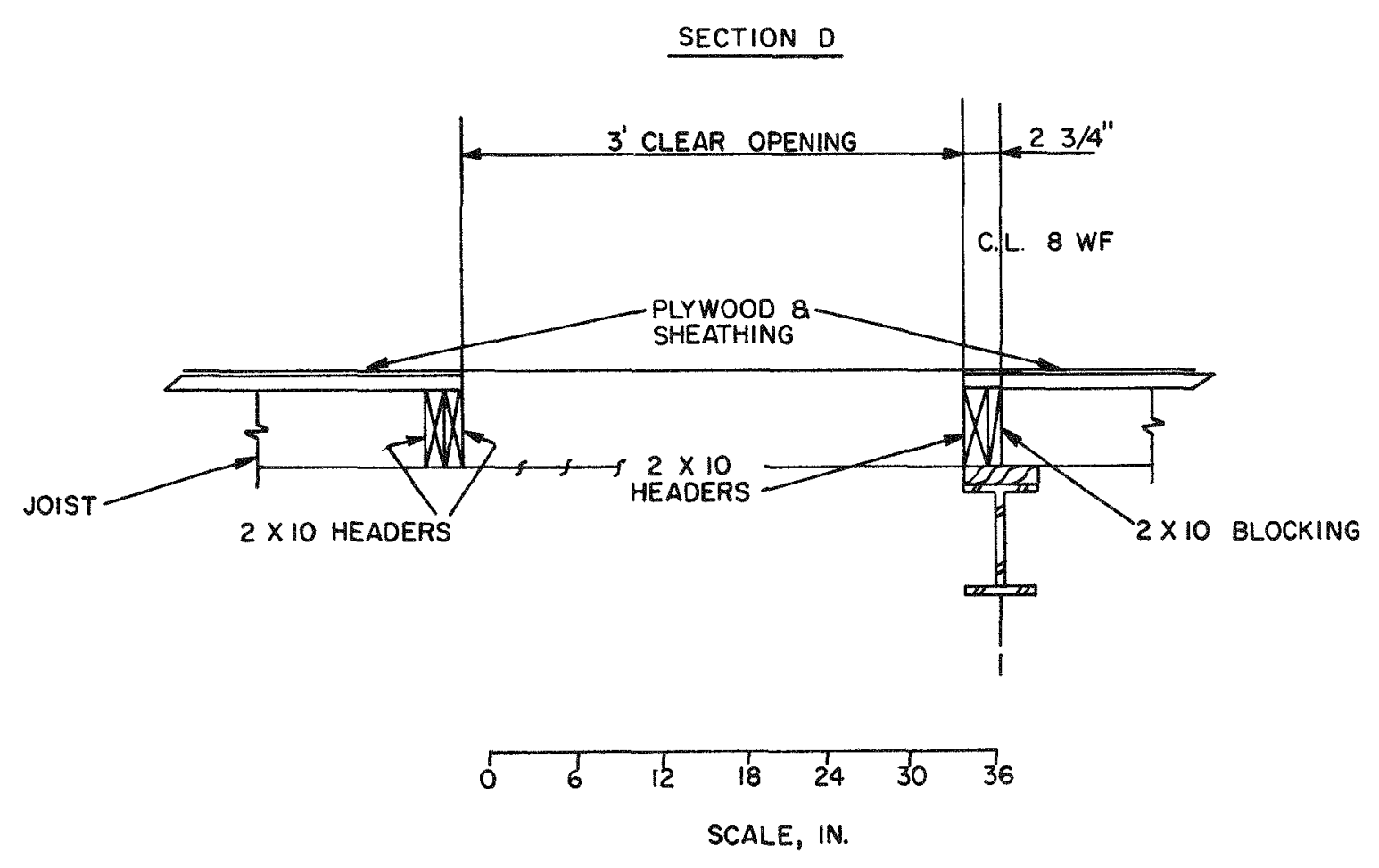

Fig. A.7-Section D of wood roof. 


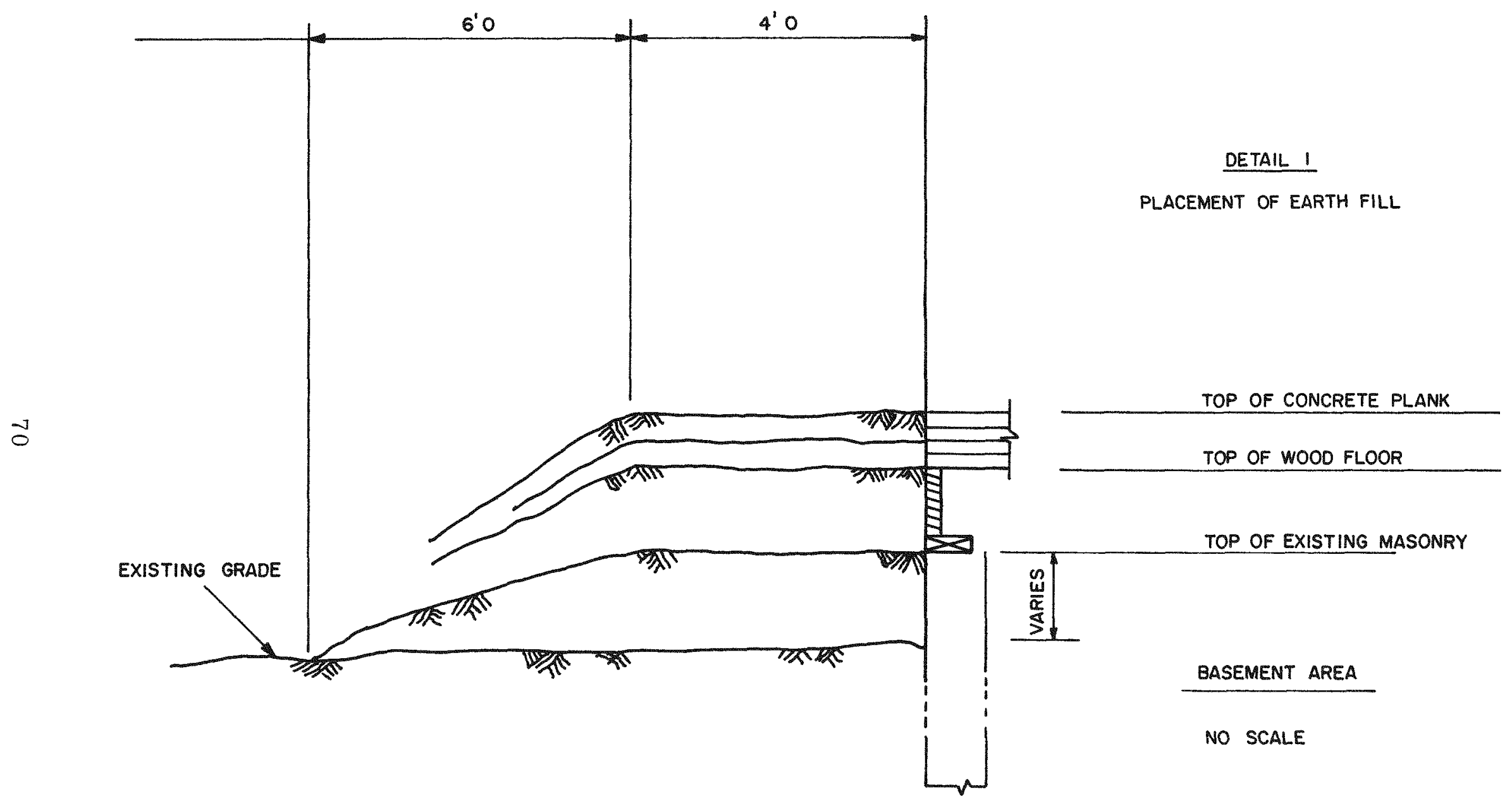

Fig. A.8-Placement of earth fill around basement area. 


\section{CIVIL HFFHTS TEST OPFRATIONS RHPORT SERIES (CEX)}

Through xts Division of Biology and Medicine and Civil Effects Test Operations Office the Atomic $f$ ne rgy Commission conducts certain techmeal tests exercises surveys and research directed primarily toward practical applications of nu clear effects information and towaid encouraging better techmeal professional and public understanding and utilization of the vast body of facts useful in the design of countermedsures aganst weapons effects rhe activities carried out in these studies do not require nuclear detonations

A complete listing of all the studies now underway is impossible in the space avalable he re Howeve 1 the following is a list of all reports avalable from studies that have been completed All reports listed ale avallable at the prices undi cated from the Clearinghouse for Federal Scientific and Technical Information U $S$ Department of Commerce Spring field $V x$

CEX 571 The Radiological Assessment and Recovery of Contarninated Areas C F Miller $1960 \$ 075$

C.X -581 Experimental Evaluation of the Radiation Protection Afforded by Residential Structures Against Distrubuted Sources J A Auxier J O Buchanan $\mathrm{C}$ Fisenhauer and $\mathrm{H} \mathrm{E}$ Menker $1959 \$ 275$

CFX 582 The Scatterung of Thermal Radiation into Open Underground Shelters $T$ P Davis $N$ D wiler $T S$ Ely $J A$ Basso and $H$ Pealse $1959 \$ 075$

CEX 587 ALC Group Shelter AEC Fachlities Division Holmes \& Narver Ine $1960 \$ 5050$

CFX 588 Comparative Nuclear Effects of Bxomedical Interest $C \mathrm{~S}$ White $I \mathrm{G}$ Bowen $\mathrm{D} R$ Richmond and R L Corsbie $1961 \$ 100$

CEX 589 A Model Designed to Predict the Motion of Objects Translated by Classical Blast Waves I G Bowen $R \mathrm{~W}$ Albright $\mathrm{E} R$ iletcher and $C S$ Whate $1961 \$ 125$

CEX 591 An Experimental Evaluation of the Radiation Protection Afforded by a Large Modern Concrete of fice Bunlding $J$ Batter Jr A L Kaplan and $F$ T Clarke $1960 \$ 060$

CEX 594 Aemal Radiological Momtomg System I Theoretical Analysis Design and Operation of a Revised System $R$ F Merian of $G$ Lackey and $J E$ Hand $1961 \quad \$ 125$

CFX 594 (Pt If) Aerual Radiological Montoring System Part II Performance Calibration and Operatronal Check-out of the EG\&G Arms-II Revised System $J \mathrm{E}$ Hand $\mathrm{R} B$ Gullou and $\mathrm{H} M$ Borella 1962 $\$ 150$

CEX-59 4 (Pt II) Aerial Radiological Montoring System Part III Electronc Processing of ARMS-II Data J Hand and $\mathrm{H} M$ Borella $1965 \$ 100$

CEX-59 7B (Pt II) Expemmental Radiation Measurements in Conventional Structures Part II Comparison of Measurements in Above-ground and Below ground structures from Simulated and Actual Fallout Radiation $Z G$ Burson $1964 \$ 150$

CEX-59 7C Methods and Techniques of Fallout Studies Using a Particulate Simulant $W$ Lee and H Borella $1962 \$ 050$

CEX-59 13 Expermental Evaluation of the Radiation Protection Afforded by Typical Oak Ridge Homes Against Distrubuted Sources T D Strickler and J A Auxier $1960 \$ 050$

C EX-59 14 Determinations of Aerodynamic-drag $\mathrm{Pa}-$ rameters of Small Irregular Objects by Means of Drop Tests $\mathrm{E} P$ Fletcher $R \mathrm{~W}$ Albright $V \mathrm{C}$ Goldizen and $I G$ Bowen $1961 \$ 175$

CEX-601 Fvaluation of the Fallout Protection Afforded by Brookhaven National Laboratory Medical Research Center H Borella $Z$ Burson and J Jacovitch 1961 \$ 175

CEX-603 Extended-and Pount-source Radiometric Program $F$ J Dav1s and $P$ W Reinhardt $1962 \quad \$ 150$

CFX 605 Experimental Evaluation of the Falloutradiation Protection Afforded by a Southwestern Residence $\mathrm{Z}$ Burson $\mathrm{D}$ Parry and $\mathrm{H}$ Borella $1962 \$ 050$
CEX-606 ixperimental Evaluation of the Radiation Pro tection Provided by an Earth-covered Shelter $\mathrm{Z}$ Bur son and H. Borella $1962 \$ 100$

CFX 611 (Prelim) Gamma Radiation at the Ar-Ground Interface $\mathrm{K} O$ Brien and $\mathrm{J} \mathrm{E}$ McLaughlin $\mathrm{Jr} 1963$

C FX-61 4 Experimental Evaluation of the Fallout radidtion Protection Provided by Selected Structures in the Los Angeles Area $Z$ G Burson $1963 \quad \$ 225$

CLX-62 01 Techneal Concept-Operation BREN J A Auxier $F W$ Sanders $F$ Haywood of $H$ Thorn gate and $\mathrm{S}$ Cheka $1962 \$ 050$

CFX-62 02 Operation Plan and llazards RegortOperation BRFN FW Sander's $I$ I Haywood M I Lundun $L$ Glley $J$ S Chekd and $D R$ Ward $1962 \$ 225$

CLX-6203 General Correldive Studies - Operation BREN I A Auxier $F F$ Haywood and $L W$ Gilley $1963 \$ 100$

CFX 622 Nuclear Bomb Effects Computer (Including Shide-rule Design and Curve Fits for Weapons Effects) $F$ R Fletcher $R$ W Albright $R$ F $D$ Perret Mary $E$ Franklin $I \mathrm{G}$ Bowen and $\mathrm{C} S$ Whrte 1963 $\$ 100$

CEX -6211 Distrubution of Weapons Radiation in Japanese Residentaal Structures o $\mathrm{S}$ Cheka F W Sanders $T$ D Jones and $\mathrm{W}$ H Shmpaugh $1965 \$ 100$

CEX 6214 An Experimental Investigation of the Spatid Distribution of Dose in an Anr over-Ground Geometry F F Haywood $J$ A Auxier and E T Loy 1964 $\$ 400$

CEX 6250 Neutron-field and Induced actrvty Measurements-Operation BREN F M Tomnovec and $J$ M Ferguson $1965 \$ 100$

CEX-62 81. (Prehm) Ground Roughness Effects on the Cnergy and Angular Distribution of Gamma Radiation from Fallout $C$ M Huddleston $Z$ G Burson $R$ M Kunkaid and Q G Klinger $1963 \quad \$ 125$

CEX-63 3, Barrier Attenuation of Atr-scattered Gamma Radiation $Z$ G Burson and $R$ L Summers 1965 $\$ 100$

CEX-63 7 A Comparative Analysis of Some of the $7 m-$ mediate Environmental Effects at Huroshma and Nagasaki $C$ S White I $G$ Bowen and $D$ R Rich mond $1964 \$ 200$

CFX-63 11 Mobile Radiological Measuring Unit De scription and Operating Information $Z$ G Burson R L Summers and J T Brashears $1965 \$ 100$

CLX-64 3 lckiban The Dosimetry Program for Nuclear Bomb Survivors of Hiroshima and Nagasaki - A Status Report as of April 11964 J A Auxier 1964 $\$ 050$

CEX-65 02 Techncal Concept-Operation HENRE $\rightarrow$ Haywood and $\mathbb{f}$ A Auxier $196 \mathrm{~b} \$ 100$

CEX-65 4 Brological Tolerance to Arr Blast and Related Bromedical Criteria, C \& White I Gerald Bowen and D R Richmond $1965 \$ 275$ 